NUREG/CR-6257

INEL-95/0070

\title{
CANDU 3 Transient Analysis Using Atomic Energy of Canada Ltd. Codes
}

Prepared by

J. L. Judd, R. W. Shumway/INEL

D.D. Ebert/NRC

Idaho National Engineering Laboratory

Prepared for

U.S. Nuclear Regulatory Commission 


\section{AVAILABILITY NOTICE}

Availability of Reference Materia's Cited in NRC Publications

Most documents clted In NRC publications will be avallable from one of the following sources:

1. The NRC Public Document Room, 2120 L Street, NW., Lower Level, Washington, DC 20555-0001

2. The Superintendent of Documents, U.S. Government Printing Office, P. O. Box 37082, Washington, DC 20402-9328

3. The National Technical Information Service, Springfield, VA 22161-0002

Although the listing that follows represents the majority of documents cited in NRC publications, it is not intended to be exhaustive.

Referenced documents available for Inspection and copying for a fee from the NRC Publlc Document Room Include NRC correspondence and internal NRC memoranda; NRC bulletins, circulars, informatlon notices, inspection and Investigation notices; licensee event reports; vendor reports and correspondence; Commisslon papers; and appllcant and licensee documents and correspondence.

The following documents in the NUREG series are avallable for purchase from the Government Printing Office: formal NRC staff and contractor reports, NRC-sponsored conference proceedings, international agreement reports, grantee reports, and NRC booklets and brochures. Also available are regulatory guldes, NRC regulations in the Code of Federal Regulations, and Nuclear Regulatory Commission Issuances.

Documents avallable from the National Technical information Service include NUREG-series reports and technical reports prepared by other Federal agencles and reports prepared by the Atomic Energy Commission, forerunner agency to the Nuclear Regulatory Commission.

Documents available from public and speclal technical libraries include all open literature items, such as books, journal articles, and transactions. Federal Register notices, Federal and State legislation, and congresslonal reports can usually be obtained from these libraries.

Documents such as theses, dissertations, foreign reports and translations, and non-NRC conference proceedings are available for purchase from the organization sponsoring the publication cited.

Single coples of NRC draft reports are avallable free, to the extent of supply, upon written request to the Office of Administration, Distribution and Mail Services Section, U.S. Nuclear Regulatory Commission, Washington, DC 20555-0001.

Coples of industry codes and standards used in a substantive manner in the NRC regulatory process are maintained at the NRC Library. Two White Flint North, 11545 Rockville Pike, Rockville, MD 20852-2738, for use by the public. Codes and standards are usually copyrighted and may be purchased from the originating organization or, If they are American National Standards, from the American National Standards Institute, 1430 Broadway, New York, NY 10018-3308.

\section{DISCLAIMER NOTICE}

This report was prepared as an account of work sponsored by an agency of the United States Govemment. Neither the United States Govemment norany agency thereof, nor any of their employees, makes any warranty, expressed or implied, or assumes any legal liability or responsibility for any third party's use, or the results of such use, of any information, apparatus, product, or process disclosed in this report, or represents that its use by such third party would not infringe privately owned rights. 


\section{DISCLAIMER}

Portions of this document may be illegible in electronic image products. Images are produced from the best available original. document. 
NUREG/CR-6257

INEL-95/0070

\section{CANDU 3 Transient Analysis \\ Using Atomic Energy of \\ Canada Ltd. Codes}

Manuscript Completed: October 1994

Date Published: January 1995

Prepared by

J. L. Judd, R. W. Shumway/INEL

D.D. Ebert/NRC

Idaho National Engineering Laboratory

Managed by the U.S. Department of Energy

Lockheed Idaho Technologies Company

Idaho Falls, ID 83415

Prepared for

Division of Systems Technology

Office of Nuclear Regulatory Research

U.S. Nuclear Regulatory Commission

Washington, DC 20555-0001

NRC Job Code L2445

DISTRIEUTION OF THIS DOCUMENT IS UNLIMITED WW 


$$
\begin{aligned}
& +\frac{7}{3} \\
& =
\end{aligned}
$$




\begin{abstract}
A limited number of transient scenarios were calculated using a computer code suite and input modeling provided by the Atomic Energy of Canada Limited (AECL) for the CANDU 3 design. Emphasis was placed on a large-break loss-of-coolant accident with delays in actuation of the two independent shutdown systems (shutdown rods and liquid poison injection). Although this is expected to be an extremely unlikely scenario, it was studied because of the potential consequences which would result from a positive void coefficient of reactivity. Results indicate that a few second delay in shutdown would result in quickly reaching fuel or cladding melting temperatures, before the emergency core cooling system would be activated. Only small changes in the timing and consequences of the scenario result when several parameters, of potential importance to the progression of the accident, are varied. The severity of the accident is dramatically reduced when it is assumed that one of the two independent shutdown systems functions as designed. The LOCA results presented in this paper are consistent with related studies performed by AECL and others, and do not reveal any new characteristics or phenomena.

In addition to the loss-of-coolant analyses, five calculations were also performed for loss-of-offsite-power scenarios. These calculations assumed that the plant failed to enter the "island mode"; i.e., power to the main coolant pumps was not restored using on-site power generation. Three functions were varied during the five calculations: pressure relief valves opening, the scram system rods dropping and the mechanical control absorber rods dropping. The total power rise, caused by a positive void reactivity coefficient, was negligible as long as either the scram rods or the mechanical control absorber rods entered the core.
\end{abstract}

\title{
L2445 - CANDU 3 Transient Analysis
}




\section{CONTENTS}

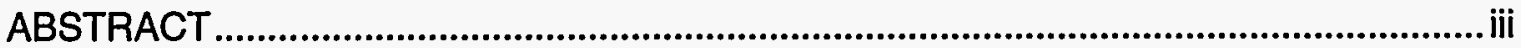

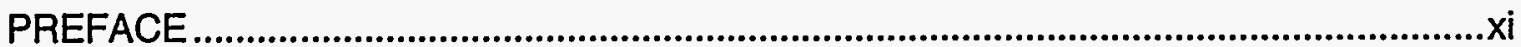

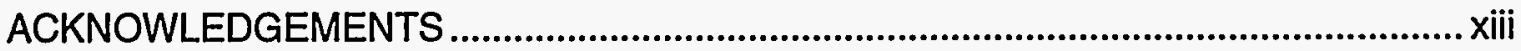

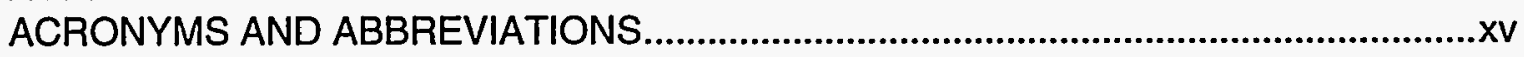

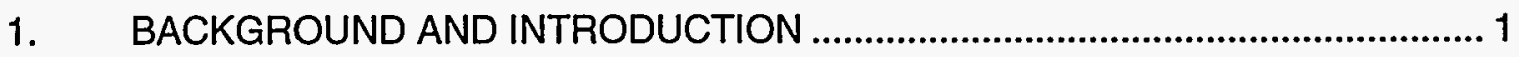

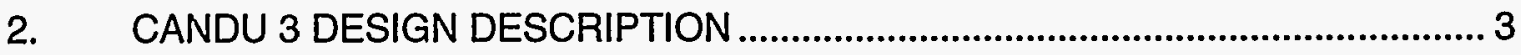

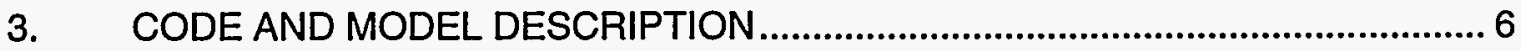

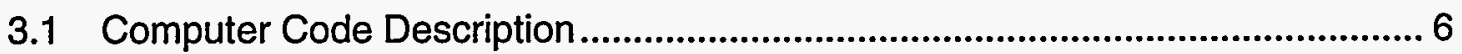

3.2 Ten-Channel CATHENA Primary Loop............................................................ 7

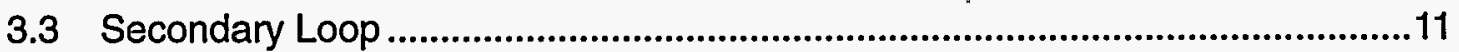

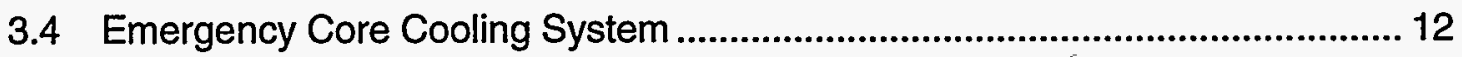

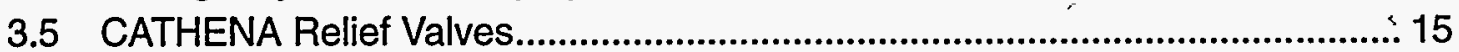

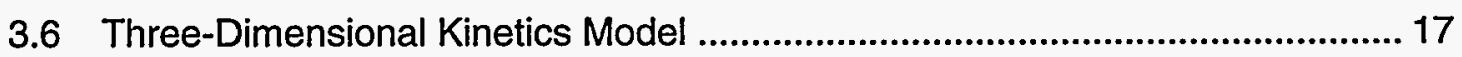

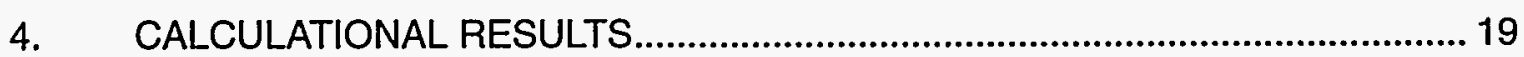

4.1 Large-Break LOCA Sensitivity Calculations .................................................. 19

4.1.1 Large-Break LOCA with Scram ............................................................ 19

4.1.2 Large-Break LOCA with Failure to Shutdown ........................................ 27

4.2 Rod Bank Withdrawal Movement Transient ................................................. 35

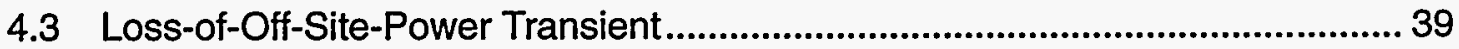

4.3.1 Pump Coastdown and Core Flow.......................................................... 40

4.3.2 Core Power, Voids and Reactivity ....................................................... 43

4.3.3 Fuel and Cladding Temperatures......................................................... 47

4.3.4 Primary Pressure................................................................................ 50

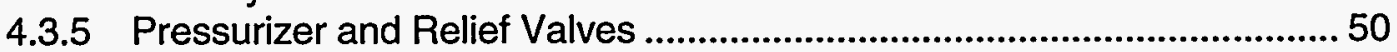

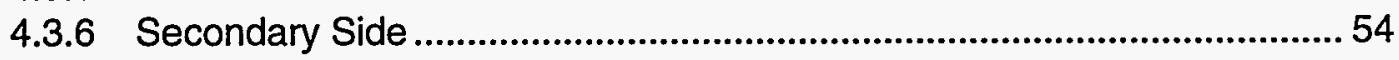

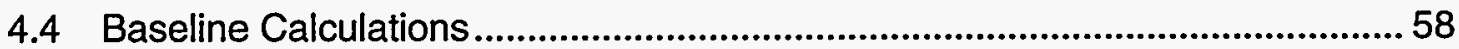

4.4.1 100\% Inlet Header Break with Scram and ECCS .................................. 58

4.4.2 $0.76 \%$ Inlet Header Break with Scram and ECCS ................................ 64

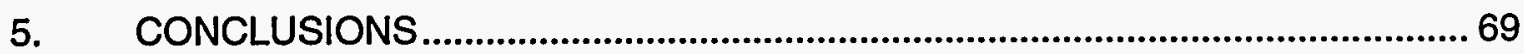

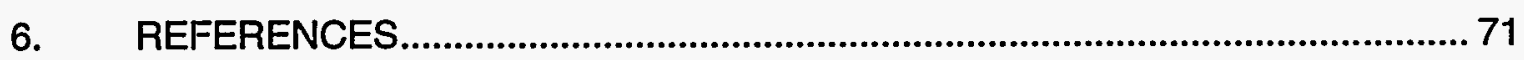




\section{FIGURES}

Schematic of the CANDU 3 PHWR steam supply system. .................................................5

Sequence of codes used for the coupled calculations.....................................................

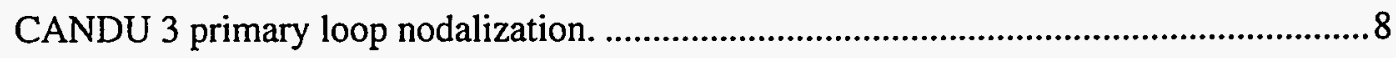

Core cross-section showing CATHENA channel groups...................................................9

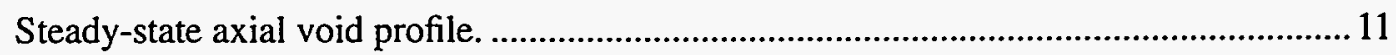

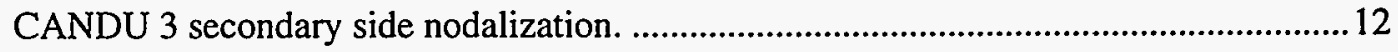

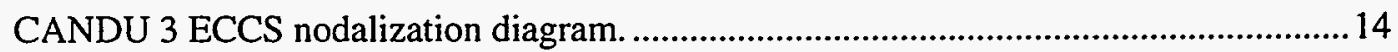

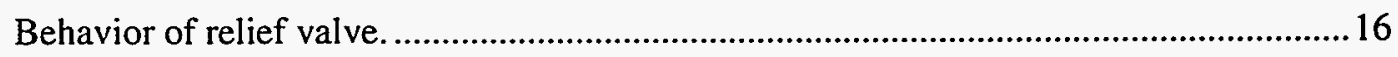

Location of shutoff and mechanical control absorbers in the CANDU 3 core................. 18

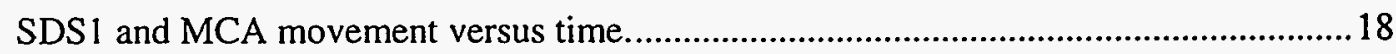

Normalized power for the large-break LOCA sensitivity calculations.............................21

Break flow for the large-break LOCA sensitivity calculations. ......................................22

CHAN I flow for the large-break LOCA sensitivity calculations......................................22

CHAN9 flow for the large-break LOCA sensitivity calculations.....................................23

Reactivity for the large-break LOCA sensitivity calculations............................................23

Chan1 average void fraction for the large-break LOCA sensitivity

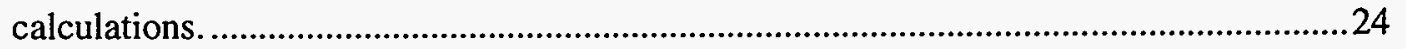

CHAN2 average void fraction for the large-break LOCA sensitivity

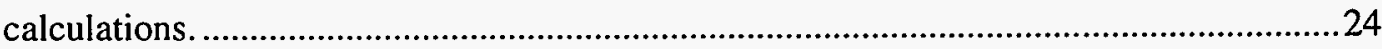

CHAN9 average void fraction for the large-break LOCA sensitivity

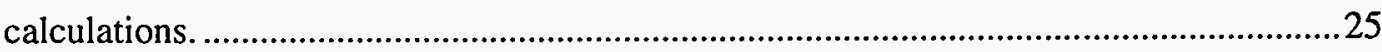

CHAN1 peak clad surface temperature for the large-break LOCA

sensitivity calculations................................................................................................25

CHAN9 peak clad surface temperature for the large-break LOCA

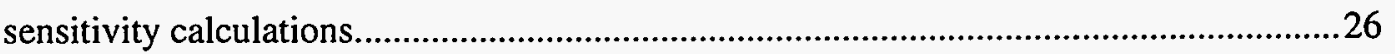

CHAN1 peak fuel centerline temperature for the large-break LOCA

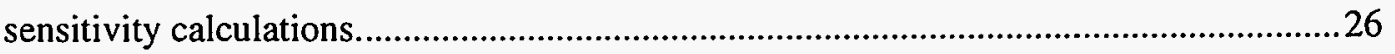

CHAN9 peak fuel centerline temperature for the large-break LOCA

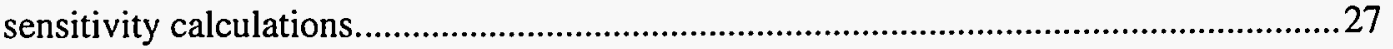

Normalized power for the large-break LOCA sensitivity calculations

with failure to shutdown.............................................................................................29

Break flow for the large-break LOCA sensitivity calculations with

failure to shutdown.

CHAN1 flow for the large-break LOCA sensitivity calculations with

failure to shutdown.

CHAN9 flow for the large-break LOCA sensitivity calculations with

failure to shutdown.

Reactivity for the large-break LOCA sensitivity calculations with

failure to shutdown.

CHANl average void fraction for the large-break LOCA sensitivity calculations with failure to shutdown. 


\section{FIGURES (cont.)}

CHAN2 average void fraction for the large-break LOCA sensitivity calculations with failure to shutdown.

CHAN9 average void fraction for the large-break LOCA sensitivity

calculations with failure to shutdown.

FUEL1 peak clad surface temperature for the large-break LOCA

sensitivity calculations with failure to shutdown.

FUEL9 peak clad surface temperature for the large-break LOCA

sensitivity calculations with failure to shutdown.

FUEL1 peak fuel centerline temperature for the large-break LOCA

sensitivity calculations with failure to shutdown.

FUEL9 peak fuel centerline temperature for the large-break LOCA

sensitivity calculations with failure to shutdown.

Normalized power for the rod bank withdrawal transient.............................................36

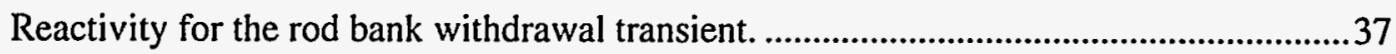

Channel average void fractions for the rod bank withdrawal transient...........................37

Channel peak clad surface temperatures for the rod bank withdrawal transient................38

Channel peak fuel centerline temperatures for the rod bank withdrawal transient............38

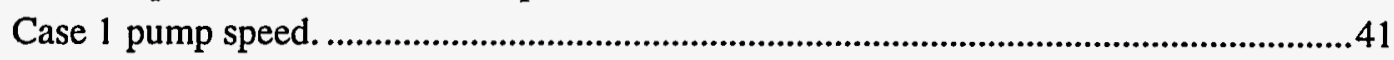

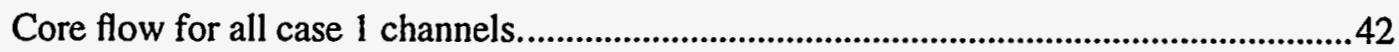

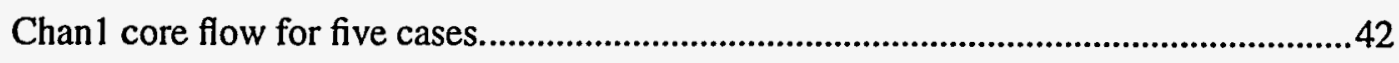

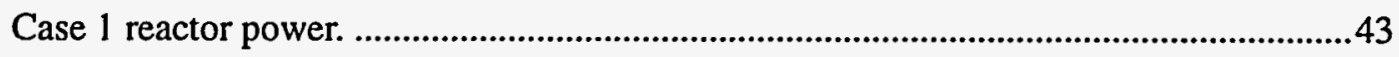

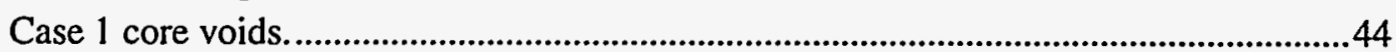

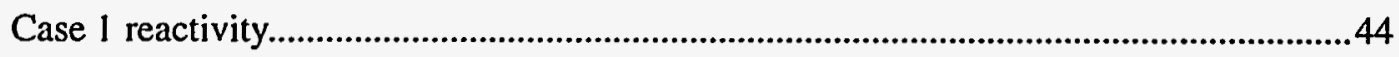

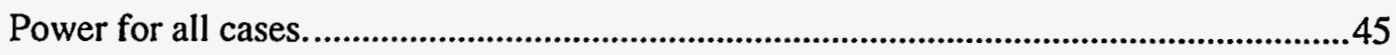

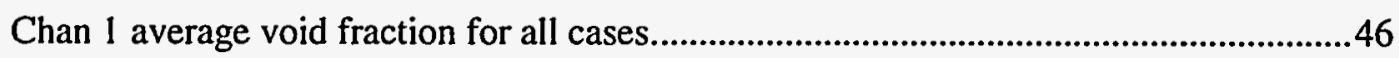

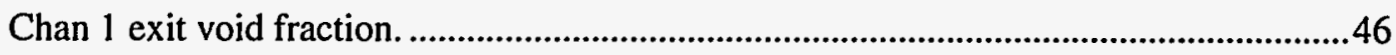

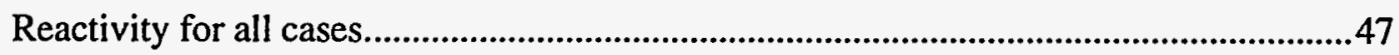

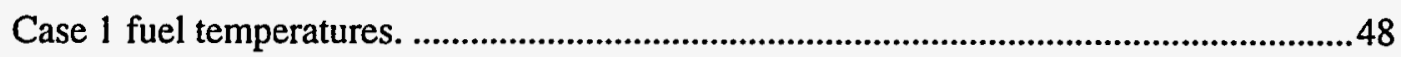

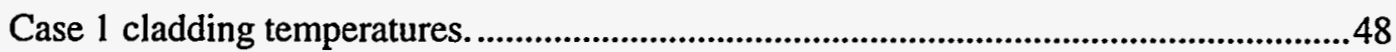

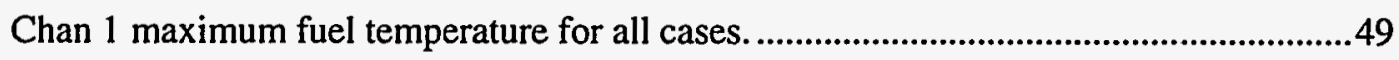

Chan 1 cladding temperature all case.............................................................................49

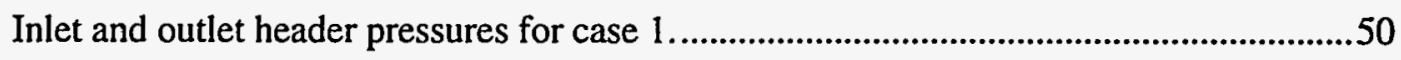

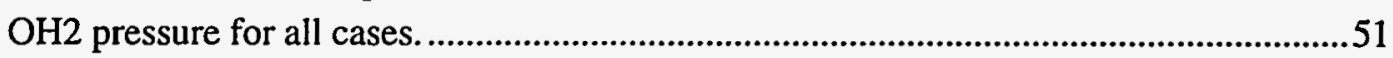

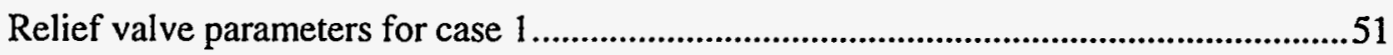

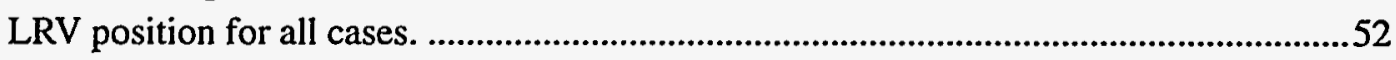

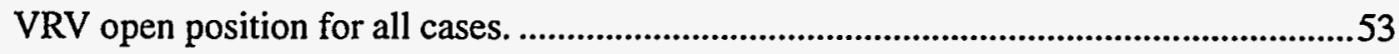

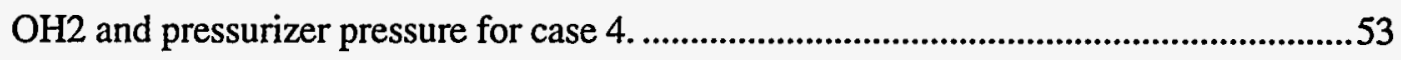

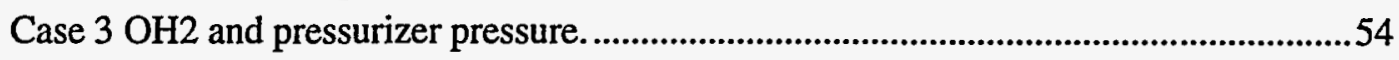

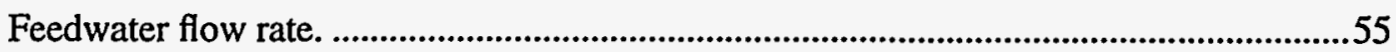

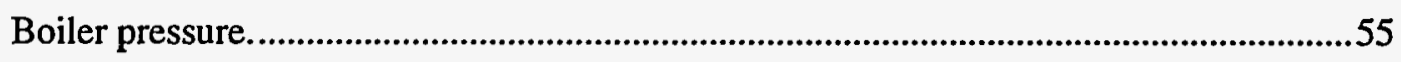

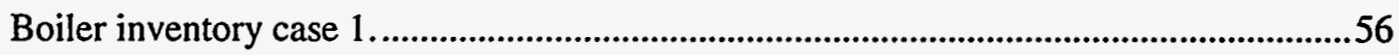

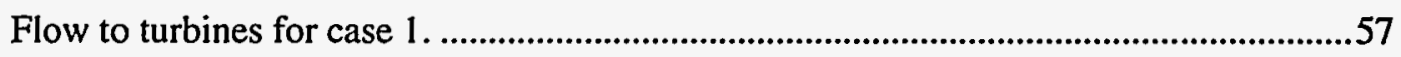




\section{FIGURES (cont.)}

LBLOCA break flow rate.

LBLOCA pressure in inlet and outlet header 2 .........................................................60

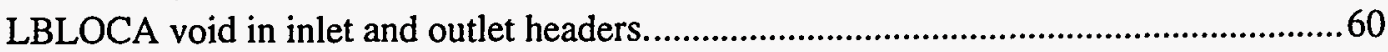

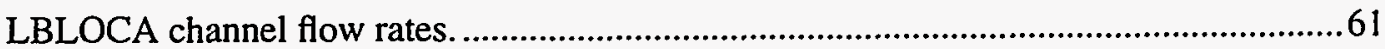

LBLOCA maximum cladding temperatures. ..............................................................62

LBLOCA channel average void fractions.

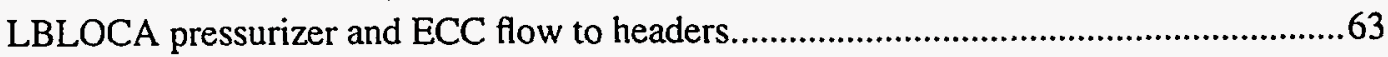

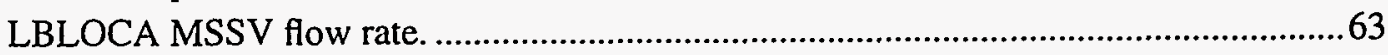

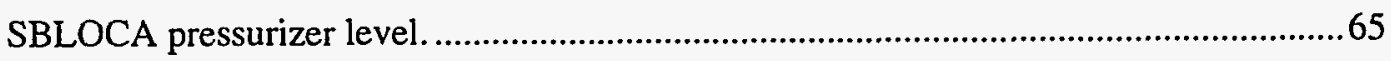

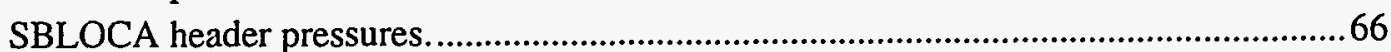

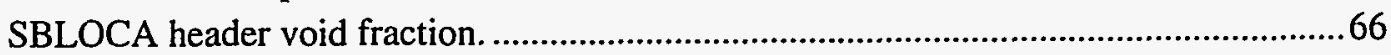

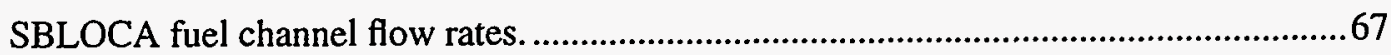




\section{TABLES}

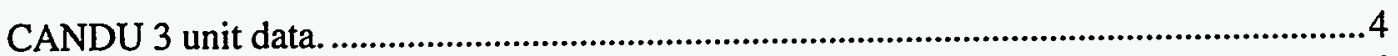

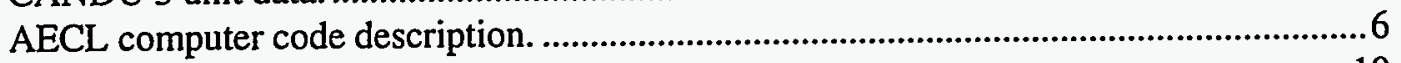

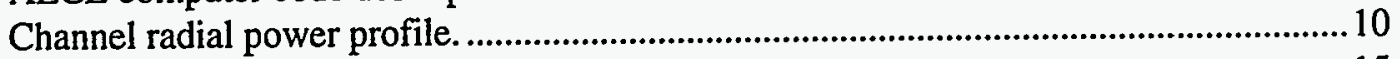

Relief pipe parameters. ................................................................................................ 15

Parameters used for replacement relief valves. ................................................................... 16

Trip setpoints used in these calculations. .......................................................................... 17

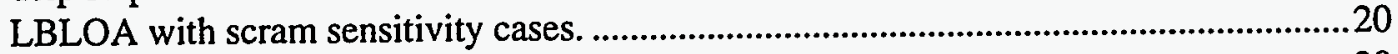

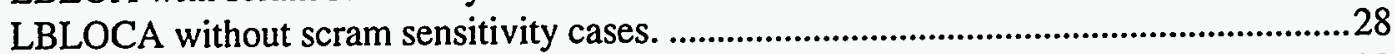

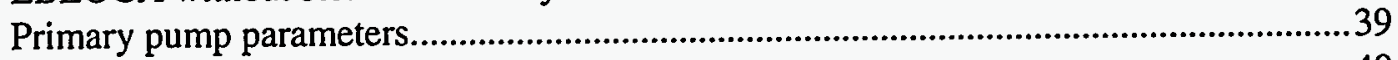

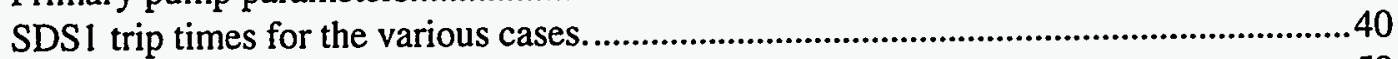

$10 \quad$ Relationship between the ten and four channel models. .................................................58

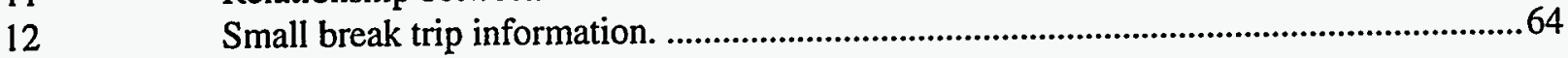





\section{PREFACE}

In its advanced reactor policy statement, the Commission encouraged the earliest possible interaction of applicants with the NRC to enhance stability and predictability in the licensing and regulation of advanced reactors. ${ }^{a}$ To accomplish this, AECL Technology, a subsidiary of Atomic Energy of Canada Limited, submitted preliminary technical information on the CANDU 3 reactor design for a preapplication review by the NRC. As part of that review, the NRC's Office of Nuclear Regulatory Research performed an analytical study of the CANDU 3 design, as it was doing for three other designs undergoing pre-application reviews at the same time. In all cases, analytical codes were being used that had not received the degree of validation by the NRC that has been achieved in LWR licensing, but this was considered adequate for preliminary assessments.

The analytical studies for each of the designs were focused on transients and accidents of special interest, usually involving design aspects that have been identified as issues.. In the case of CANDU 3, our study focused on events involving the design's positive void coefficient of reactivity, which tends inherently to increase reactor power during some postulated transients and accidents. This design characteristic has been identified as an issue that required policy direction from the Commission. ${ }^{\mathrm{b}}$ The position endorsed by the Commission was that a positive void coefficient should not necessarily disqualify a reactor design, but that an analysis would be required of the consequences of events that could lead to core damage as a result of the positive void coefficients.

The analyses reported here examined only the early phase of affected transients and accidents, during the time period prior to core damage (i.e., for times when temperatures remained below the melting point of fuel and cladding). While the scope of these analyses is quite limited, they are useful in indicating how rapidly events progress toward core damage. An unusual aspect of these analyses is that they were performed with the applicant's own codes. Although the NRC generally performs independent analyses with its own computer codes, AECL's generous offer of the use of its codes and input decks was accepted for this preliminary work where the loss of independence was not thought to be critical.

It should be kept in mind that most of the event sequences analyzed in this study assume the failure to promptly shut down the reactor after the initiation of an accident. It is well known by the CANDU designers and others that failure to shut down can lead to run-away power excursions because of the positive void coefficient. Because of this, the designers have included a second, fast shutdown system that is not found on designs with negative void coefficients like LWRs. As a result, the failure of two independent and diverse safety shutdown systems has to be postulated to produce many of the sequences that were analyzed. Since these sequences already involve low-probability initiators, and in some cases failure of the reactor regulating systems, the overall probability of such sequences without shutdown is extremely remote. Nevertheless, the NRC has decided that such accident sequences must be analyzed.

Because event sequences of this kind are of a lower likelihood than traditional design-basis accidents, their analysis would normally be done with best-estimate code input rather than conservatively biased input as used for design-basis-accident analysis. Since the input decks provided by AECL were developed for the analysis of design-basis accidents, they contained conservative biases. These biases have been considered and lead to only minor timing differences in the results.

In October, 1993, a paper was presented on this work at the NRC 21st Water Reactor Safety Information Meeting. ${ }^{c}$ At that time, most of the calculations were for loss-of-coolant accidents without

a. U.S. Nuclear Regulatory Commission, "Regulation of Advanced Nuclear Power Plants; Statement of Policy," Federal Register Vol. 51, July 8, 1986, p. 24643; see also P. M. Williams and T. L. King, "Development and Utilization of the NRC Policy Statement on the Regulation of Advanced Nuclear Power Plants," NUREG-1226, June 1988.

b. U.S. Nuclear Regulatory Commission Paper, "Issues Pertaining to the Advanced Reactor (PRISM, MHTGR, and PIUS) and CANDU 3 Designs and their Relationship to Current Regulatory Requirements," SECY-93-092, April 8, 1993. 
scram, and initial fuel temperatures were thought to be unrealistically high in the calculations. Although the effect of initial fuel temperature was shown to be minor, an error that produced those temperatures was subsequently found in the input deck. The calculations have been repeated with corrected input and are reported here. In addition, new calculations have been done for more probable initiating events (loss of off-site power, and control-rod bank withdrawal), and those calculations are reported here as well. This report summarizes the calculations performed in the study and is the final report for the project.

c. R. W. Shumway, J. L. Judd, and D. D. Ebert, "CANDU 3 Transient Analysis Using AECL Codes," NUREG/CP-0133 Vol. 1, April 1994, p. 41. 


\section{ACKNOWLEDGEMENTS}

The computer code used in this study were provided by Atomic Energy of Canada Ltd. (AECL), who also provided instruction in the use of the codes and assisted with the installation of the codes on the authors' computers.

The CANDU 3 design description was provided by D. E. Carlson and R. O. Meyer of the NRC.

Erma Jenkins of the INEL provided many of the schematics used in this report. 



\section{ACRONYMS AND ABBREVIATIONS}

ACCUM accumulator

ANC

Aerojet Nuclear Company

BINT

steam line interconnect

BIP

boiler (steam generator) inlet plenum

BOP boiler (steam generator) outlet plenum

BRKBC break boundary conditions

CHAN fuel channel

CHF critical heat flux

DWN downcomer

ECI emergency core cooling to inlet headers

ECO emergency core cooling to outlet headers

FW feedwater

GRLVL grade level tank

HPECC high pressure emergency cooling

HTS heat transport system

IEF inlet end fitting

IF inlet feeder

IH inlet header

LOCA loss of coolant accident

LPECC low pressure emergency cooling

LRV liquid relief valve

MCA mechanical control absorbers

MSSV main steam safety valves

OEF outlet end fitting

OF outlet feeder

$\mathrm{OH} \quad$ outlet header

PD pump discharge

PIP main steam lines

PRE preheater

PRLN pressurizer line

PS pump suction

PSR pressurizer

RIS riser 


$\begin{array}{ll}\text { SDS1 } & \text { Shutdown System 1 } \\ \text { SDS2 } & \text { Shutdown System 2 } \\ \text { SEP } & \text { separator } \\ \text { SG } & \text { steam generator } \\ \text { SINT } & \text { primary coolant interconnect } \\ \text { TUR } & \text { turbine } \\ \text { VRV } & \text { vapor relief valve }\end{array}$




\section{BACKGROUND AND INTRODUCTION}

The CANDU 3 design was submitted to the Nuclear Regulatory Commission (NRC) for preapplication design review by Atomic Energy of Canada Limited (AECL) through its U.S. affiliate, AECL Technologies. AECL extended an offer to the NRC and its contractor at the Idaho National Engineering Laboratory (INEL) to use the AECL thermal-hydraulic and neutronic-analysis computer code suite in the review. Analysis of a limited number of transient scenarios using UNIX workstations, both at the NRC and INEL, was undertaken. NRC and INEL staff received training in the use of the code suite at AECL facilities in Canada, and have run a variety of sensitivity studies using base-case input decks supplied by AECL. The input model for the base case, a large-break loss-of-coolant accident (LOCA), was identical to that used by AECL in the "Power Pulse Break Survey Analysis" report".

The purpose of this analysis was to: (a) gain familiarity with CANDU 3 transient response, (b) look at a spectrum of accident scenarios, (c) look at sensitivity of these scenarios to delayed shutdown, and (d) gain insights to modifications of NRC codes that will be needed in order to perform independent analysis of the CANDU 3 design. It should be emphasized that the AECL codes used here have not yet been reviewed by the NRC for adequacy of validation or applicability over the range of parameters investigated. However, the codes were not modified and have been used according to instructions provided by AECL. Therefore, this study should be viewed as providing unverified background information prior to the beginning of the licensing design review rather that as a part of that review.

One of the accidents that was analyzed in this study, namely a large break (100\% break of an inlet header) LOCA with failure to shutdown, is an extremely unlikely scenario that involves (a) a low probability header break, (b) failure of the shutdown rods, and (c) failure of the liquid poison injection.

The positive void reactivity coefficient of CANDU 3 was raised as a policy issue in a formal Commission paper (SECY-93-092) dated April 8, 1993. This issue arose because General Design Criterion 11 in NRC's regulations requires that a reactor be designed so that, "the reactor core and associated coolant system shall be designed so that in the power operating range the net effect of the prompt inherent nuclear feedback characteristics tends to compensate for a rapid increase in reactivity." While the CANDU design may satisfy this criterion, because it has a slightly negative overall power coefficient during normal power operation, void reactivity increases dramatically during a large-break LOCA. The Commission paper recommended that the presence of a positive void coefficient should not necessarily disqualify such a design, but the consequences of events which have the potential for rapid increases in reactivity, such as a large-break LOCA, should be analyzed. The calculations performed in this study provide some of the background needed to deal with this issue.

AECL codes and input decks were used in this study and were set up with conservative input to analyze postulated accidents of the type assessed in Chapter 15 of a Final Safety Analysis Report (FSAR). A lower probability accident, like a large-break LOCA with failure to shutdown, would be more appropriately analyzed using a best-estimate code input deck. However, such an input deck was not available and the base-case input deck was not changed for these analyses. The effect of the conservatively biased initial conditions is discussed within the report.

Parameter variations were selected to provide a sensitivity study, and do not correspond to any postulated mechanisms. For each transient studied, important parameters are varied. Also, the code output is assumed to be invalid beyond the time at which cladding or fuel melting temperatures are reached, so all the output has been truncated correspondingly and not considered in our analyses. Any analysis beyond melting temperatures would have to include severe accident treatment with fuel relocation.

Section 2 provides a brief summary of the CANDU 3 design characteristics.

Section 3 presents a description of the suite of computer codes developed by AECL to perform thermal-hydraulic and neutronic analysis and the modeling of the CANDU 3 design. The plant models used for the analyses are also described in Section 3. 
Section 4 presents the results of sensitivity studies performed for several transients with the "coupled" thermal-hydraulics and neutron kinetics code system provided by AECL. These transients include a large-break LOCA with shutdown systems operable, a large-break LOCA with failure to shutdown, a rod bank withdrawal transient with failure to shutdown, and a loss-of-off-site-power transient with and without shutdown. In Section 4.4, we also studied the large-break LOCA and small-break LOCA scenarios with successful shutdown and emergency core cooling system activation. Conclusions are drawn in Section 5 from the results of these calculations. 


\section{CANDU 3 DESIGN DESCRIPTION}

The CANDU 3 design is a derivative of the CANDU reactors that have been in operation for almost 30 years. Twenty-three CANDU-type reactors have been built and operated to date. The CANDU 3 is a lower power version of the currently operating CANDU concept and builds on an extensive data and information base, but at present CANDU 3 is in a conceptual design stage. Therefore, many details needed for extensive safety assessment and for PRAs are not available. The plant unit data are given in Table 1. A schematic of the CANDU 3 steam supply system is shown in Figure 1.

The reactor is cooled and moderated by heavy water and is fueled by natural uranium. The fuel is in the form of uranium dioxide pellets in zirconium alloy tubes. The cylindrical fuel bundles are $50 \mathrm{~cm}$ in length and each contains 37 fuel rods; 12 fuel bundles are contained within each of the zirconium-alloy pressure tubes. Two hundred and thirty-two pressure tubes are arranged so that each is fed by a coolant feeder tube from one of four inlet headers ${ }^{1}$. The heated coolant exits the pressure tubes and is collected in two outlet headers, which supply the primary-coolant side of two steam generators. The pressure tubes, feeder tubes, headers, pumps, pressurizer, fuel loading machine, and associated supply systems form the main pressure boundary.

The pressure tubes are contained inside zirconium-alloy calandria tubes; these penetrate the calandria vessel, which contains heavy water moderator at low pressure. The moderator system includes a moderator level control system, a pressure relief system employing rupture discs, a moderator cover gas control system that controls pressure as well as the buildup of combustible concentrations in the cover gas, and a moderator neutron poison system. The calandria vessel is contained within a shield tank that contains light water.

Refueling is performed continuously while at power. This is necessary because of the low excess reactivity due to the use of natural uranium. On-line refueling contributes to the historically very high capacity factors achieved by the CANDU class reactors. Refueling for the CANDU 3 differs from previous CANDUs in that all refueling is performed from one face of the reactor, whereas in prior designs fuel was inserted from one face and removed from the opposite face. For fuel removal, coolant pressure forces are relied upon to propel fuel bundles into the refueling machine. The refueling is automatically controlled by computer and can be observed remotely by the operators in the control room.

The reactor is controlled by a distributed digital control system. The major reason for this is that the core is sufficiently large in physical size to be potentially subject to spatial variations in neutron flux which must be locally monitored and controlled; manual control is not feasible.

Normal reactor control is accomplished by mechanical adjuster rods, zone controllers, and absorber rods, all of which enter the core from the top. Also, reactivity is controlled over the long term by the refueling scheme, which shuffles new and irradiated fuel, and by a boron liquid poison system in the moderator.

The reactor has a positive coolant void reactivity coefficient and could theoretically experience a power excursion from fuel channel voiding in, for example, a large LOCA. To rapidly shut down the reactor under large LOCA conditions, there are two independent safety shutdown systems designated as SDS1 and SDS2. SDS1 uses mechanical spring injected rods that enter the core from the top. SDS2 uses a helium pressure driven injection of a gadolinium nitrate poison solution, with the injectors entering the moderator vessel from the side (at right angles to the fuel and calandria tubes).

An emergency core cooling system (ECCS) employs a gas-driven high pressure injection system and a low pressure injection system, with long-term residual heat removal using pump-driven cooling water.

The containment system utilizes a steel-lined reinforced concrete building which has space coolers, but it does not have a spray or deluge system. It is designed to withstand a large break LOCA with loss of ECCS. However, a break in the main steam system internal to containment could exceed the design 
basis without exceeding the ultimate capability of the containment. The containment has a heavy-water vapor recovery system and a hydrogen-igniter system.

The plant is designed to provide physical separation between Group 1 systems and Group 2 systems. Generally, Group 1 systems provide for normal operation of the plant, and Group 2 systems provide safety backup. Group 2 systems are environmentally qualified, including seismic qualification. Electrical power supplies are arranged in four classes, I, II, III, and IV, depending on interruptablilty and reliability requirements.

More detail on the CANDU 3 design is provided in References 1,2, and 3.

Table 1. CANDU 3 unit data.

\begin{tabular}{|c|c|}
\hline $\begin{array}{l}\text { Reactor } \\
\text { Type } \\
\text { Coolant } \\
\text { Moderator } \\
\text { Number of fuel channels }\end{array}$ & $\begin{array}{l}\text { Horizontal pressure tube } \\
\text { Pressurized heavy water } \\
\text { Slightly pressurized heavy water } \\
232\end{array}$ \\
\hline $\begin{array}{l}\text { Fuel type } \\
\text { Form } \\
\text { Length of bundle } \\
\text { Outside diameter of bundle } \\
\text { Bundle weight } \\
\text { Bundles per fuel channel }\end{array}$ & $\begin{array}{l}\text { Rods consisting of natural } \mathrm{UO}_{2} \text { pellets clad in } 1.3 \\
\mathrm{~cm} \text { diameter Zircaloy- } 4 \text { tubes } \\
\text { Round fuel bundle array of } 37 \text { rods } \\
49.5 \mathrm{~cm} \\
10.2 \mathrm{~cm} \\
23.5 \mathrm{~kg} \text { (includes } 19.1 \mathrm{~kg} \mathrm{U} \text { ) } \\
12\end{array}$ \\
\hline $\begin{array}{l}\text { Heat Transport System } \\
\text { Number of steam generators } \\
\text { Steam generator type } \\
\text { Number of heat transport pumps } \\
\text { Heat transport pump type } \\
\text { Reactor outlet header pressure } \\
\text { Reactor outlet temperature } \\
\text { Reactor outlet void fraction } \\
\text { Reactor coolant flow } \\
\text { Steam temperature (nominal) } \\
\text { Steam quality (minimum) } \\
\text { Steam pressure }\end{array}$ & $\begin{array}{l}2 \\
\text { Vertical U-tube with integral steam drum and pre- } \\
\text { heater } \\
4 \\
\text { Vertical, centrifugal, single suction, single dis- } \\
\text { charge } \\
9.9 \mathrm{MPa} \text { (gauge) } \\
583 \mathrm{~K} \\
40 \% \\
5300 \mathrm{~kg} / \mathrm{s} \\
533 \mathrm{~K} \\
99.75 \% \\
4.6 \mathrm{MPa} \text { (gauge) }\end{array}$ \\
\hline Total fission heat & $1440 \mathrm{MW}(\mathrm{th})$ \\
\hline Net electrical output (nominal) & $450 \mathrm{MW}(\mathrm{e})^{\mathrm{a}}$ \\
\hline
\end{tabular}

a. Typical for a cold water site; net electrical output is dependent on cooling water temperature and on turbine-generator and condenser design. 


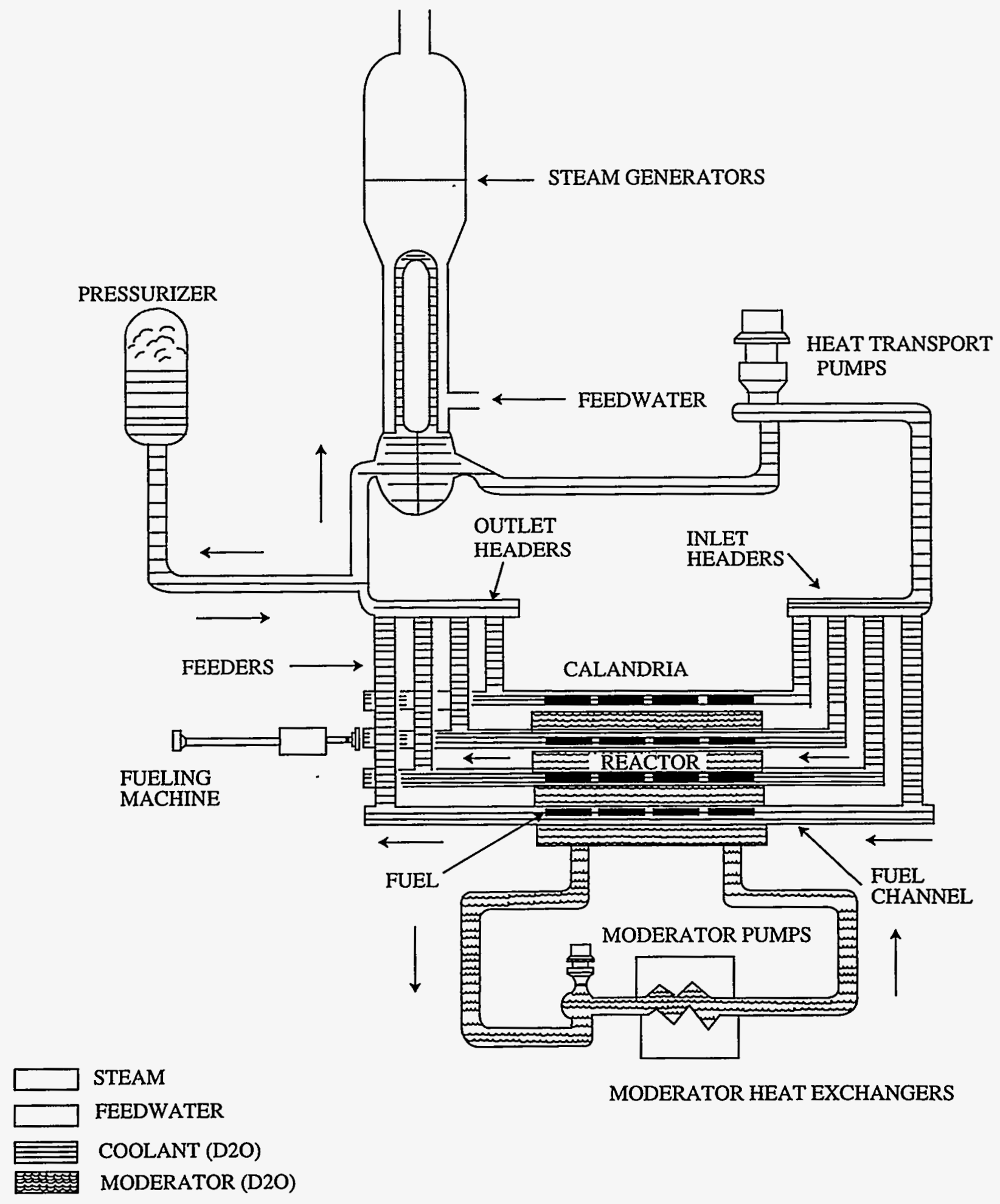

Figure 1. Schematic of the CANDU 3 PHWR steam supply system. ${ }^{1}$ 


\section{CODE AND MODEL DESCRIPTION}

This chapter describes the computer codes and input models used to perform the calculations discussed in this report. A ten-channel model of the primary loop was used for most of the calculations and is described in Section 3.2. Two baseline calculations described in Section 4.4 used a simpler fourchannel model, and its relation to the ten-channel model is also described in Section 4.4.

\subsection{Computer Code Description}

The computer codes used in these calculations are those developed by AECL to perform the design scoping analysis of the CANDU 3 reactor. The codes are identified in Table 2 along with a brief description of each code.

Table 2. AECL computer code description.

\begin{tabular}{|l|l|}
\hline \multicolumn{1}{|c|}{ Code } & \multicolumn{1}{|c|}{ Description } \\
\hline CATHENA $^{7}$ & $\begin{array}{l}\text { A one-dimensional two-fluid six-equation thermal hydraulics code capable } \\
\text { of modeling horizontal stratified flow. }\end{array}$ \\
\hline KINGPIN & $\begin{array}{l}\text { Extracts coolant temperature and density and fuel temperature from the } \\
\text { CATHENA model and builds an input file for POWDERPUFS-V. }\end{array}$ \\
\hline POWDERPUFS-V $^{8}$ & $\begin{array}{l}\text { Cross section generation code. Calculates cross sections for each fuel } \\
\text { channel axial segment for use in the CERBERUS code. }\end{array}$ \\
\hline MATMAP & $\begin{array}{l}\text { Processes geometric information, material assignments, and cross section } \\
\text { data from POWDERPUFS-V for use by CERBERUS. }\end{array}$ \\
\hline CERBERUS & $\begin{array}{l}\text { Calculates the time-dependent three-dimensional neutron flux distribution } \\
\text { using the Improved Quasi-static method. }\end{array}$ \\
\hline CERBSPOW & $\begin{array}{l}\text { Calculates the three-dimensional power distribution from the three-dimen- } \\
\text { sional flux distribution calculated by CERBERUS. }\end{array}$ \\
\hline INTREP & $\begin{array}{l}\text { Calculates the instrument response of in-core and ex-core detectors from } \\
\text { the CERBERUS flux distribution. }\end{array}$ \\
\hline CATCERB & $\begin{array}{l}\text { Constructs the CATHENA input file for the next time step based on the lat- } \\
\text { est power distribution calculated by CERBSPOW. }\end{array}$ \\
\hline TRIPDPG & $\begin{array}{l}\text { Calculates the time at which the trip setpoints are reached from the instru- } \\
\text { ment responses calculated by INTREP. }\end{array}$ \\
\hline
\end{tabular}

Most of the calculations discussed in Section 4 were performed with all the codes listed in Table 2 and are labeled as "Coupled" in this report. The power during these "Coupled" transients was calculated with the full three-dimensional kinetics model with temperature and density effects on the cross section data explicitly taken into account. Figure 2 shows the relationship between the different codes during a coupled transient calculation. The minimum communication time interval between CATHENA and CERBERUS calculations was 50 milliseconds for all the calculation discussed in this report. A result of this coupling is that the power in the CATHENA is held constant over each 50 millisecond interval and the CERBERUS calculations are based on thermal-hydraulic conditions at the end of the 50 milli-second step. 
Calculations were performed with a 10 millisecond communication time interval, and no discernible differences were found between the two calculations.

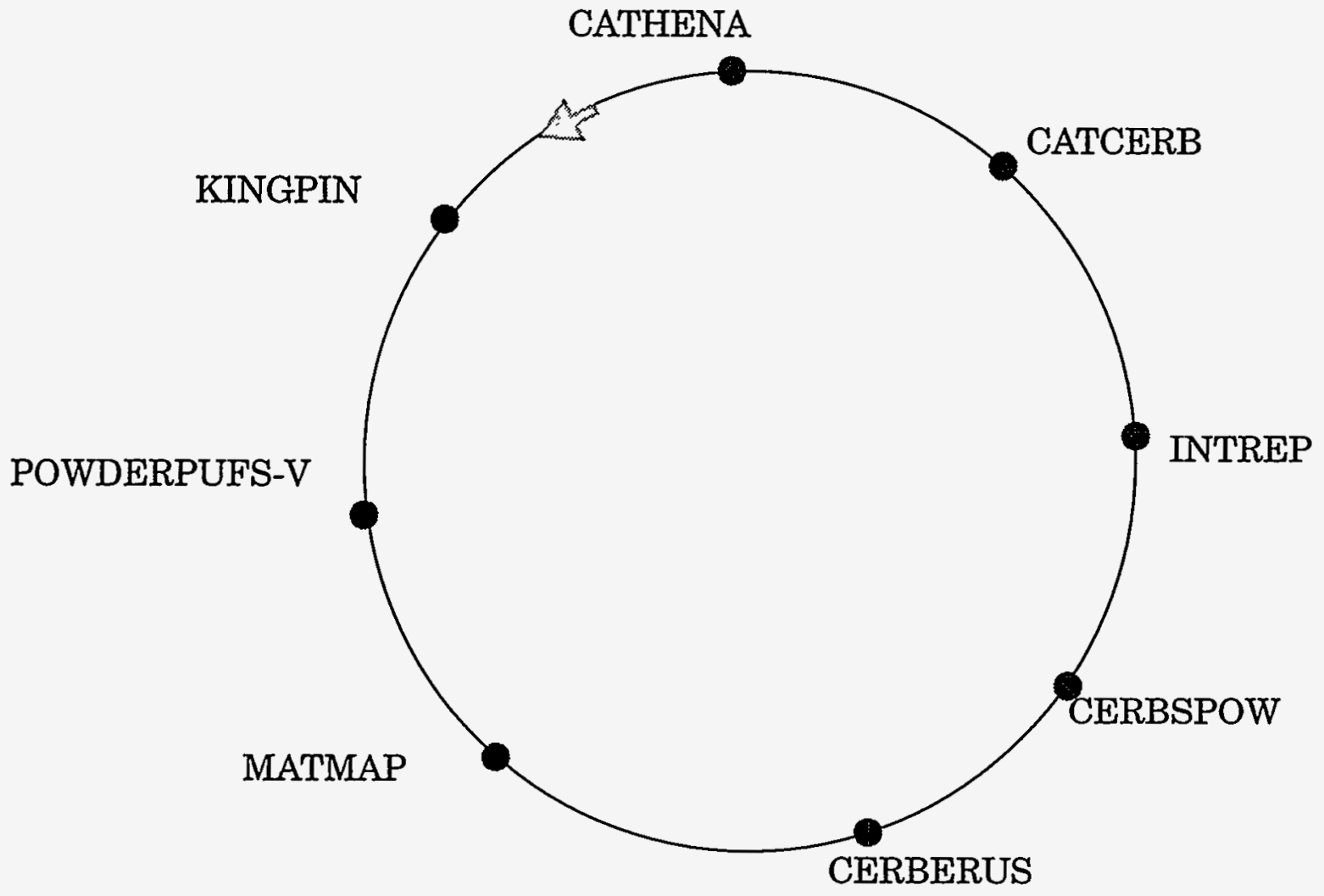

Figure 2. Sequence of codes used for the coupled calculations.

Calculations performed with CATHENA using an input power history are labeled as "Uncoupled" in this report and discussed in Section 4.4. Power during the transient with SDS1 activated was precalculated and input to the code. The power history used was that provided by AECL.

\subsection{Ten-Channel CATHENA Primary Loop}

CATHENA is a two-fluid six-equation code. The version of CATHENA used for these calculations is 3.4b Rev 6 with three additional updates to allow it to run on the INEL UNIX workstations. Figure 3 shows a CATHENA nodalization diagram of the primary loop. CANDU 3 reactors have two steam generators and four primary pumps. Consequently they have two headers at the core exit and four headers at the inlet. The primary loop is filled with heavy water and the secondary loop uses light water. The primary loop has a figure-8 type flow path since fluid goes through both steam generators during a complete loop through the system. The numbers in the boxes in Figure 3 represent the number of hydraulic cells for that component. Empty boxes represent one cell 


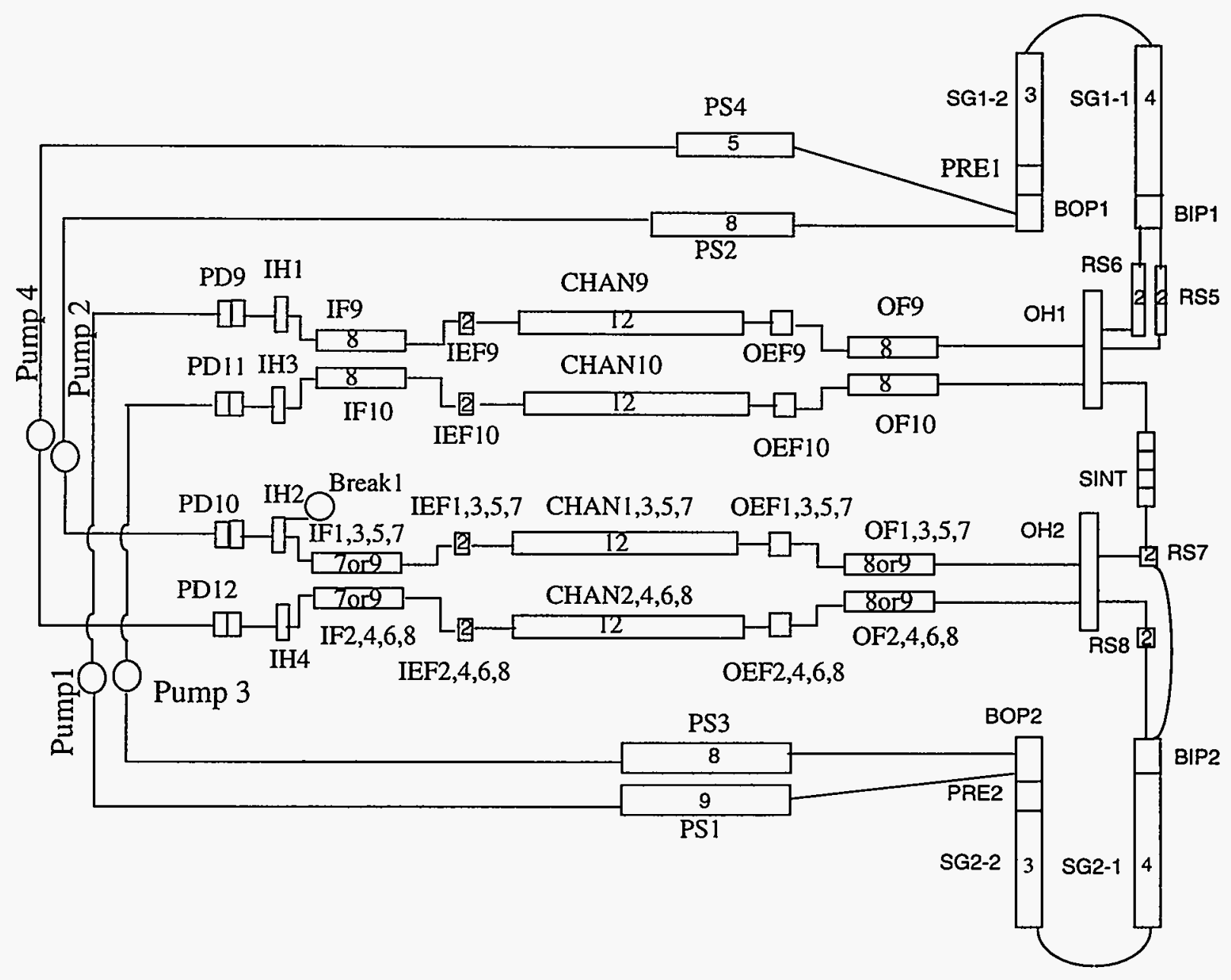

Figure 3. CANDU 3 primary loop nodalization.

The 232 core pressure tubes are modelled by ten CATHENA channels. Eight channels model half the core and two channels model the other half. Figure 4 illustrates the channel groupings. This figure demonstrates that the 58 feeder pipes connected to each inlet header distribute liquid to a one-half core sector rather than to a one-quarter sector of the core. This is because the feeder pipes from each header delivers fluid to vertically alternating pressure tubes in each core half.

Table 3 gives the number of core pressure tubes each CATHENA channel represents. It also gives the power per channel and the power per unit flow. This input file models a $6 \%$ power tilt which contributes to the mismatch in power per unit flow among the channels. Power is tilted toward the right hand side of the core. 


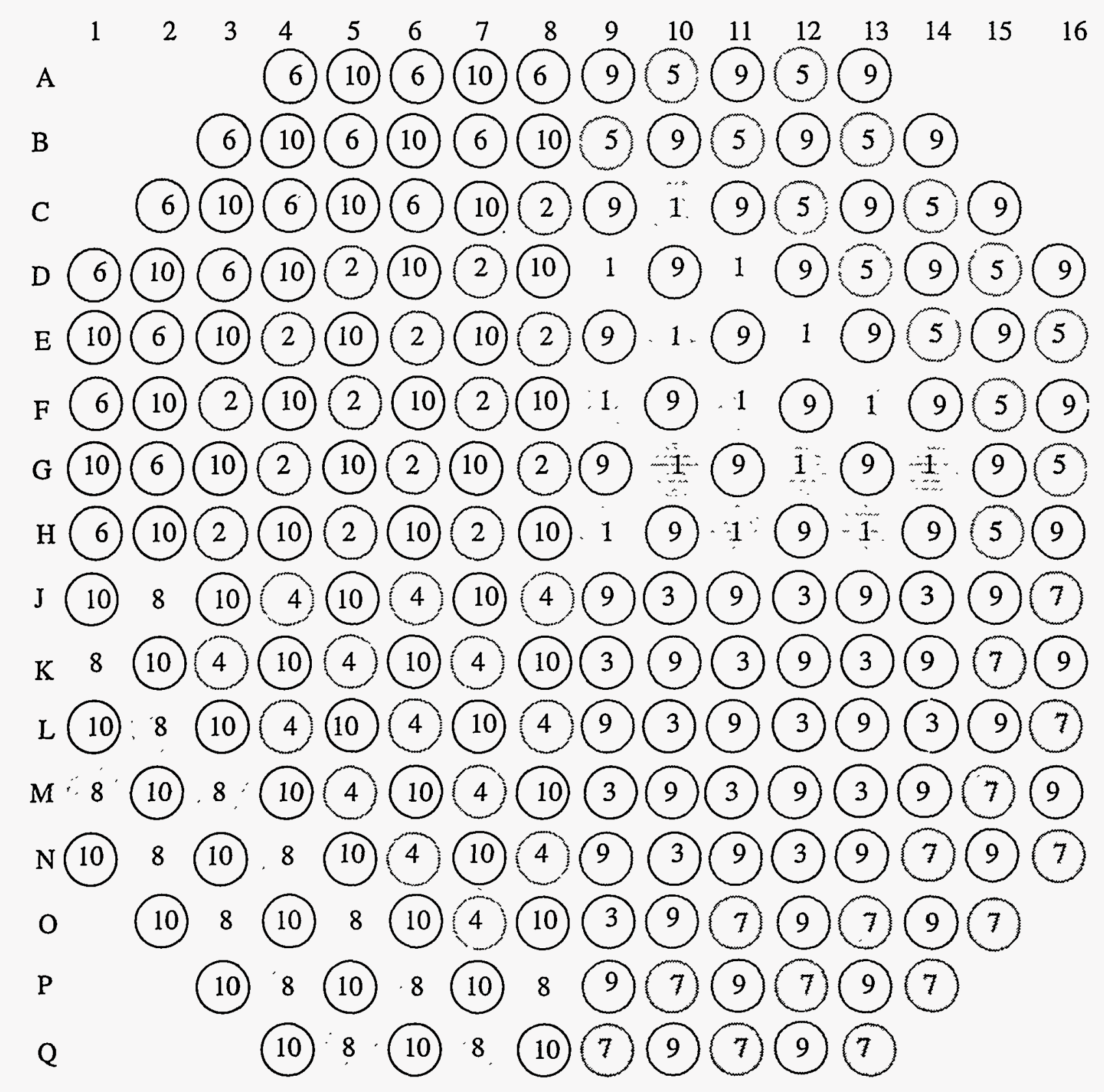

Figure 4. Core cross-section showing CATHENA channel groups. 
Table 3. Channel radial power profile.

\begin{tabular}{|c|c|r|r|r|r|r|r|}
\hline $\begin{array}{c}\text { CATHENA } \\
\text { Channel } \\
\text { Number }\end{array}$ & $\begin{array}{c}\text { Connected } \\
\text { to Inlet } \\
\text { Header }\end{array}$ & $\begin{array}{c}\text { Power } \\
\text { MW }\end{array}$ & $\begin{array}{c}\text { Number } \\
\text { CANDU } \\
\text { Fuel } \\
\text { Channels }\end{array}$ & $\begin{array}{c}\text { MW/ } \\
\text { Channel }\end{array}$ & $\begin{array}{c}\text { Radial } \\
\text { Peaking } \\
\text { Factor }\end{array}$ & $\begin{array}{c}\text { Flow per } \\
\text { Channel } \\
\mathrm{kg} / \mathrm{s}\end{array}$ & $\begin{array}{c}\text { Power/ } \\
\text { Flow } \\
\mathrm{MW} / \mathrm{kg} / \mathrm{s}\end{array}$ \\
\hline 1 & IH2 & 104.89 & 14 & 7.49 & 1.23 & 24.17 & 0.31 \\
\hline 2 & IH4 & 99.37 & 15 & 6.63 & 1.09 & 25.02 & 0.26 \\
\hline 3 & IH2 & 112.24 & 15 & 7.48 & 1.23 & 24.61 & 0.30 \\
\hline 4 & IH4 & 94.67 & 14 & 6.76 & 1.11 & 25.23 & 0.27 \\
\hline 5 & IH2 & 79.32 & 14 & 5.67 & 0.93 & 20.68 & 0.27 \\
\hline 6 & IH4 & 67.84 & 15 & 4.52 & 0.74 & 21.63 & 0.21 \\
\hline 7 & IH2 & 79.16 & 15 & 5.28 & 0.87 & 21.18 & 0.25 \\
\hline 8 & IH4 & 68.27 & 14 & 4.88 & 0.80 & 21.39 & 0.23 \\
\hline 9 & IH1 & 375.61 & 58 & 6.48 & 1.06 & 22.76 & 0.28 \\
\hline 10 & IH2 & 330.12 & 58 & 5.69 & 0.94 & 23.36 & 0.24 \\
\hline Total & & $1411.5^{\mathrm{a}}$ & 232 & 6.08 & & & \\
\hline
\end{tabular}

a. Because of heat losses to the moderator, the total channel power is slightly lower than the total fission heat given in Table 1.

The first eight channels have 19 fuel rod groups modelled in them while channels nine and ten have only one. A fuel rod group is a collection of fuel rods that are lumped together for the temperature calculations. The 19 rod group set assumes half bundle symmetry while the single rod group set lumps all fuel rods together. Each pressure tube has 37 fuel rods per bundle and 12 fuel bundles are placed end-toend in each pressure tube.

The CANDU 3 steady-state core power is high enough to cause saturated boiling at the channel exit. During normal operation of the CANDU 3 core, the core exit flow quality is roughly $4 \%$ (equivalent to 30 to $40 \%$ void fraction). The initial void profile influences the transient power profile because it affects how much the void fraction can change during the transient. Figure 5 shows the axial void profile for three of the ten channels. Notice that channel 9 has a higher exit void fraction than channel 2 even though power is lower (see Table 3). The input power and flow resistances are such that channel 9 has a higher power/flow than channel 2. Table 3 gives the power per unit flow for each channel. Although the flow resistance values given in the input file for channels 2 and 9 are about the same, channels 6 and 8 have larger resistances than 2. Since 2 is in parallel with 6 and 8 it gets a larger flow rate than does the average channel 9. 


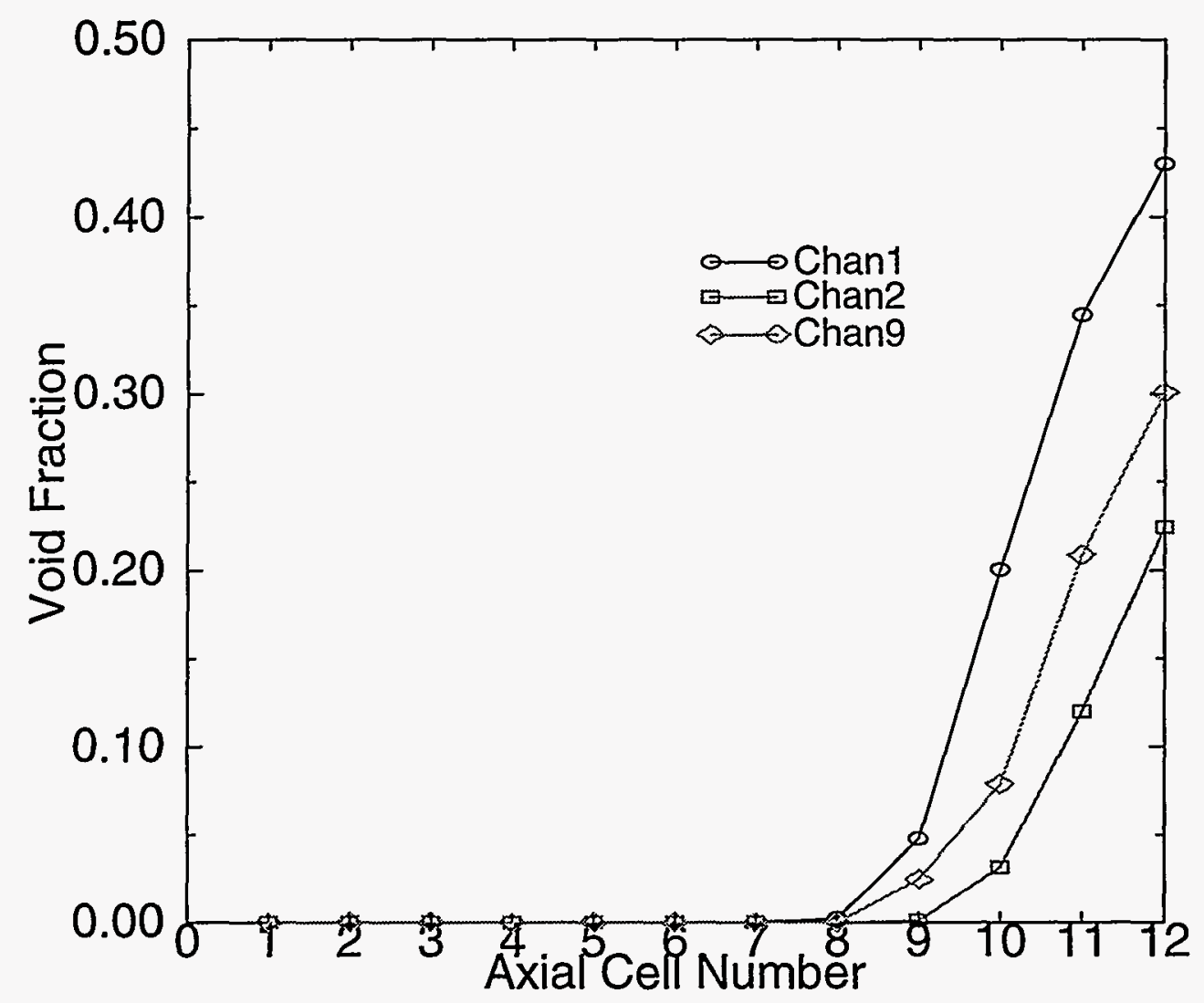

Figure 5. Steady-state axial void profile.

CANDU transients are sensitive to whether off-site power is available. When this power is available, all four primary loop pumps continue to operate for 15 minutes after a LOCA signal is generated. This pump-trip time delay is intended to allow the emergency core cooling system to bring the fuel temperature down. For the cases analyzed here, a LOCA signal was generated when the pressure in outlet header 1 dropped below $6 \mathrm{MPa}$. Outlet header 1 is used for this signal detection rather than outlet header 2 because it is hydraulically further from the pressurizer. In the event of a loss of off-site-power the pumps have no long term power source.

\subsection{Secondary Loop}

The secondary loop has a feedwater reservoir which supplies the secondary side of both steam generators. Separators at the top of the steam generators send steam to the turbine and water to the downcomer. The CATHENA nodalization is shown in Figure 6.

A LOCA signal causes the Emergency Core Cooling system to activate and allows the main steam safety valves to begin opening. Flow from these valves causes the secondary to blowdown and helps cool the primary water more rapidly (crash cooldown). 


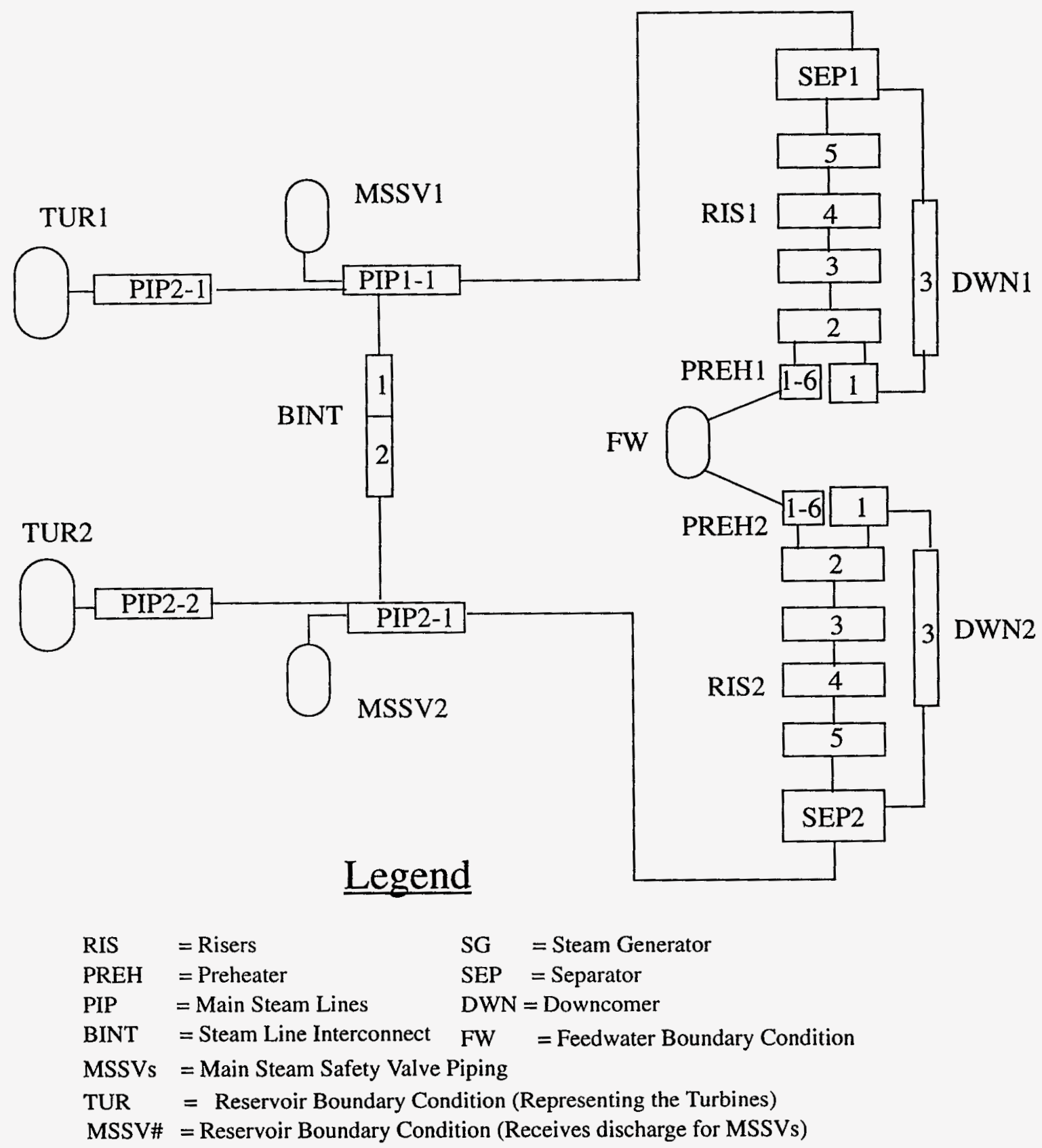

Figure 6. CANDU 3 secondary side nodalization.

\subsection{Emergency Core Cooling System}

The emergency core cooling system was part of the input file for the long transient calculations and was not actuated during the short time span of the coupled calculations described in Section 4. However, since its nodalization diagram contains part of the primary loop, it is illustrated at this point (see Figure 7). The pressurizer is attached between ECO 11 and 12. All but ECO12 and the pressurizer were eliminated from the input file for the power pulse calculations to save computer time. 
All six headers are fed by water from the Emergency Core Cooling system. The train labeled ECO in Figure 7 connects to the two outlet headers and the train labeled ECI in Figure 7 connects to the four inlet headers. Rupture discs in the Emergency Core Cooling lines burst when a differential rupture pressure of $0.35 \mathrm{MPa}$ is reached. High pressure Emergency Core Cooling injection comes from an accumulator and low pressure injection is pumped from a grade level tank. The accumulator tank has 150 $\mathrm{m}^{3}$ of air and $300 \mathrm{~m}^{3}$ of light water at an initial pressure of $6.43 \mathrm{MPa}$ and a temperature of $323 \mathrm{~K}$. One control volume models the two accumulator tanks in the plant. One of two low pressure pumps cause water to flow in a circular path until low pressure loop check valves open. They open after the accumulator has dumped enough effluent to reduce the pressure downstream below the pump pressure. Low pressure water comes from a grade level tank at a temperature of $323 \mathrm{~K}$. 


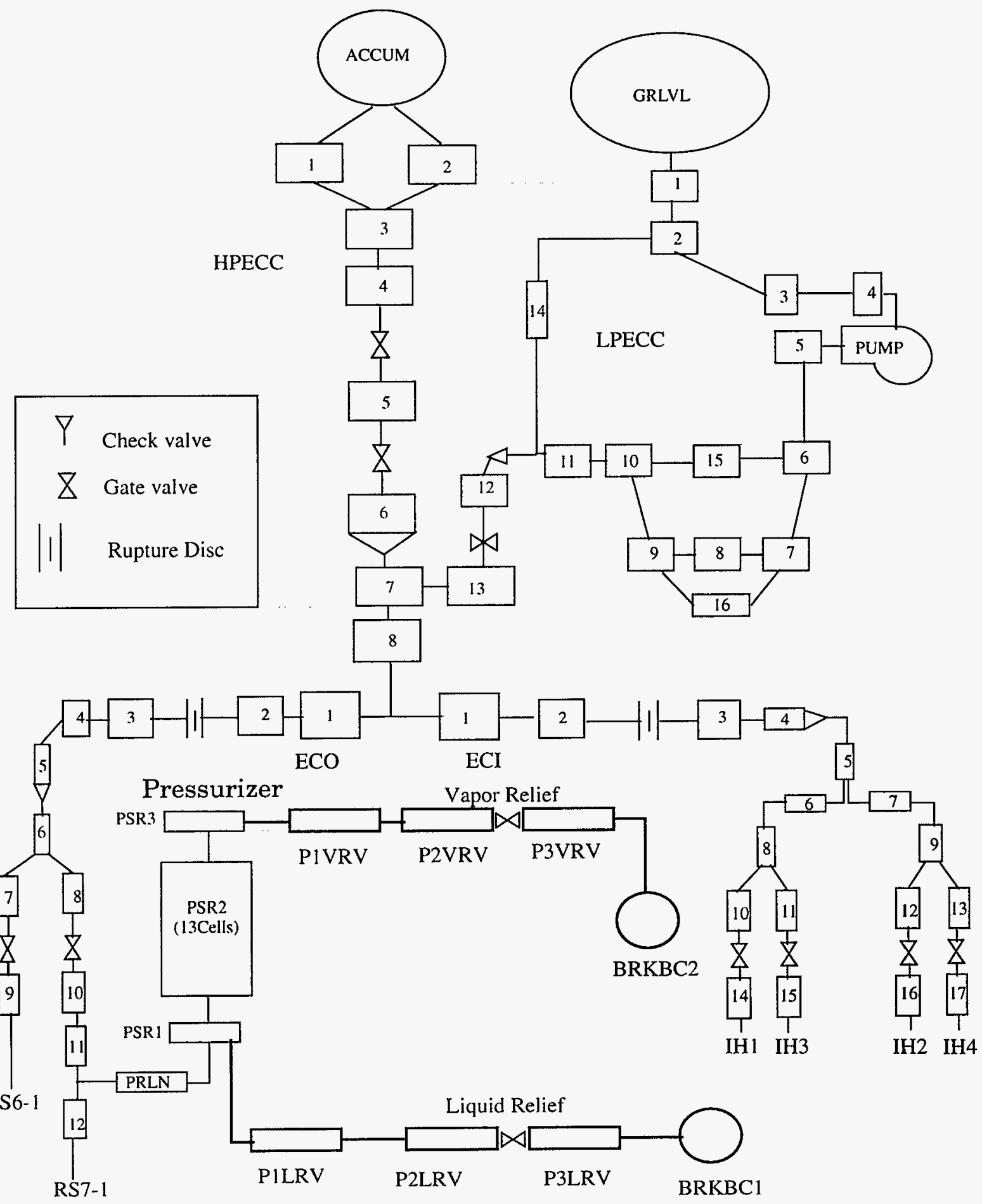

Figure 7. CANDU 3 ECCS nodalization diagram. 


\subsection{CATHENA Relief Valves}

The power pulse models received from AECL did not contain the liquid and vapor relief valves that were needed to perform the loss-of-off-site power calculations. These valves were added based on discussions with AECL.

The pressurizer is attached between CATHENA pipes ECO11 and 12 as shown in Figure 7. In the CANDU 3 plant, the pressurizer is connected to the bleed condenser tank by two pipes. There is a liquid relief valve in each of the two lines. The pipes have a diameter of 0.09205 meters, a total length of about 16 meters and a pressure loss coefficient of 4.79. The parallel pipes and valves are modelled as one in CATHENA. A vapor relief valve is modelled the same as the liquid relief valve and it is attached to the top of the pressurizer. Table 4 contains the length, area and loss coefficient for each CATHENA pipe segment added to the model.

Table 4. Relief pipe parameters.

\begin{tabular}{|l|l|l|l||l|l|l|}
\hline Parameter & $\begin{array}{c}\text { Liquid } \\
\text { P1LRV }\end{array}$ & $\begin{array}{c}\text { Liquid } \\
\text { P2LRV }\end{array}$ & $\begin{array}{c}\text { Liquid } \\
\text { P3LRV }\end{array}$ & $\begin{array}{c}\text { Vapor } \\
\text { P1 VRV }\end{array}$ & $\begin{array}{c}\text { Vapor } \\
\text { P2VRV }\end{array}$ & $\begin{array}{c}\text { Vapor } \\
\text { P3VRV }\end{array}$ \\
\hline length $(\mathrm{m})$ & 6.0 & 1.0 & 9.0 & 6.0 & 1.0 & 9.0 \\
\hline area $\left(\mathrm{m}^{2}\right)$ & 0.006655 & 0.01331 & 0.01331 & 0.006655 & 0.01331 & 0.01331 \\
\hline $\mathrm{K}$ loss & 2.4 & 0.4 & 2.0 & 2.4 & 0.4 & 2.0 \\
\hline
\end{tabular}

The CATHENA relief valve did not function properly in the mode where repeated restarts were required during the "coupled" calculations. The relief valve was set to open at a pressure of $10.34 \mathrm{MPa}$ and close at $10.1 \mathrm{MPa}$. The opening time was one second and the closing time was three seconds. CATHENA was restarted at the end of each kinetics calculation. However, CATHENA did not keep track of where in the opening sequence it was as illustrated in Figure 8. Restarts were occurring every quarter second. The graph does not show the open fraction starting at zero at each restart only because plot points were not exactly sequenced with restart times. Another problem with the CATHENA 'relief' valves is that they can only monitor the pressure in the cell just upstream of the valve. This can result in flow oscillations. 


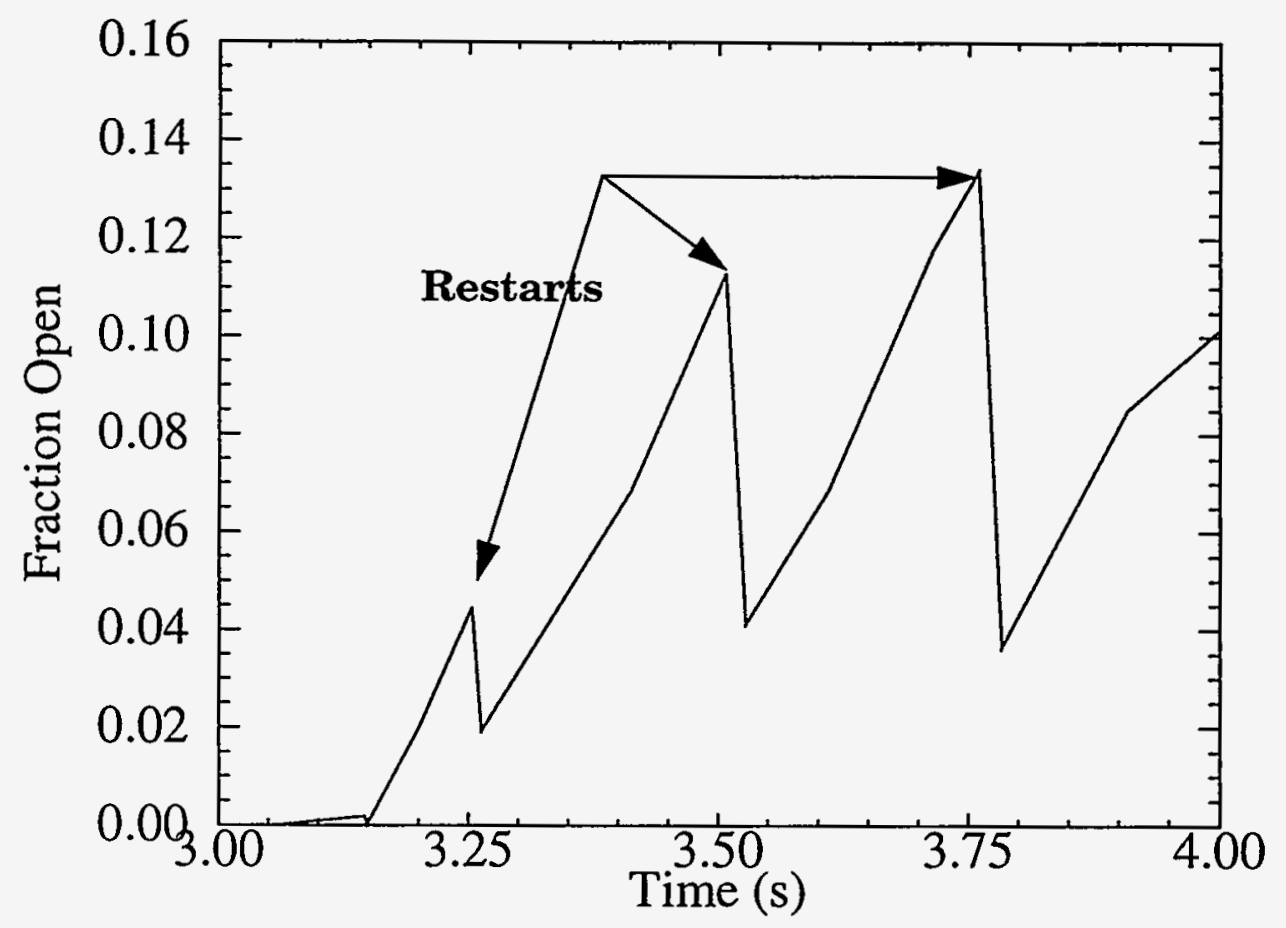

Figure 8. Behavior of relief valve.

To work around the relief valve problem, both the liquid and vapor relief valves were replaced with generic valves opened by a control system. The time ramps and pressure hysteresis were not modelled. They were opened and closed linearly with pressurizer pressure as shown in Table 5. (After the analysis was completed, we found that in the latest CANDU 3 design, the valves actually monitor the outlet header.) Since the pressurizer is a much larger volume than the cell next to the valve, the valve flow is stable. The liquid valve control pressure was in cell PSR1 at the bottom of the pressurizer and the vapor valve controller monitored the pressure at the top of the pressurizer (cell PSR3).

Table 5. Parameters used for replacement relief valves.

\begin{tabular}{|l|l|l|}
\hline \multicolumn{1}{|c|}{ Pressure (MPa) } & \multicolumn{1}{|c|}{$\begin{array}{c}\text { Liquid Relief Valve } \\
\text { Fraction Open }\end{array}$} & \multicolumn{1}{|c|}{$\begin{array}{c}\text { Vapor Relief Valve } \\
\text { Fraction Open }\end{array}$} \\
\hline 10.0 & 0.0 & 0.0 \\
\hline 10.2 & 0.0 & \\
\hline 10.5 & 1.0 & 0.0 \\
\hline 10.3 & & 1.0 \\
\hline 10.6 & & 1.0 \\
\hline 20.0 & 1.0 & 0.61 \\
\hline Discharge Coefficient & 0.61 & 0.006655 \\
\hline Area (m2) & 0.006655 & \\
\hline
\end{tabular}




\subsection{Three-Dimensional Kinetics Model}

The three-dimensional kinetics model is the same one described in Reference 4 and only a brief description is given here. There are primarily three sets of input files used for the kinetics modeling and each is discussed below.

The POWDERPUFS- $\mathrm{V}^{8}$ code is used to calculate the cross section data for the thermal-hydraulic conditions that exist in each axial segment of each of the ten fuel channels modeled in CATHENA. A basic input file is developed that contains input sections for each of the 120 fuel types used in the model. A fuel type is a unique combination of thermal-hydraulic parameters used to calculate cross sections. The CATHENA model has 10 fuel channels and each has 12 volumes along the fuel channel, and these 120 volumes define the thermal-hydraulic conditions for each fuel type. At each time point, the coolant density, coolant temperature, and fuel temperature data from each of these 120 volumes are extracted from the CATHENA results and processed into a POWDERPUFS-V input file for the current time step.

The MATMAP code input consists of geometric information concerning mesh sizes, cross section set assigned to each mesh cell, and the location and type of all reactivity devices present in the core. Basically, the X-Y geometric model is as shown in Figure 4, with either one or two mesh intervals per pressure tube and additional mesh intervals for modeling the reactivity devices. These constraints result in 36 mesh intervals in the X-direction and 24 mesh intervals in the Y-direction. The axial model consists of fourteen mesh intervals, which is one per fuel bundle except for the bundle on each end which has two equal size mesh intervals. The mesh interval information and the cross sections from POWDERPUFS-V are then processed into coefficients of the diffusion equation for use by CERBERUS.

The CERBERUS code solves the time-dependent diffusion equation using the improved quasistatic method with data calculated by MATMAP. The CERBERUS input includes information about the number of delayed neutron groups, the steady-state power, steady-state or transient solution, and flux shape re-calculation time interval.

The CERBERUS model used in previous studies ${ }^{4}$ did not model the Mechanical Control Absorbers (MCAs). AECL provided the location of the MCAs and stated that they were of the same design as the shutoff rods, but with a higher resistance to movement that resulted in a slower insertion time. Figure 9 shows the relative locations of the four MCAs and the 24 shutoff rods.

For these calculations, both the Mechanical Control Absorbers and the Shutoff Rods (SDS1) are dropped into the core at various times. A delay of 380 milli-seconds from trip signal to the time the rods reach the first row of fuel channels is assumed for both types of rods. This is the same value used by AECL and INEL for the LOCA calculations reported in Reference 12. Table 6 shows the trip setpoints used in these calculations obtained from Reference 13. Figure 10 shows the rod movement for the different banks. The times and distances for SDS1 were reported in Reference 4 and the MCA times were assumed to be 3 times those of the SDS1 based on AECL comments of a 3 second insertion time for the MCAs. When the SDSI rods are activated, the two most reactive shutoff rods are not released in these simulations. This is consistent with the calculations performed in Reference 12.

Table 6. Trip setpoints used in these calculations.

\begin{tabular}{|c|c|}
\hline Parameter & Setpoint \\
\hline Outlet Header Pressure & $10.55 \mathrm{MPa}$ \\
\hline Core Flow & $70 \%$ \\
\hline Neutron Flux Level & $114 \%$ \\
\hline High Log Rate & $15 \% / \mathrm{sec}$ \\
\hline
\end{tabular}




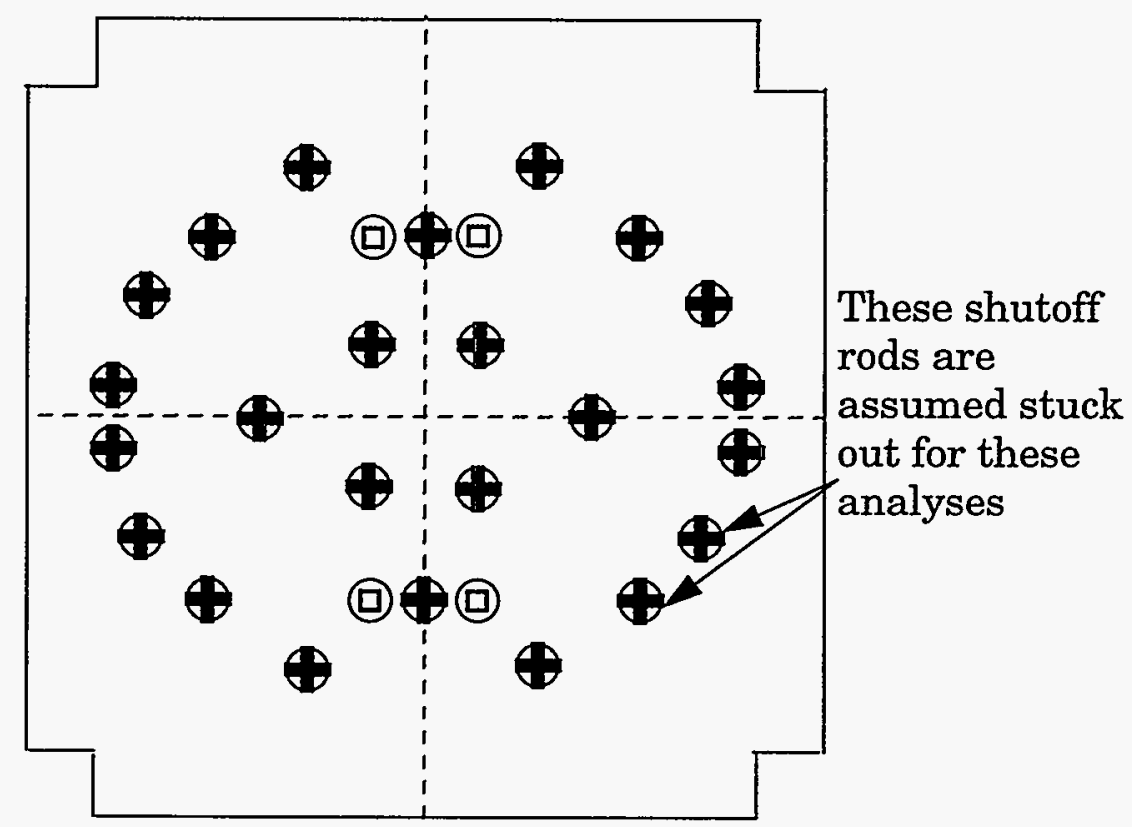
QD
Shutoff Rods
(D) Control Absorbers

Figure 9. Location of shutoff and mechanical control absorbers in the CANDU 3 core.

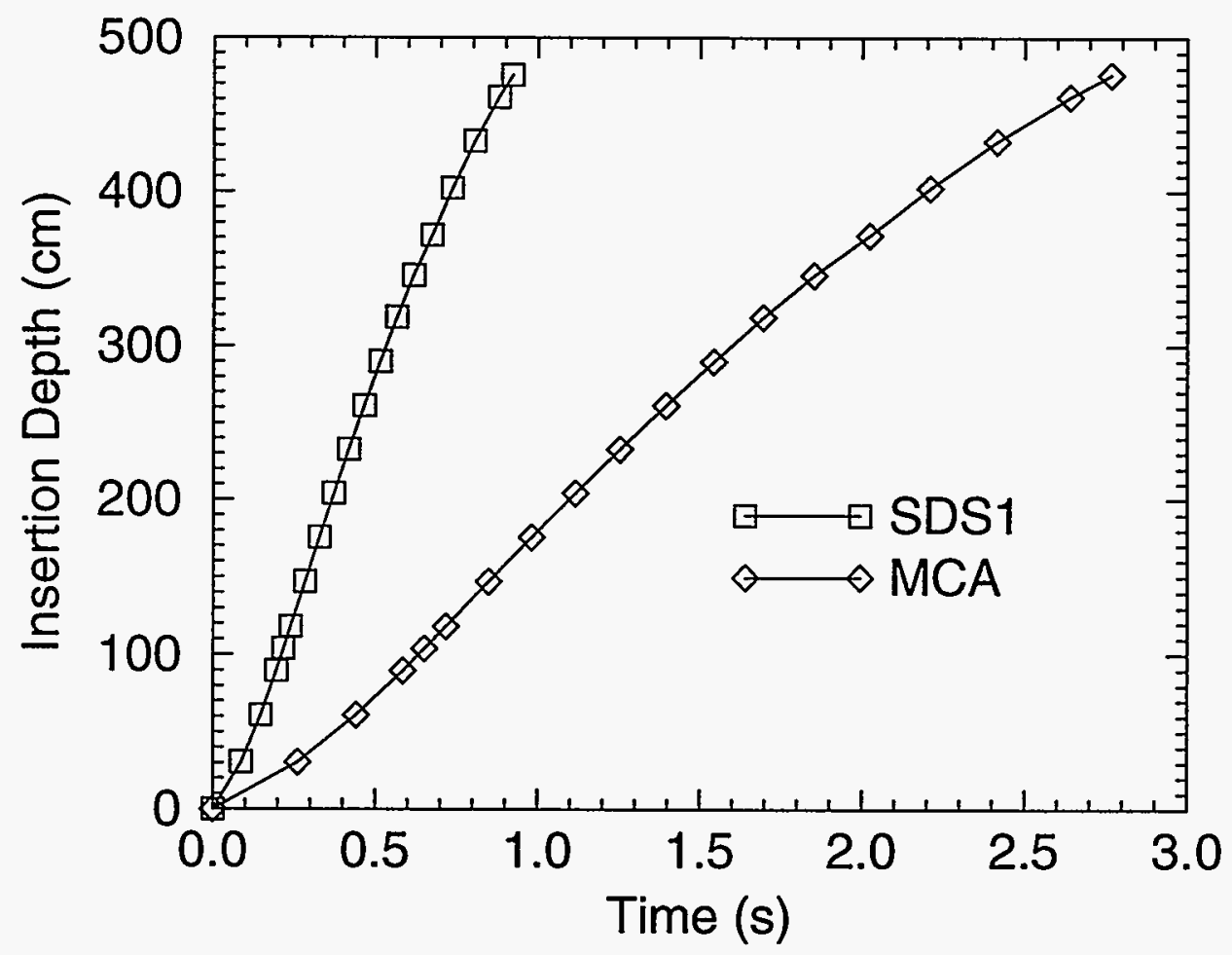

Figure 10. SDS1 and MCA movement versus time. 


\section{CALCULATIONAL RESULTS}

This section presents the results of calculations performed for three transients; a LOCA, a rod bank withdrawal, and a loss-of-off-site-power. These transients were selected to assess the transient response of the CANDU 3 design to positive reactivity insertions, either from an uncontrolled adjuster rod withdrawal, or from void formation. The calculations in Sections Section 4.1, Section 4.2, and Section 4.3 were performed with the codes identified in Figure 2, the 10 channel CATHENA input model described in Section 3.2 and Section 3.3, and the kinetics models described in Section 3.6. The calculations in Section 4.4 were performed with CATHENA alone with the CATHENA model described in Section 3.2, Section 3.3, and Section 3.4.

The initial conditions of the reactor for these calculations were $103 \%$ power, a $6 \%$ power tilt towards the side of the core where the inlet header break is modelled, and a value of coolant purity of 96.36\% which increases the void reactivity insertion. These are conservative conditions which are used for design basis accidents. Some of the transients discussed in this section are performed with failure to shutdown which would have a lower likelihood than a design-basis accident, and therefore should be performed with best-estimate inputs. The effect of performing these severe accident calculations with conservative input leads to differences of at most 1 second in the time to onset of core damage.

Section 4.1 describes the sensitivity calculations performed for the large-break LOCA, Section 4.2 describes the adjuster rod bank withdrawal calculations, and Section 4.3 discusses the loss-of-off-sitepower calculations. Section Section 4.4 describes the baseline calculations made with the CATHENA code alone to gain familiarity with the ECCS response during large-break and small-break LOCAs.

\subsection{Large-Break LOCA Sensitivity Calculations}

The LOCA event for a CANDU-3 reactor results in a quick partial voiding of the core which causes a positive reactivity insertion due to the positive void coefficient of the reactor. For this reason, a significant change in the spatial flux distribution results from the non-symmetric voiding behavior and this requires a full three-dimensional kinetics capability. The coupling of the spatial kinetics was discussed in Section 3.1.

Core power is calculated by the kinetics code suite during the power pulse transient. Therefore, the core power changes with time because the fuel and fluid temperatures and channel void fractions change and affect the core reactivity. The power initially shifts to the outlet end of the channels because that is where the hot water is and where voiding begins. Since CANDU 3 reactors have a positive void feedback coefficient, they are designed with two redundant shutdown systems. They have a rod injection system with rods entering the moderator tank from the top (called shutoff rods or SDS1) and a liquid poison injection system with injectors entering the tank from the side (called SDS2). Use of the phrases 'without scram' or 'failure to shutdown' in this report mean that both safety grade shutdown systems are assumed to fail and that the reactor regulating system does not operate.

The base-case input deck for the LOCA calculations was for a $100 \%$ reactor inlet header break at $103 \%$ of full power with a $6 \%$ tilt. The tilt is toward the side fed by inlet headers 1 and 2 . The break location is inlet header number 2 . The break area is twice as large as the header cross-sectional area (a double-ended guillotine break). The initial reactor power is $1411 \mathrm{MW}$.

\subsubsection{Large-Break LOCA with Scram}

A series of calculations was run to evaluate the effect of changing individual parameters on the core response. A $100 \%$ inlet header break was selected as the base case based on results given in Reference 4 that state that the $100 \%$ inlet header break is the most limiting break for the CANDU- 3 design. Sensitivity calculations were performed for cases with scram. Scram by the shutoff rods (SDS1) was simulated in the calculations, but the initiation of the scram was determined by the slowest trip signal of those presented in Table 6 . This calculation was also used to verify correct installation of the AECL code 
suite. The results presented in this report were compared to the results reported by AECL in Reference 4 and were found to be identical, which verified the code installation.

Two parameters were varied for these calculations, coolant purity and scram time. Coolant purity was selected because it affects the void reactivity that is inserted during the blowdown. The value assumed by AECL in Reference 4 was $96.36 \%$ heavy water and this value was as the base case value in these sensitivity calculations. A lower value of coolant purity results in a larger value of positive reactivity inserted during a LOCA while a higher purity results in a lower value of void reactivity. The movement of the shutoff rods was delayed one second to assess the effect on core performance of less than optimal shutdown system response.

Table 7 presents the parameters that are varied and a brief summary of the peak values of power, reactivity, cladding surface temperature, and fuel centerline temperature achieved during the transients with scram.

Table 7. LBLOA with scram sensitivity cases.

\begin{tabular}{|l|l|l|r|r|r|r|}
\hline Scram & $\begin{array}{c}\text { Parameter } \\
\text { Varied }\end{array}$ & $\begin{array}{c}\text { Parameter } \\
\text { Value }\end{array}$ & $\begin{array}{c}\text { Peak } \\
\text { Relative } \\
\text { Power }\end{array}$ & $\begin{array}{c}\text { Peak } \\
\text { Reactivity } \\
(\Delta \mathrm{k} / \mathrm{k})\end{array}$ & $\begin{array}{c}\text { Peak Clad } \\
\text { Surface } \\
\text { Temperature } \\
(\mathrm{K})\end{array}$ & $\begin{array}{c}\text { Peak Fuel } \\
\text { Centerline } \\
\text { Temperature } \\
(\mathrm{K})\end{array}$ \\
\hline Nominal & Base Case & $96.36 \%$ & 2.14 & 0.00356 & 1108 & 1953 \\
\hline Nominal & $\begin{array}{l}\text { Coolant } \\
\text { Purity }\end{array}$ & $99.722 \%$ & 1.81 & 0.00290 & 1096 & 1934 \\
\hline Nominal & $\begin{array}{l}\text { Coolant } \\
\text { Purity }\end{array}$ & $93 \%$ & 2.59 & 0.00419 & 1124 & 1979 \\
\hline Delayed & Scram Time & $\begin{array}{l}\text { Delayed } 1 \\
\text { second }\end{array}$ & 4.97 & 0.00480 & 1377 & 2239 \\
\hline
\end{tabular}

Figure 11 shows the behavior of the normalized power for each of the four cases performed. As expected, the delayed shutdown case results in the highest peak power. The coolant purity does not significantly affect the timing of the peak power, but the lower coolant purity yields a higher peak power. All four cases have returned to decay heat levels by 2.5 seconds after the break. Figure 12 presents the break flow behavior for all four cases and shows no significant difference in the break flow. The primary pressure in the inlet header is the driving force for break flow and it is not very sensitive to reactor power during the few seconds analyzed. Figure 13 shows the coolant flow through fuel channel 1 . The flow reverses very quickly in this channel because it is connected directly to the broken inlet header (IH2). There is very little difference in the flow behavior between all cases, although there is an increase in the reverse flow for the delayed scram case near the time of peak power and the beginning of shutoff rod insertion. Figure 14 shows the coolant flow through fuel channel 9, which represents $25 \%$ of the fuel channels in the core. There is a flow perturbation that occurs at approximately 1.6 seconds when the fuel transitions from nucleate boiling to film boiling. Figure 15 shows the reactivity behavior during the transient. The sensitivity of reactivity to the varied parameters is as expected. The reactivity at no time exceeds prompt critical $(0.006 \Delta \mathrm{k} / \mathrm{k})$. Figure 16 shows the channel 1 average void fraction during the transient. Since channel 1 is connected to the broken inlet header, the void fraction is highly dependent on the pressure in the channel and this is essentially the same for all four cases. Figures 17 and 18 show the channel 2 and 9 void fraction behavior, respectively. In both channels the void fraction is more sensitive to the core power because they are not connected to the broken header and the pressure in these channels has not been reduced significantly over the time of the calculation. Figure 19 shows the peak clad surface temperature response for all four cases. All cases go into film boiling immediately after the break and the 
temperature stays well below the Zircaloy melting temperature $(2100 \mathrm{~K})$ for the time of the calculation, but ECC would be required to cool the core over a longer time span. Even though the Zircaloy melting temperature is not exceeded, some fuel pins are in the temperature range of the alpha-beta phase transition $(1050 \mathrm{~K}-1200 \mathrm{~K})$. Figure 20 shows the peak clad surface temperature for channel 9 . All cases except the delayed scram case remain at $T_{\text {sat. }}$. The delayed scram case reaches the nucleate to film boiling transition at approximately 1.6 seconds and the temperature continues to rise until power has been reduced to decay heat levels. Figures 21 and 22 show the peak fuel centerline temperature behavior for channels 1 and 9 , respectively. The temperature remains below the melting point of $\mathrm{UO}_{2}$ throughout the time analyzed.

These calculations show that as long as scram occurs, no fuel damage will occur for at least the first 4 seconds of a large-break LOCA. Results for longer times into a large-break LOCA that include the effects of ECC are given in Section 4.4.1.

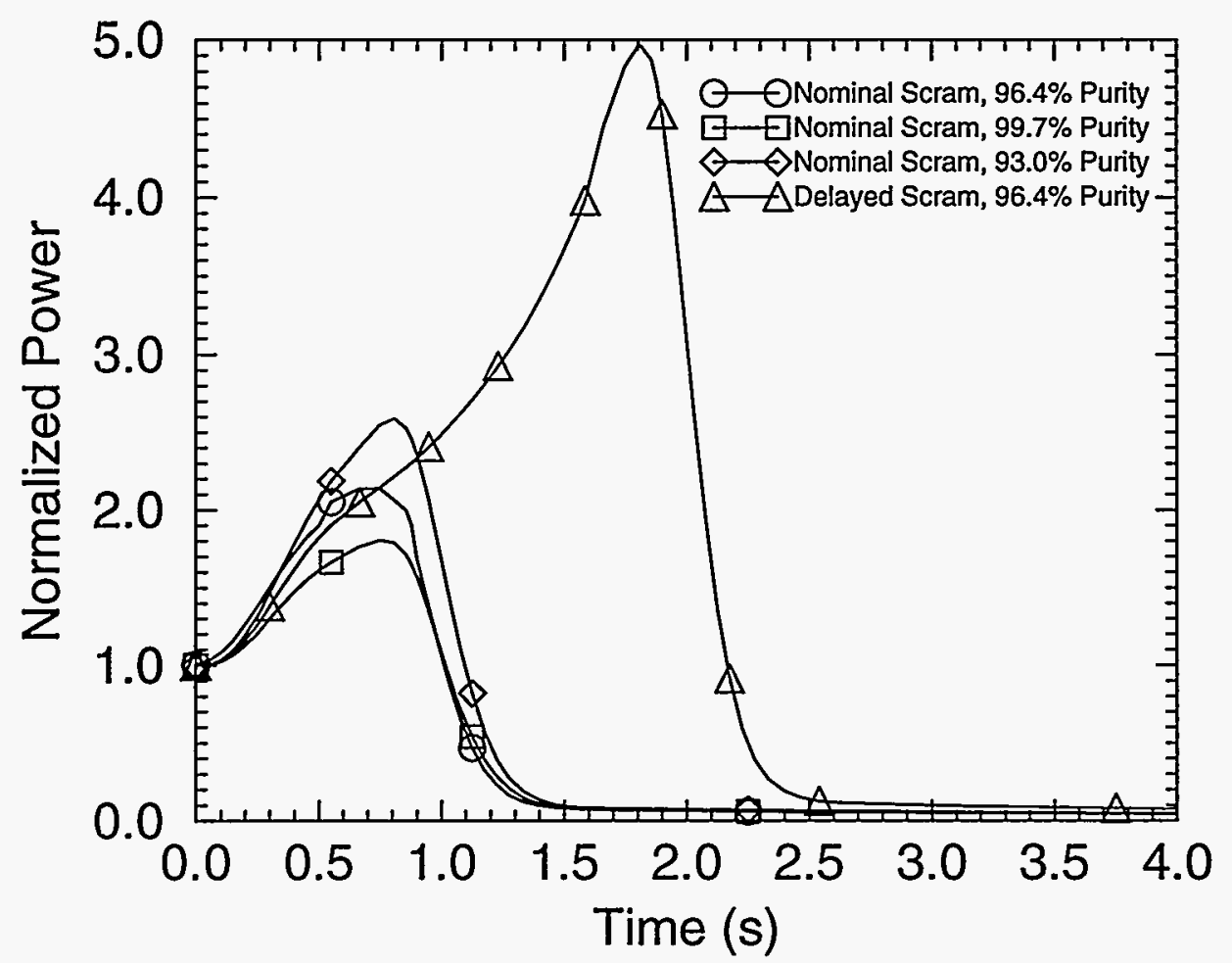

Figure 11. Normalized power for the large-break LOCA sensitivity calculations. 


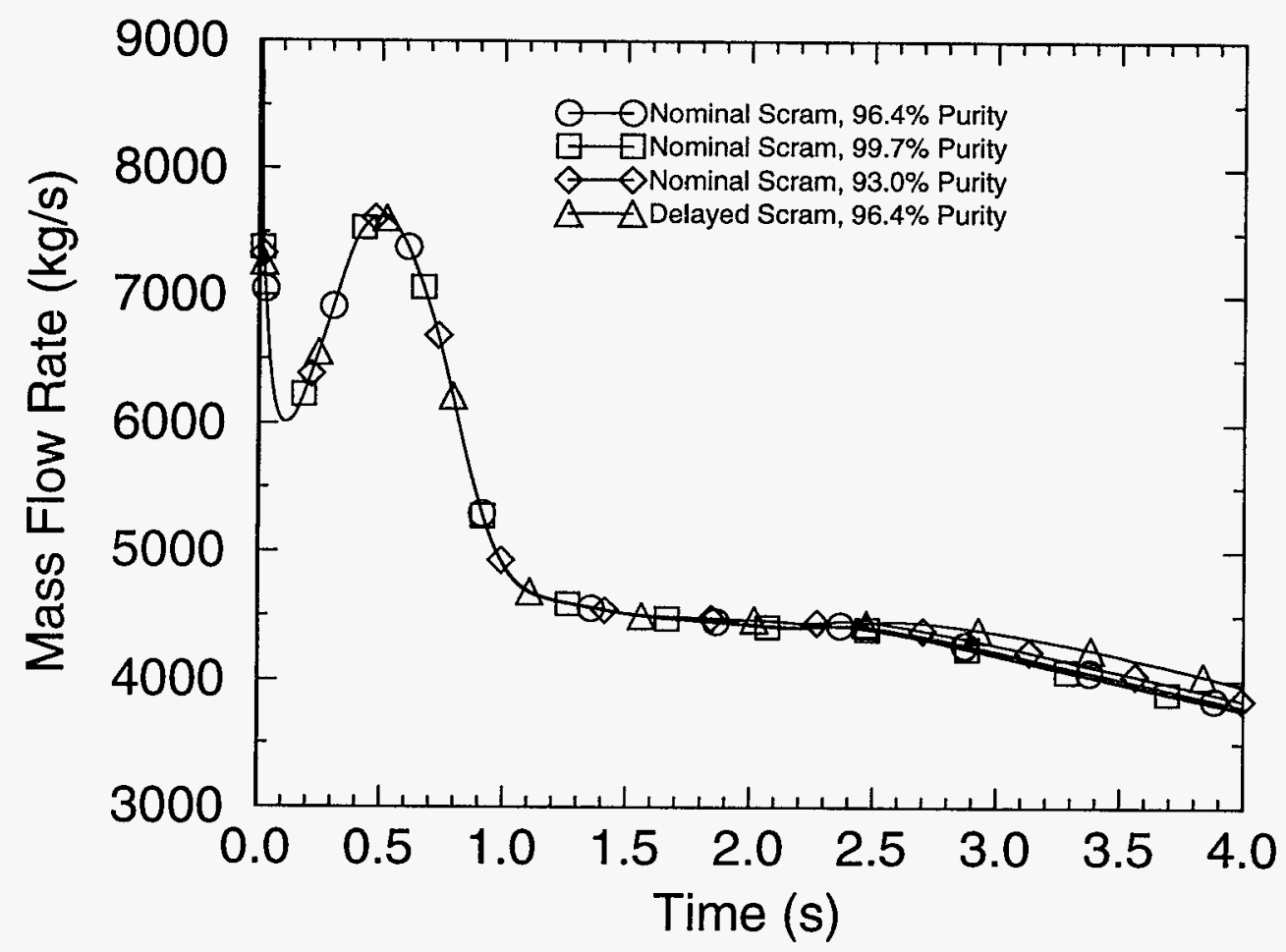

Figure 12. Break flow for the large-break LOCA sensitivity calculations.

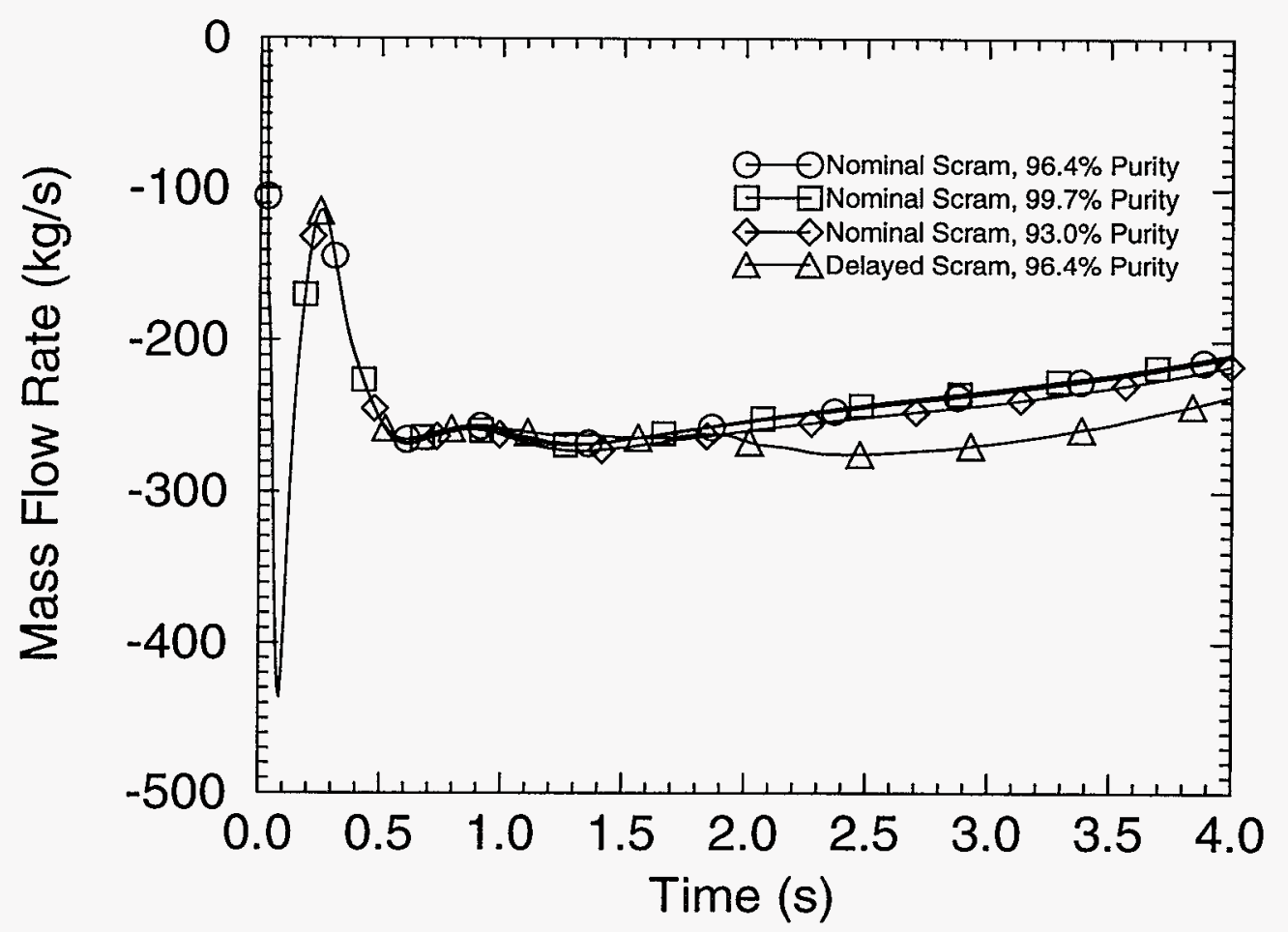

Figure 13. CHAN1 flow for the large-break LOCA sensitivity calculations. 


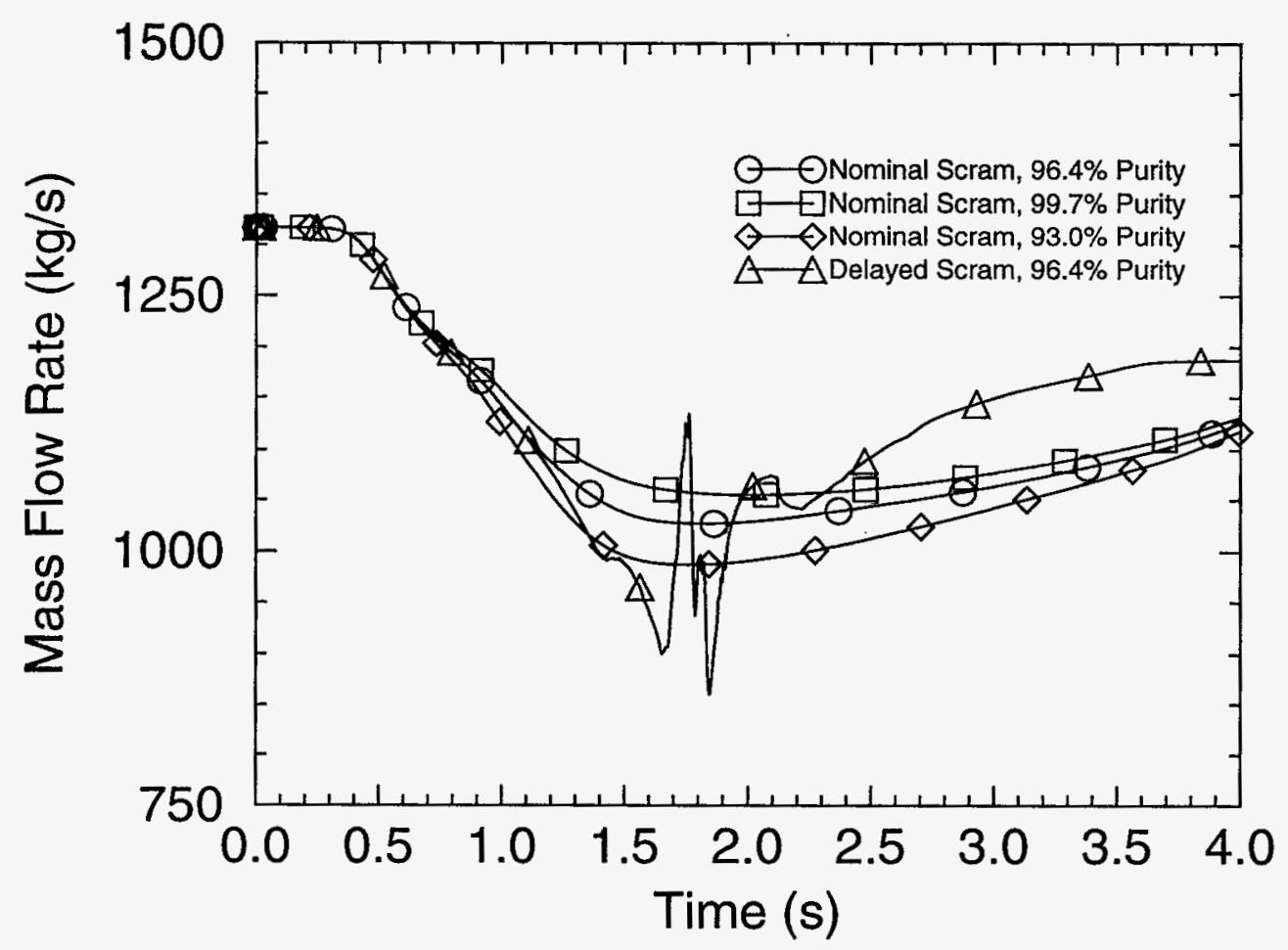

Figure 14. CHAN9 flow for the large-break LOCA sensitivity calculations.

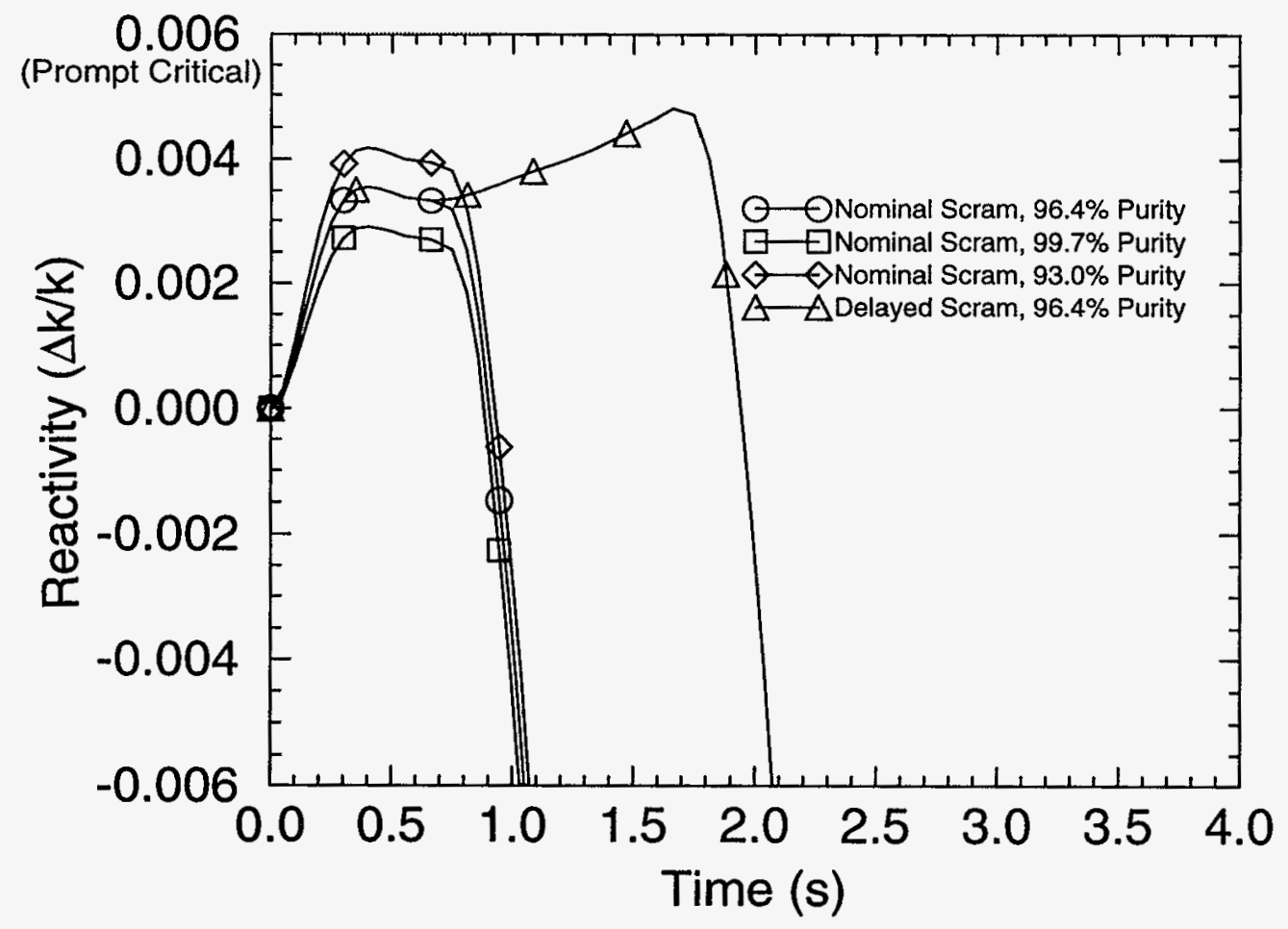

Figure 15. Reactivity for the large-break LOCA sensitivity calculations. 


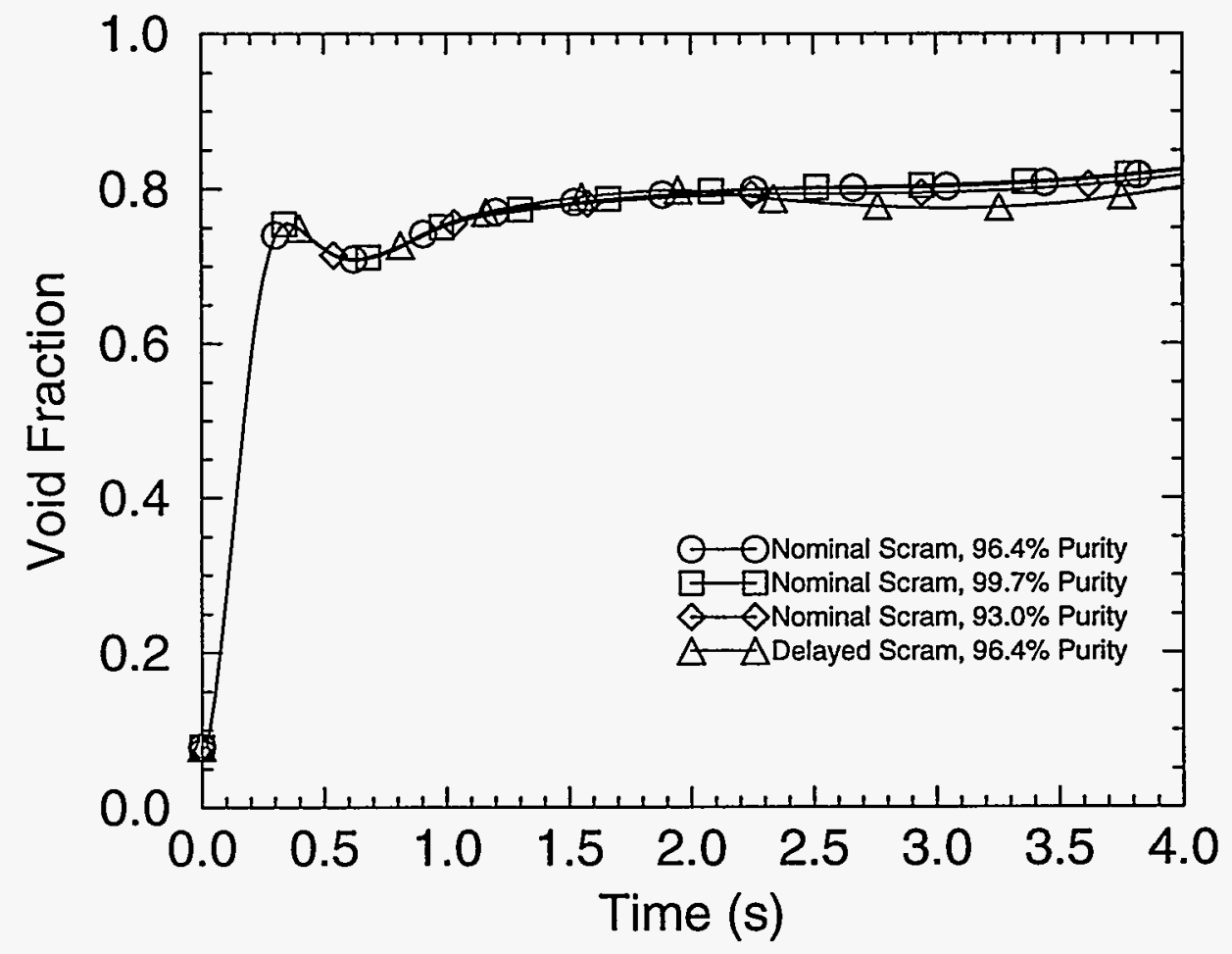

Figure 16. Chan 1 average void fraction for the large-break LOCA sensitivity calculations.

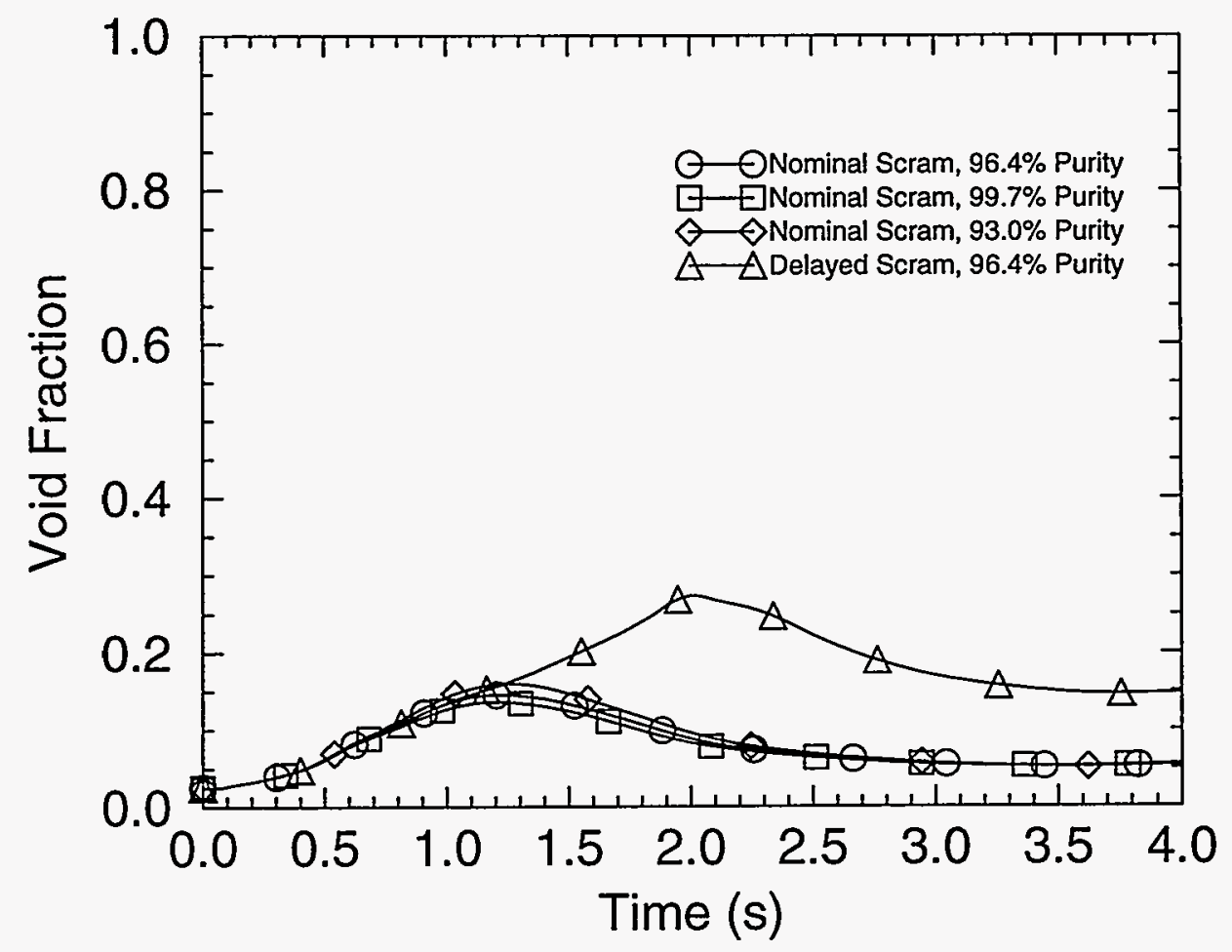

Figure 17. CHAN2 average void fraction for the large-break LOCA sensitivity calculations. 


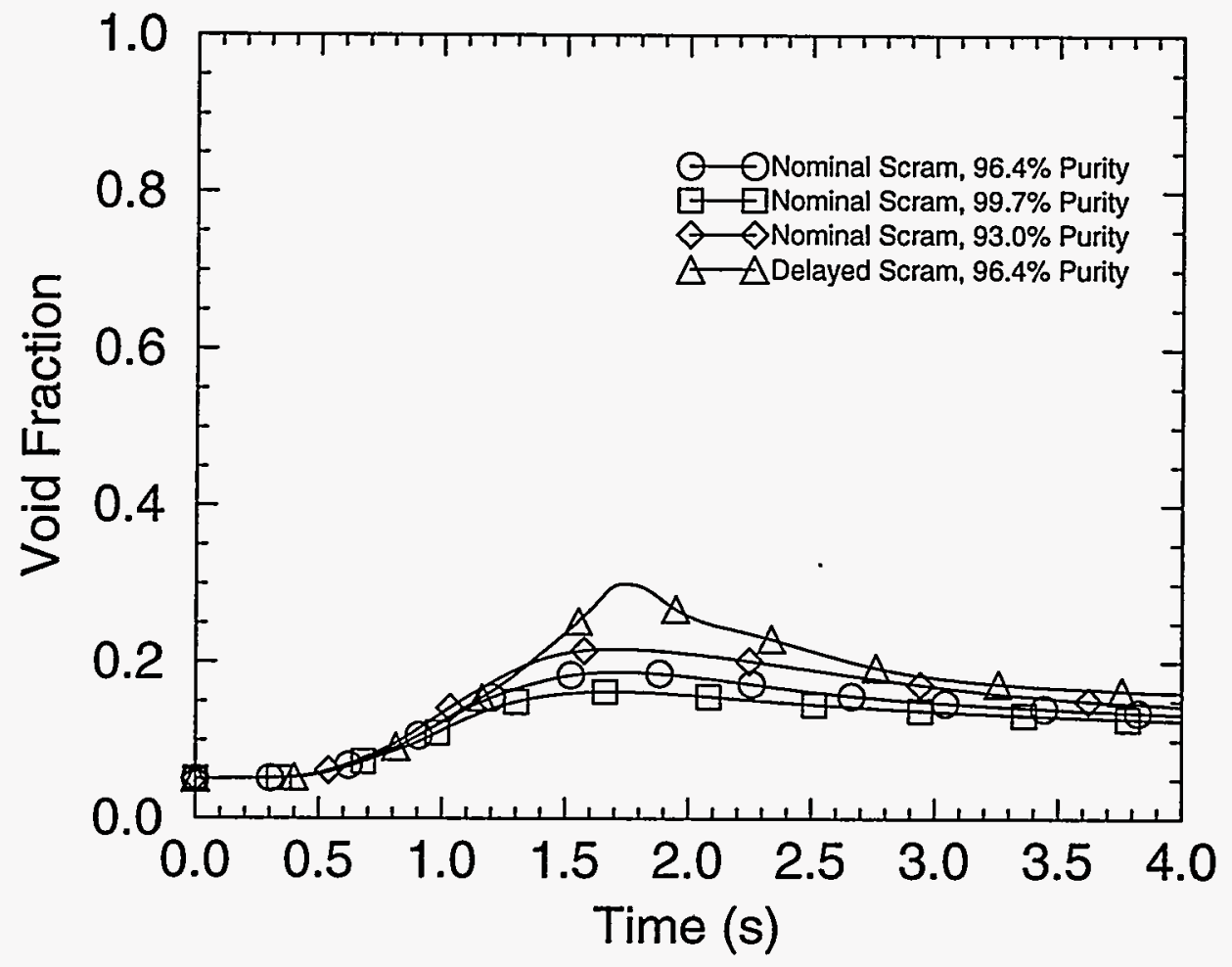

Figure 18. CHAN9 average void fraction for the large-break LOCA sensitivity calculations.

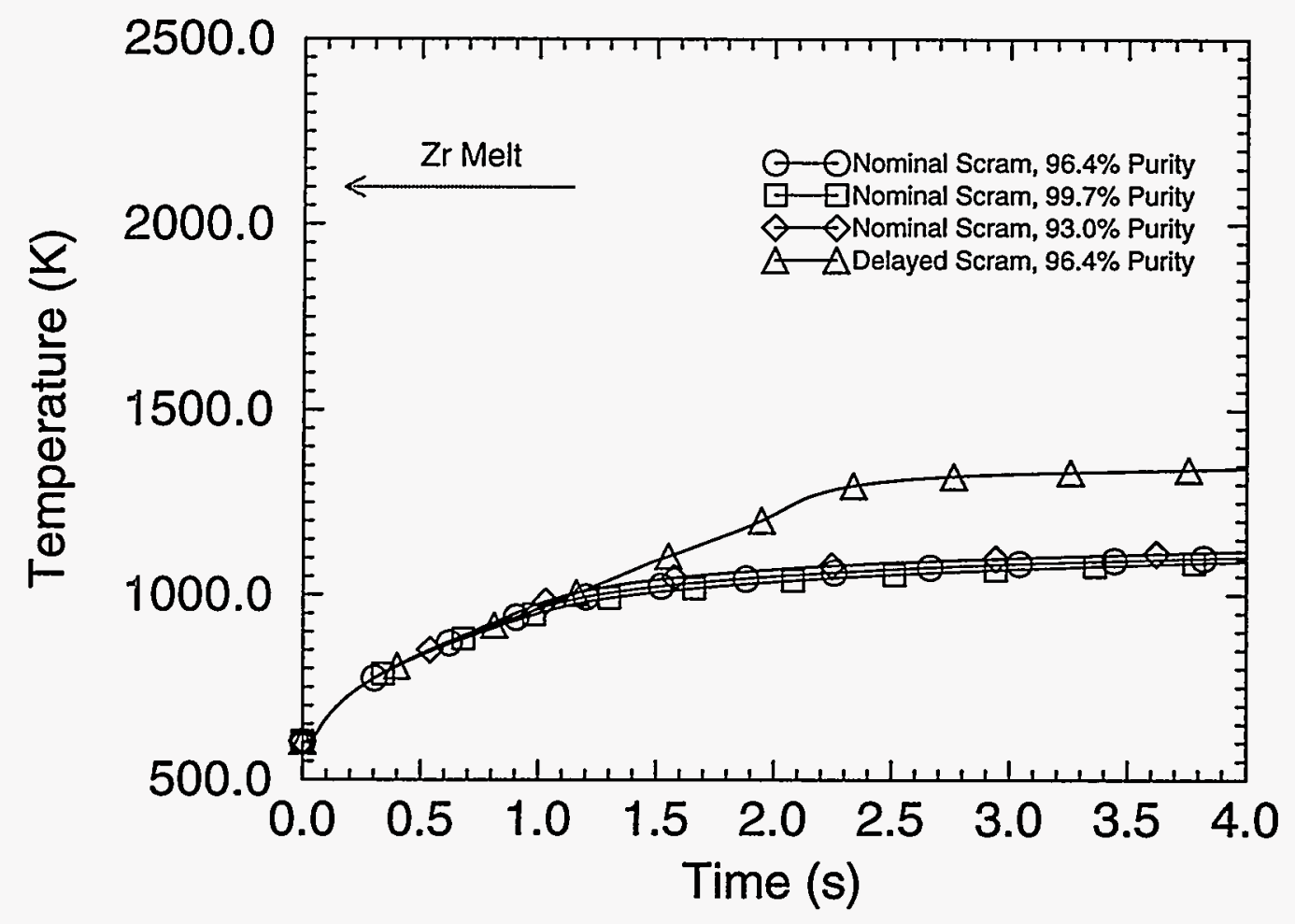

Figure 19. CHAN1 peak clad surface temperature for the large-break LOCA sensitivity calculations. 


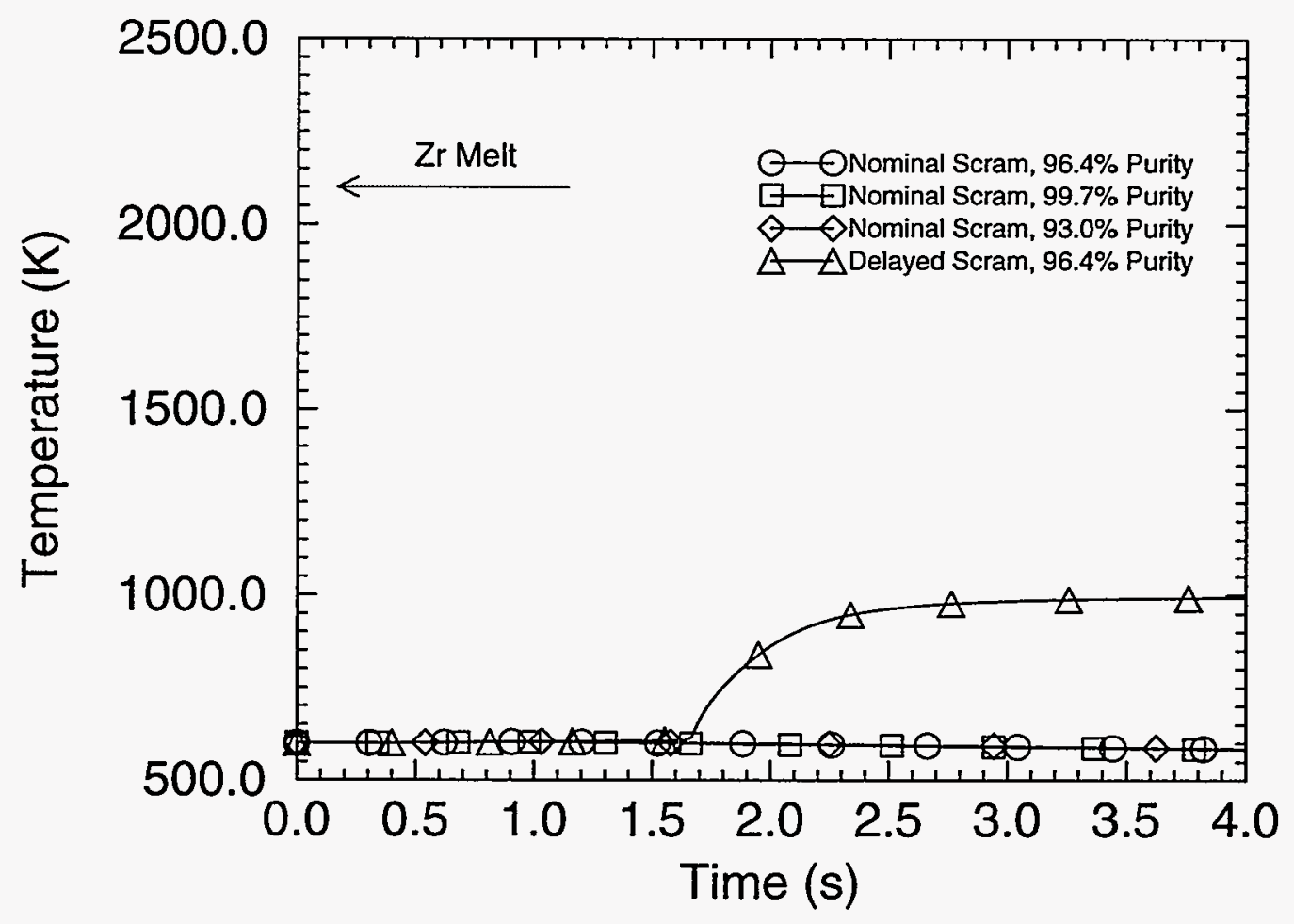

Figure 20. CHAN9 peak clad surface temperature for the large-break LOCA sensitivity calculations.

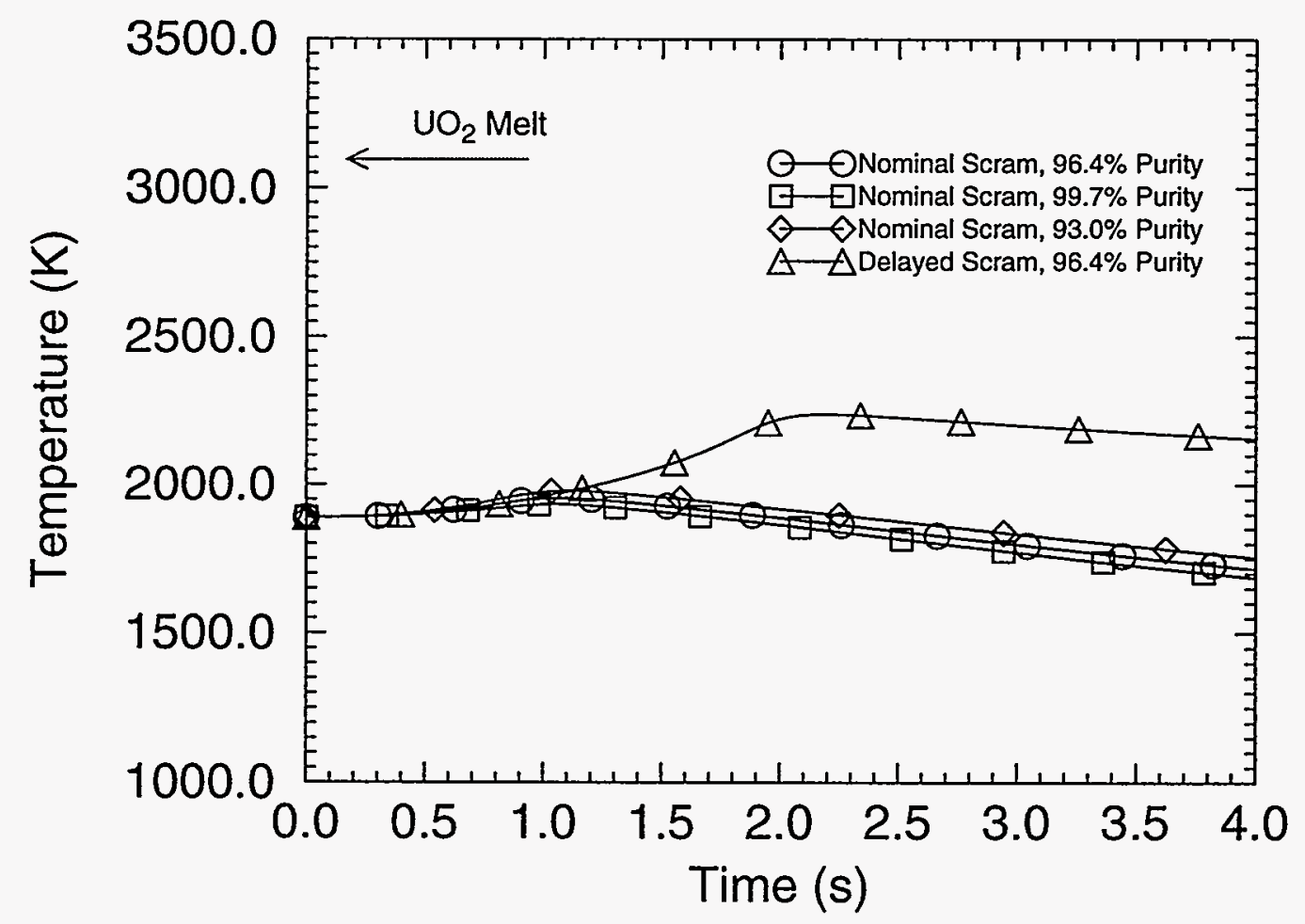

Figure 21. CHANI peak fuel centerline temperature for the large-break LOCA sensitivity calculations. 


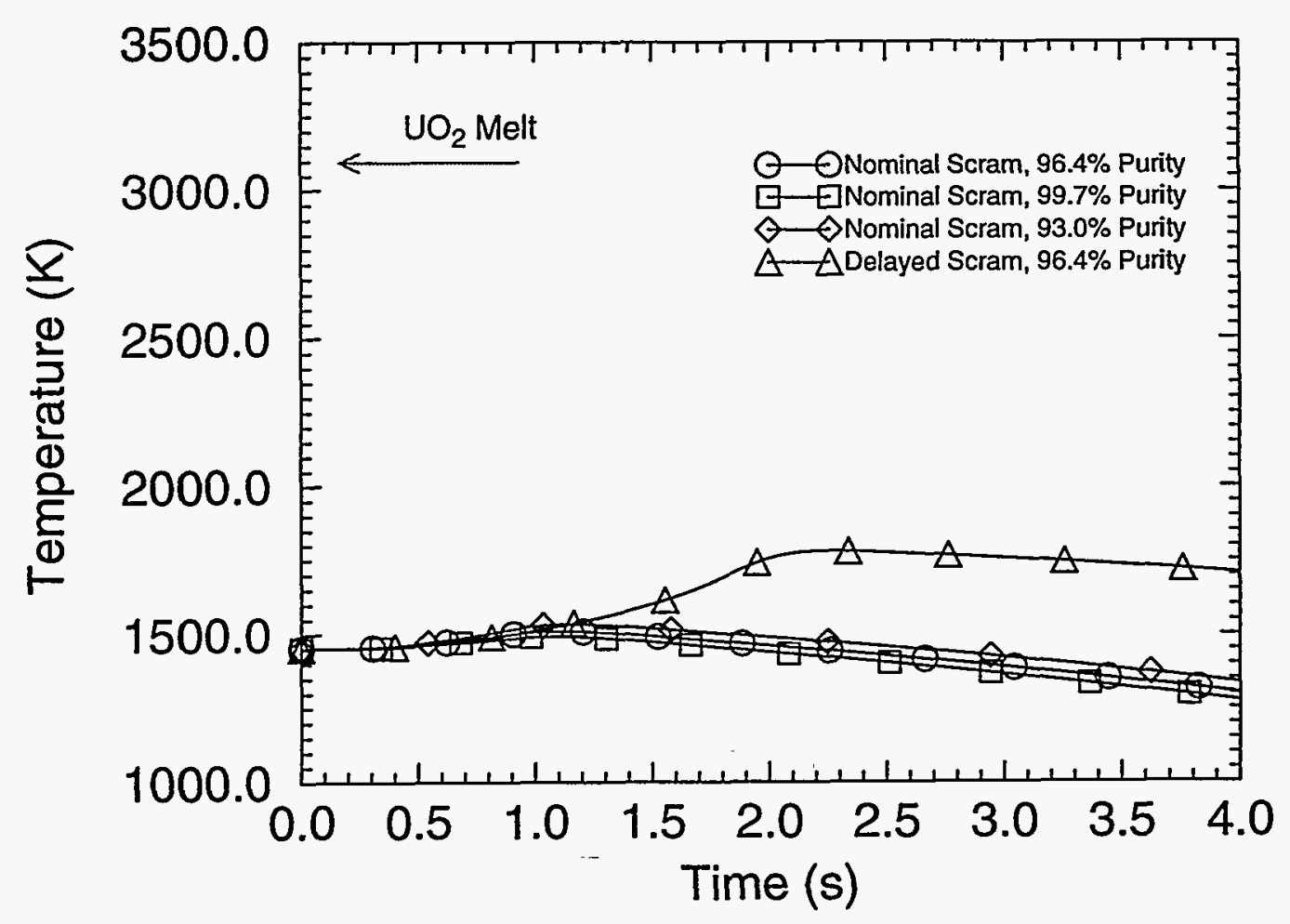

Figure 22. CHAN9 peak fuel centerline temperature for the large-break LOCA sensitivity calculations.

\subsubsection{Large-Break LOCA with Failure to Shutdown}

A series of sensitivity calculations was run to evaluate the effect of changing individual parameters on the core response for the Large-Break LOCA with failure to shutdown. Once again, the $100 \%$ inlet header break was selected as the base case. Four parameters were varied for these calculations: coolant purity, CHF value, initial power, and MCA actuation by the reactor control system. Coolant purity was selected because it affects the void reactivity that is inserted during the blowdown. The value assumed by AECL in Reference 4 was $96.36 \%$ heavy water and this value was as the base case value in these sensitivity calculations. CHF value were varied to change the voiding rate. The initial power was varied to assess the effects on core response due to the initial core power level. The actuation of the MCAs by the reactor control system was modeled with different numbers of MCAs inserting to assess their effect on core response.

Table 8 presents the parameters varied for the transient without scram and a brief summary of the values of power and reactivity when either the cladding or fuel melting temperatures are reached during the transient. The conservative gap conductance only affects the time at which fuel melt occurs. 
Table 8. LBLOCA without scram sensitivity cases.

\begin{tabular}{|l|l|r|r|r|r|}
\hline \multicolumn{1}{|c|}{$\begin{array}{c}\text { Parameter } \\
\text { Varied }\end{array}$} & \multicolumn{1}{|c|}{$\begin{array}{c}\text { Parameter } \\
\text { Value }\end{array}$} & $\begin{array}{c}\text { Relative } \\
\text { Power }^{\mathrm{a}}\end{array}$ & $\begin{array}{c}\text { Reactivity } \\
(\Delta \mathrm{k} / \mathrm{k})^{\mathrm{a} .}\end{array}$ & $\begin{array}{c}\text { Time to } \\
\text { Reach Clad } \\
\text { Melt }^{\mathrm{b}} \\
(\mathrm{s})\end{array}$ & $\begin{array}{c}\text { Time to } \\
\text { Reach Fuel } \\
\text { Melt }^{\mathrm{c}} \\
(\mathrm{s})\end{array}$ \\
\hline Base Case & $\begin{array}{l}96.36 \% \\
\text { Purity }\end{array}$ & 9.11 & 0.00396 & 3.86 & $>3.86$ \\
\hline Coolant Purity & $99.722 \%$ & 5.76 & 0.00302 & $>4.25$ & $>4.25$ \\
\hline Coolant Purity & $93 \%$ & 18.04 & 0.00518 & $>2.90$ & 2.90 \\
\hline CHF & $+20 \%$ & 9.11 & 0.00396 & 3.86 & $>3.86$ \\
\hline CHF & $-20 \%$ & 9.20 & 0.00396 & 3.85 & $>3.85$ \\
\hline Initial Power & $70 \%$ & 7.67 & 0.00338 & 4.88 & $>4.88$ \\
\hline Initial Power & $30 \%$ & 6.07 & 0.00247 & 6.68 & 6.76 \\
\hline MCA Insertion & $\begin{array}{l}\text { Four MCAs } \\
\text { inserted }\end{array}$ & 1.25 & 0.00146 & 14.58 & $>14.58$ \\
\hline MCA Insertion & $\begin{array}{l}\text { Three MCAs } \\
\text { inserted }\end{array}$ & 1.38 & 0.00112 & 9.68 & $>9.68$ \\
\hline
\end{tabular}

a. Value at time the first melting point is reached

b. Clad melting temperature is $2100 \mathrm{~K}$.

c. Fuel melting temperature is $3100 \mathrm{~K}$.

Table 8 indicates that the results of the CHF sensitivity calculations are bounded by the other cases, so details of these calculations are not presented in the rest of the discussion.

Figure 23 shows the normalized power behavior for the six cases presented. There is a large difference in the power history for these cases. The two cases with MCA insertions have an initial power peak, a power reduction when the MCAs are inserted, and a later rise in power as voiding in channels not connected to the broken inlet increase and overcome the negative MCA reactivity. The cases with lower initial power levels show an initial power peak followed by a reduction and then another increase. This behavior is caused by the transition from nucleate boiling to film boiling in the different fuel channels. Figure 24 shows the break flow behavior. All cases behave essentially the same, except for the lower initial power cases. Figures 25 and 26 show the flow through channels 1 and 9, respectively. Once again, the flow behavior is the same for all but the lower initial power cases. Figure 27 shows the reactivity behavior for each case. The behavior is as expected and the MCA insertion for those cases is very apparent, but the reactivity increase due to voiding after MCA insertion is also obvious. Figures 28,29 , and 30 show the average void fraction for channels 1,2 , and 9 , respectively. The void behavior is the same for all but the lower initial power cases. The void fraction for the lower initial power cases is initially lower than the other cases because the coolant is more subcooled in these cases. Figures 31 and 32 show the peak clad surface temperature behavior for channels 1 and 9, respectively. The lower initial power cases reach film boiling later than the other cases. The MCA insertion cases show a much slower increase in temperature due to the much lower core power during the later time of the transient. Figures 33 and 34 show the peak fuel centerline temperature behavior for channels 1 and 9 , respectively. Only the low coolant purity case reaches fuel melt before clad melt is reached. Once again, the rate of temperature increase is very similar for all the cases without MCA insertion, but the time at which the rapid increase starts is delayed for the lower power cases. The cases with MCA insertion have a much slower rate of temperature increase than the cases without MCA insertion as expected. 
These calculations show that the effects of all these variations only delay the onset of fuel or clad melt and do not prevent that condition from occurring during the transient and well before ECC could be effective.

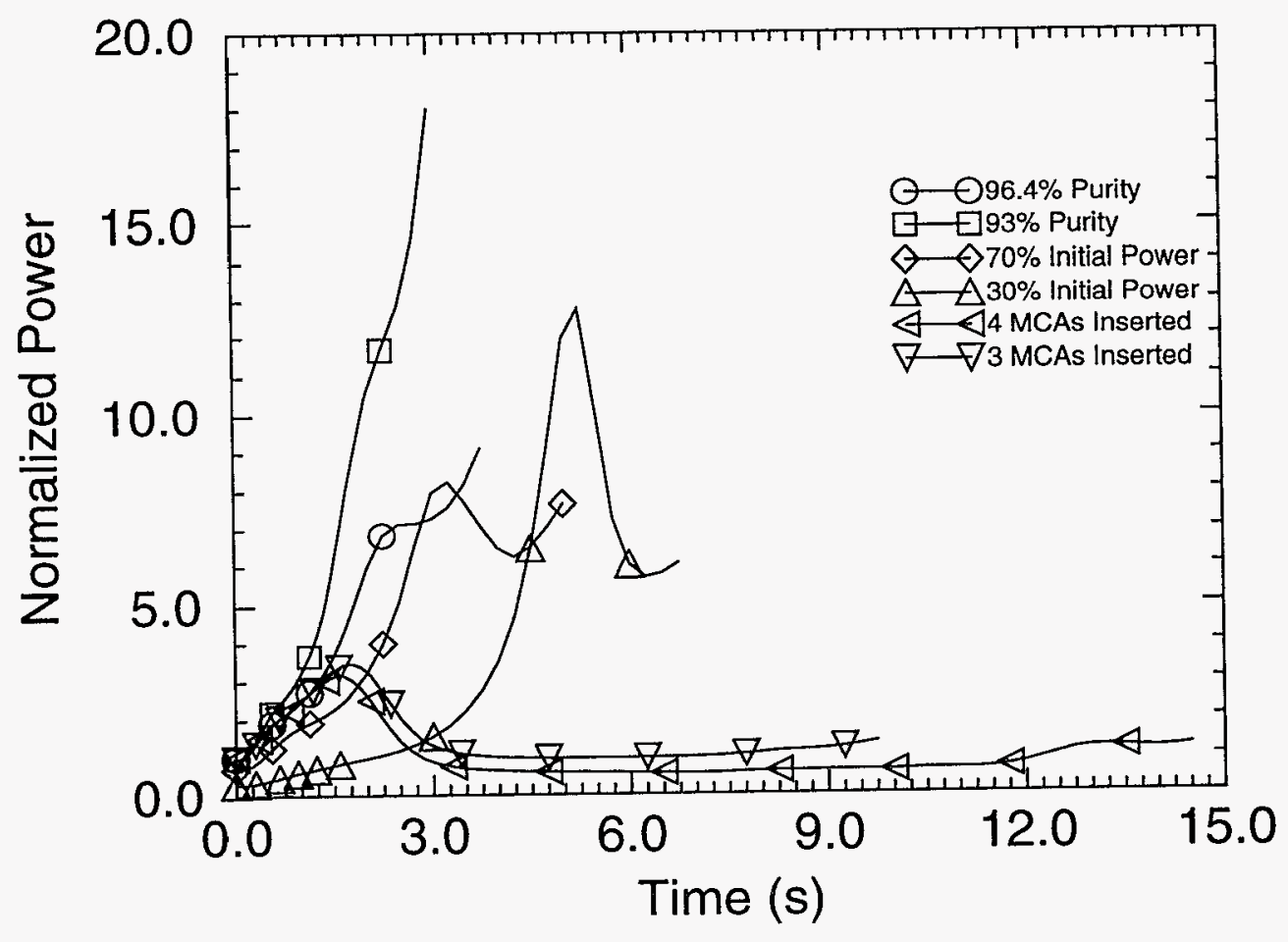

Figure 23. Normalized power for the large-break LOCA sensitivity calculations with failure to shutdown. 


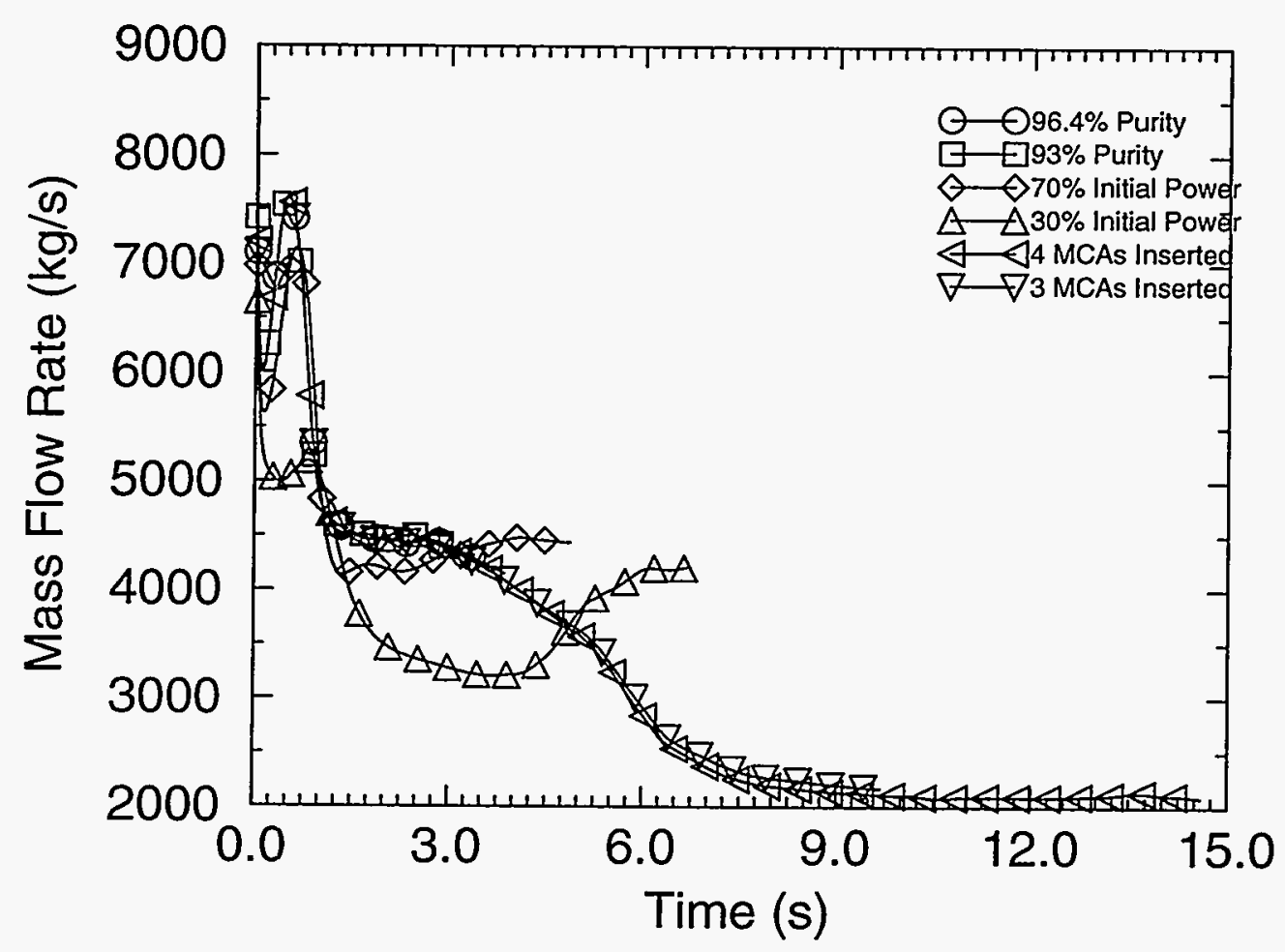

Figure 24. Break flow for the large-break LOCA sensitivity calculations with failure to shutdown.

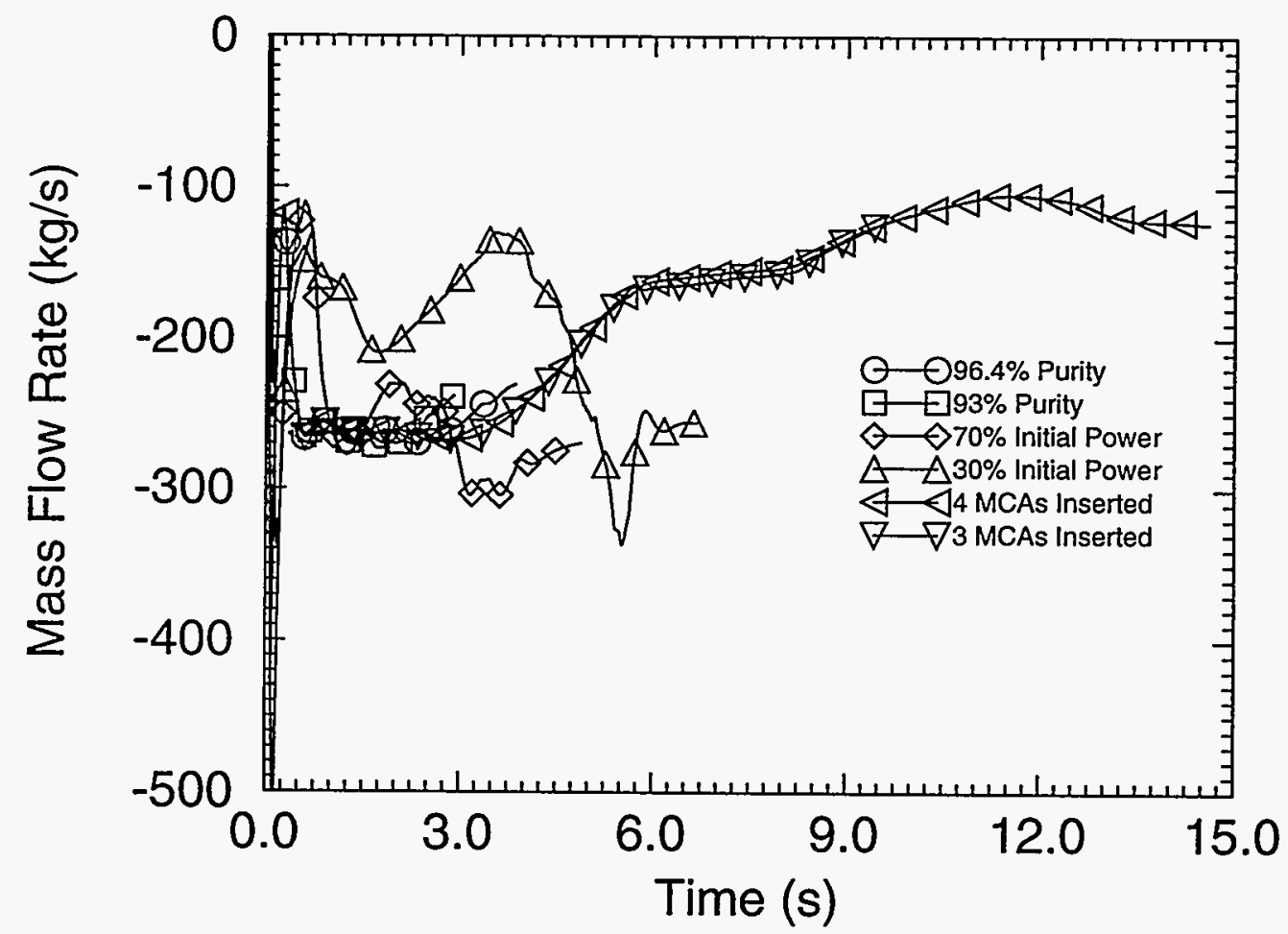

Figure 25. CHAN1 flow for the large-break LOCA sensitivity calculations with failure to shutdown. 


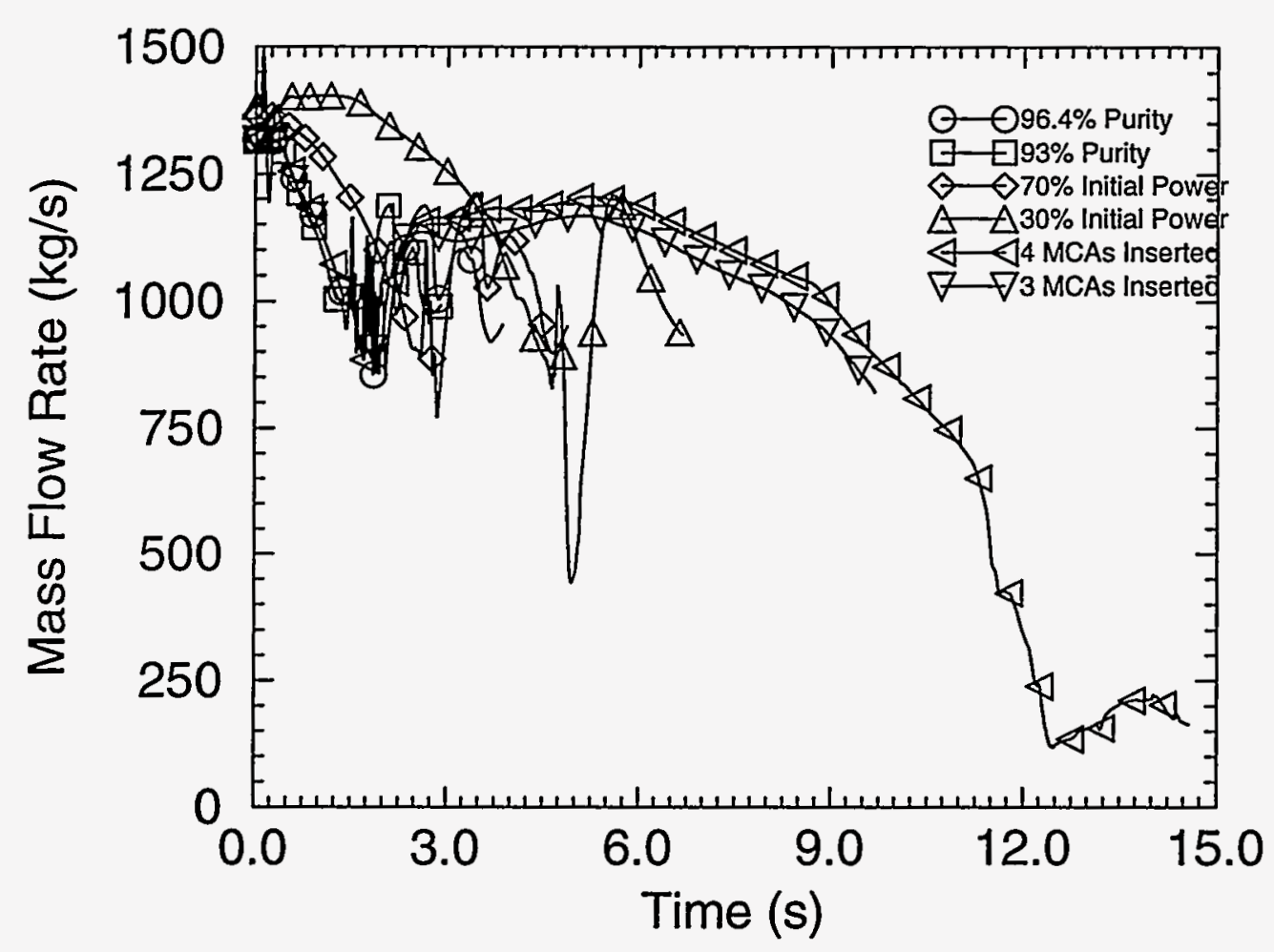

Figure 26. CHAN9 flow for the large-break LOCA sensitivity calculations with failure to shutdown.

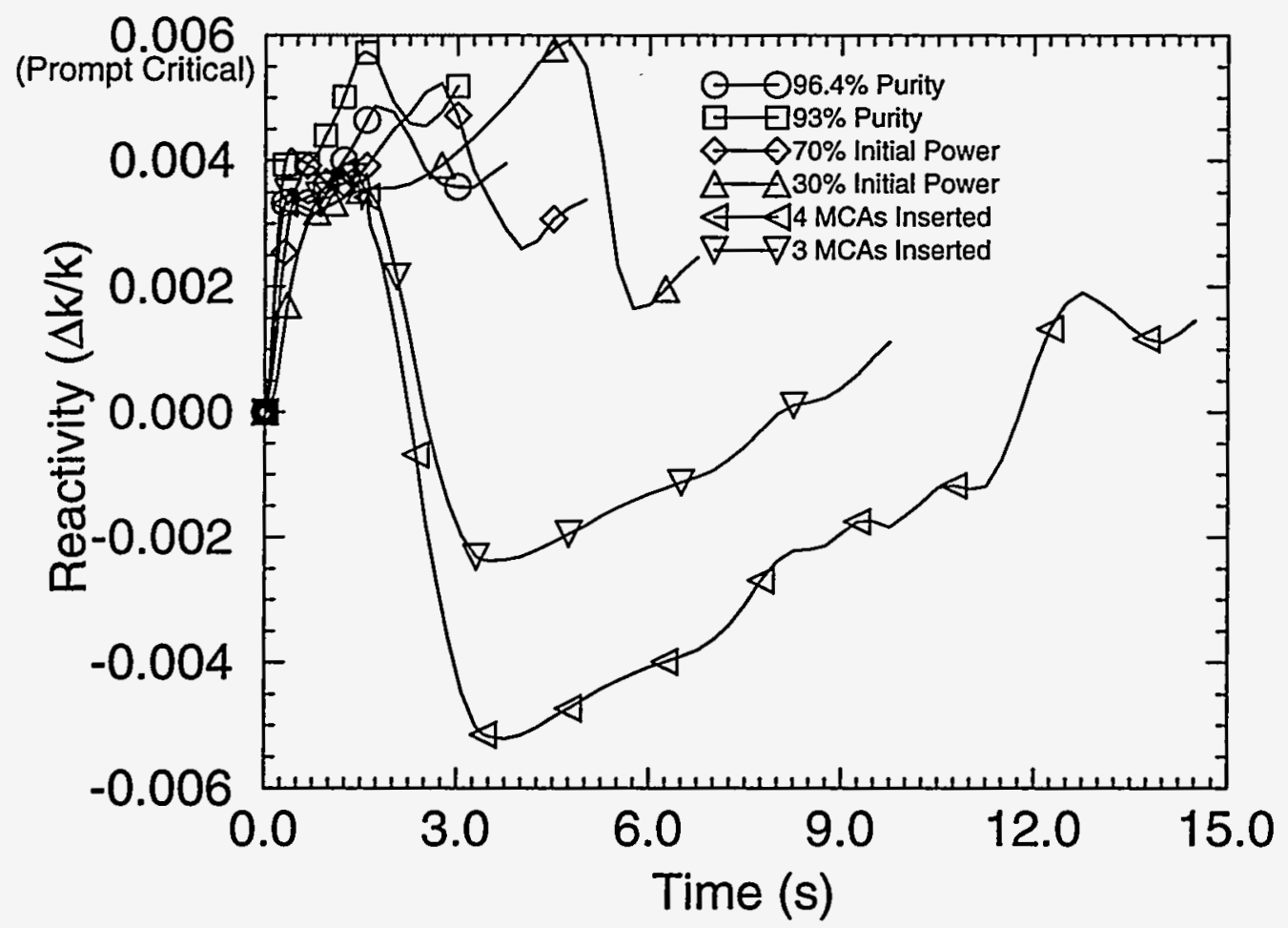

Figure 27. Reactivity for the large-break LOCA sensitivity calculations with failure to shutdown. 


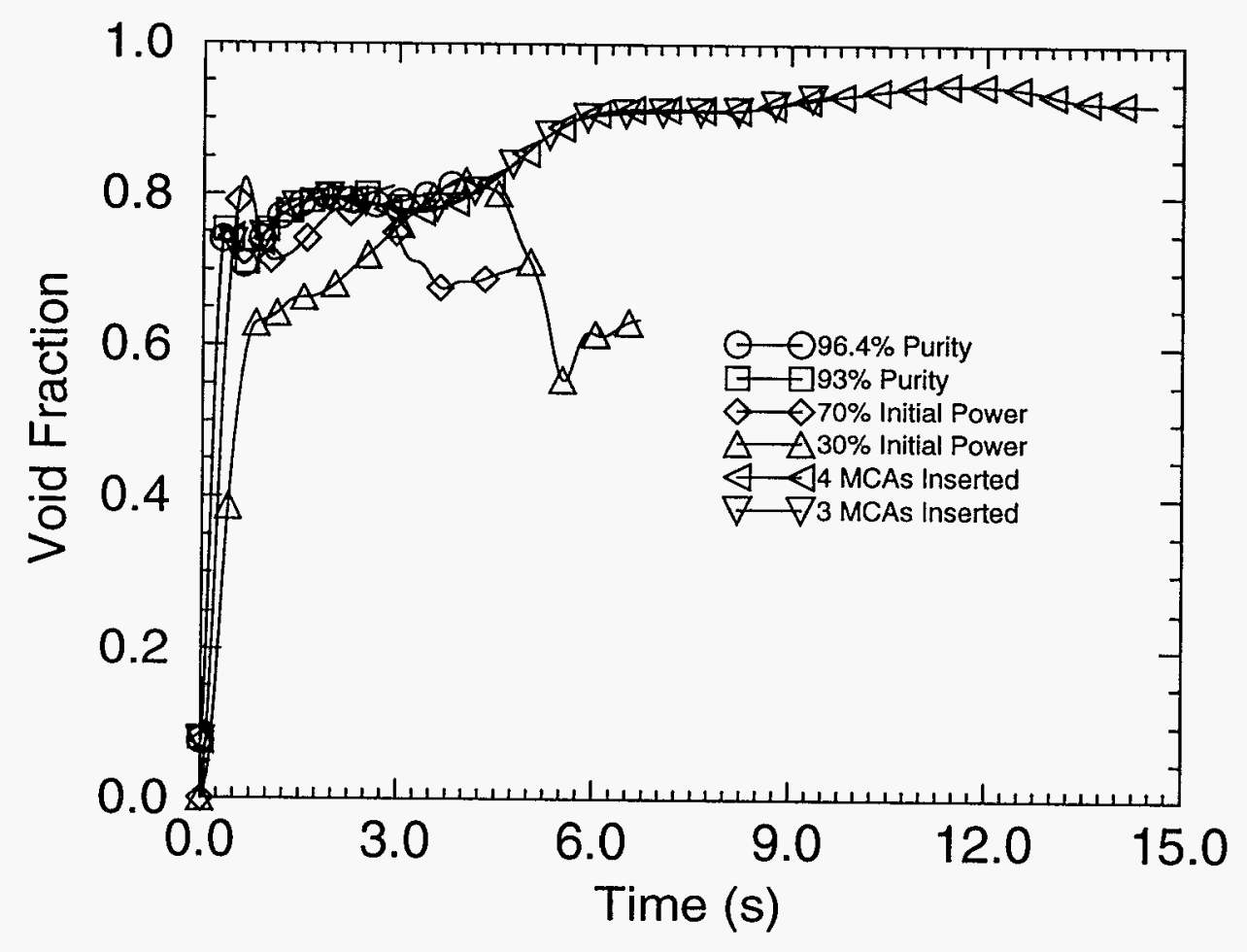

Figure 28. CHANl average void fraction for the large-break LOCA sensitivity calculations with failure to shutdown.

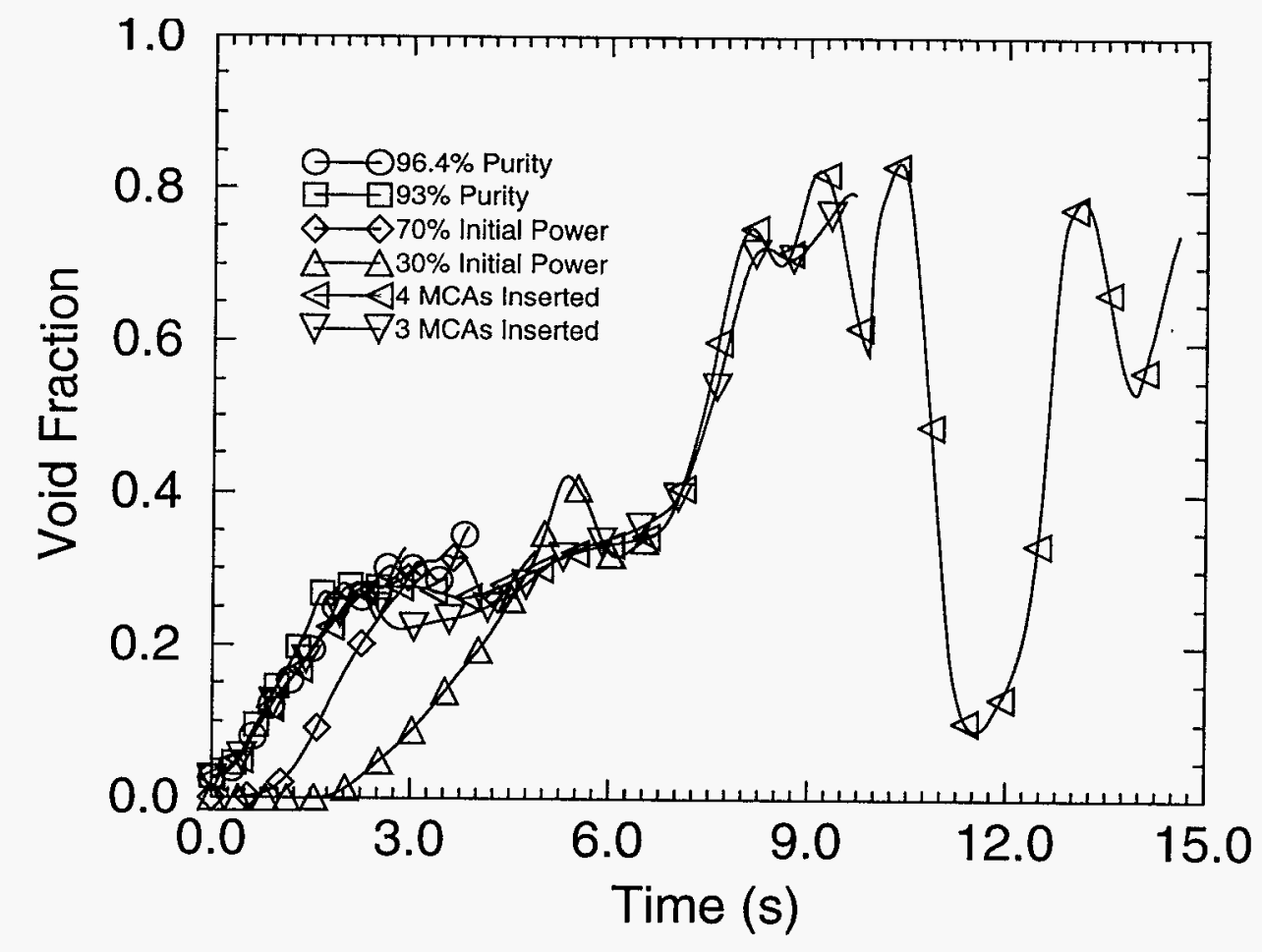

Figure 29. CHAN2 average void fraction for the large-break LOCA sensitivity calculations with failure to shutdown. 


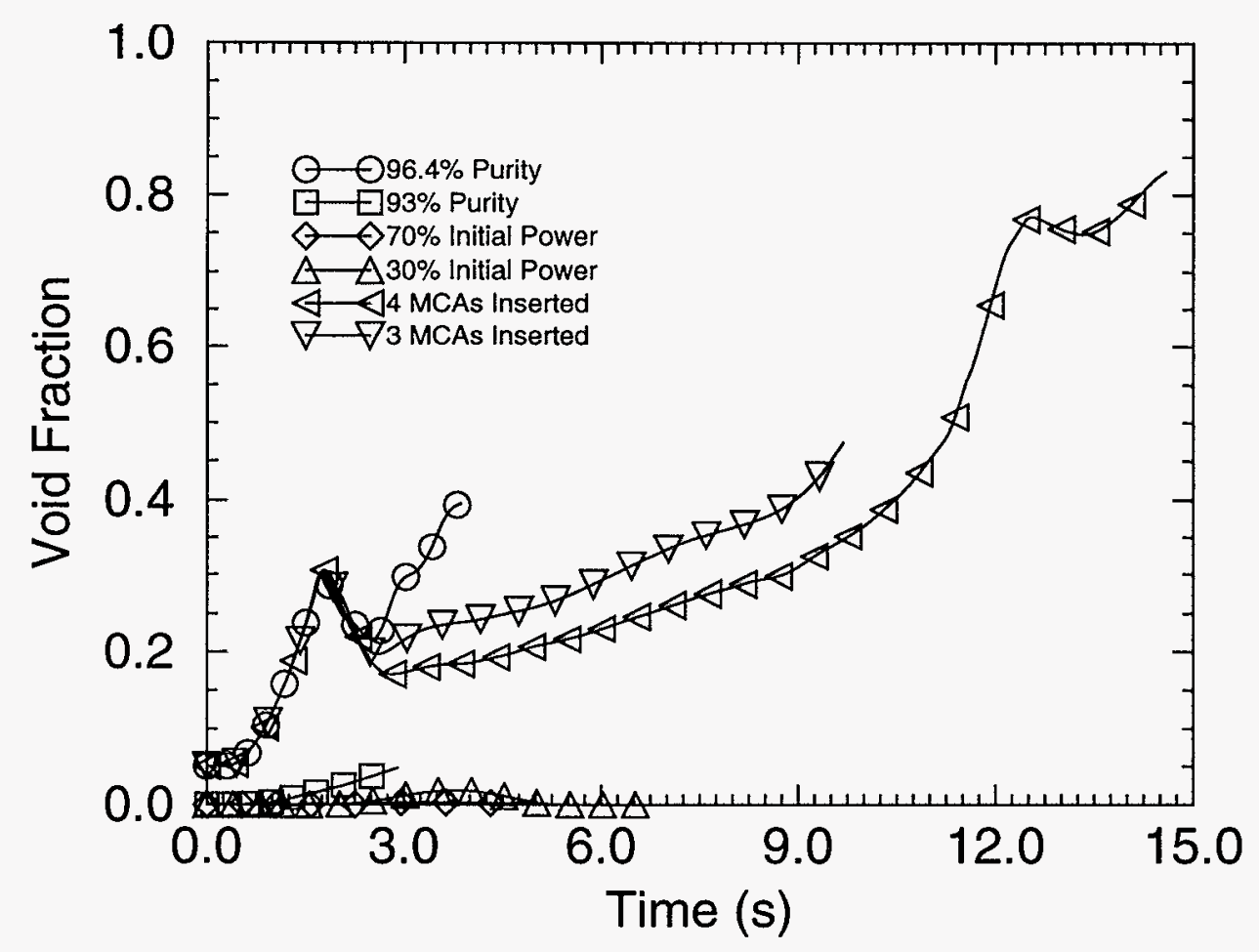

Figure 30. CHAN9 average void fraction for the large-break LOCA sensitivity calculations with failure to shutdown.

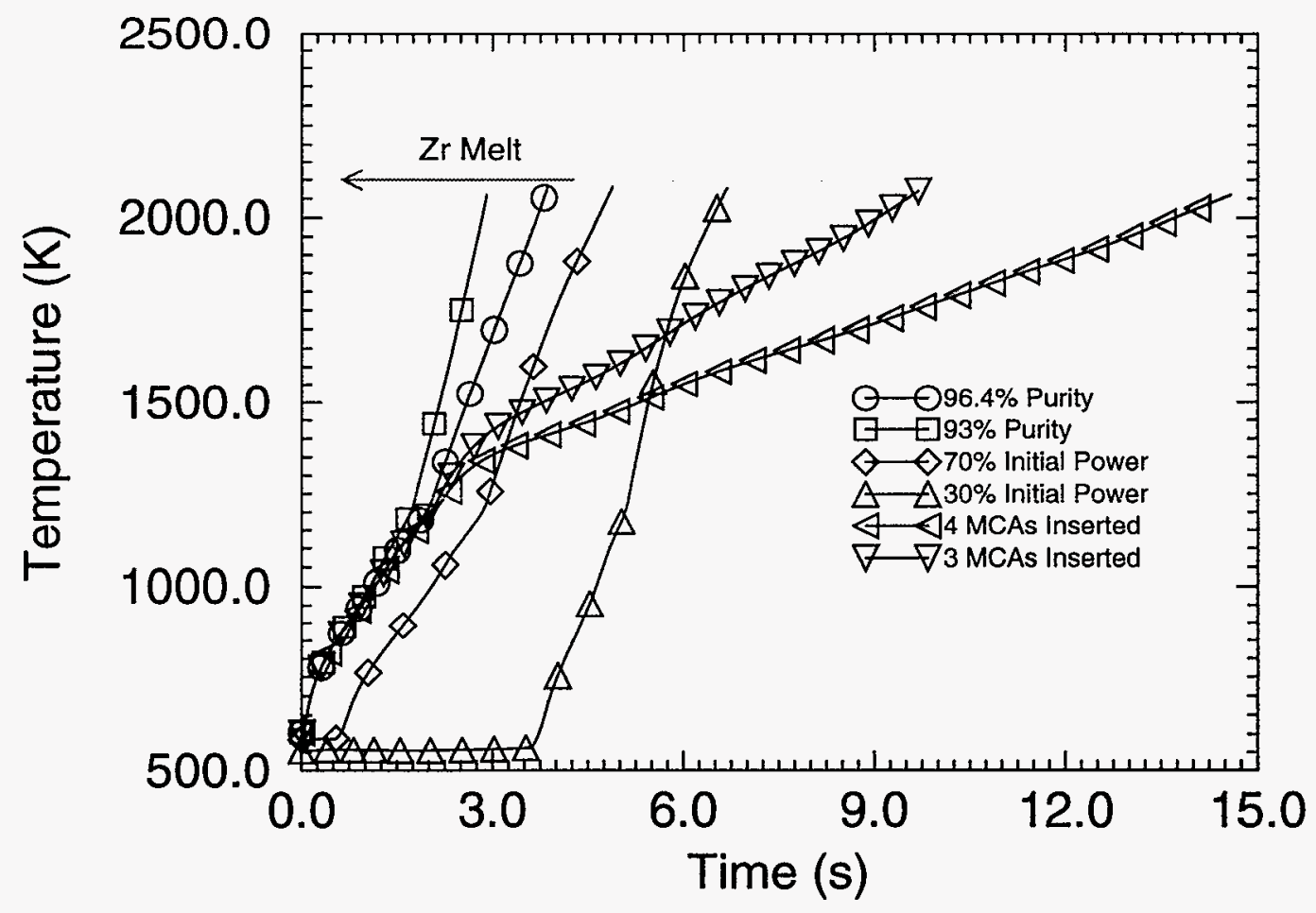

Figure 31. FUELl peak clad surface temperature for the large-break LOCA sensitivity calculations with failure to shutdown. 


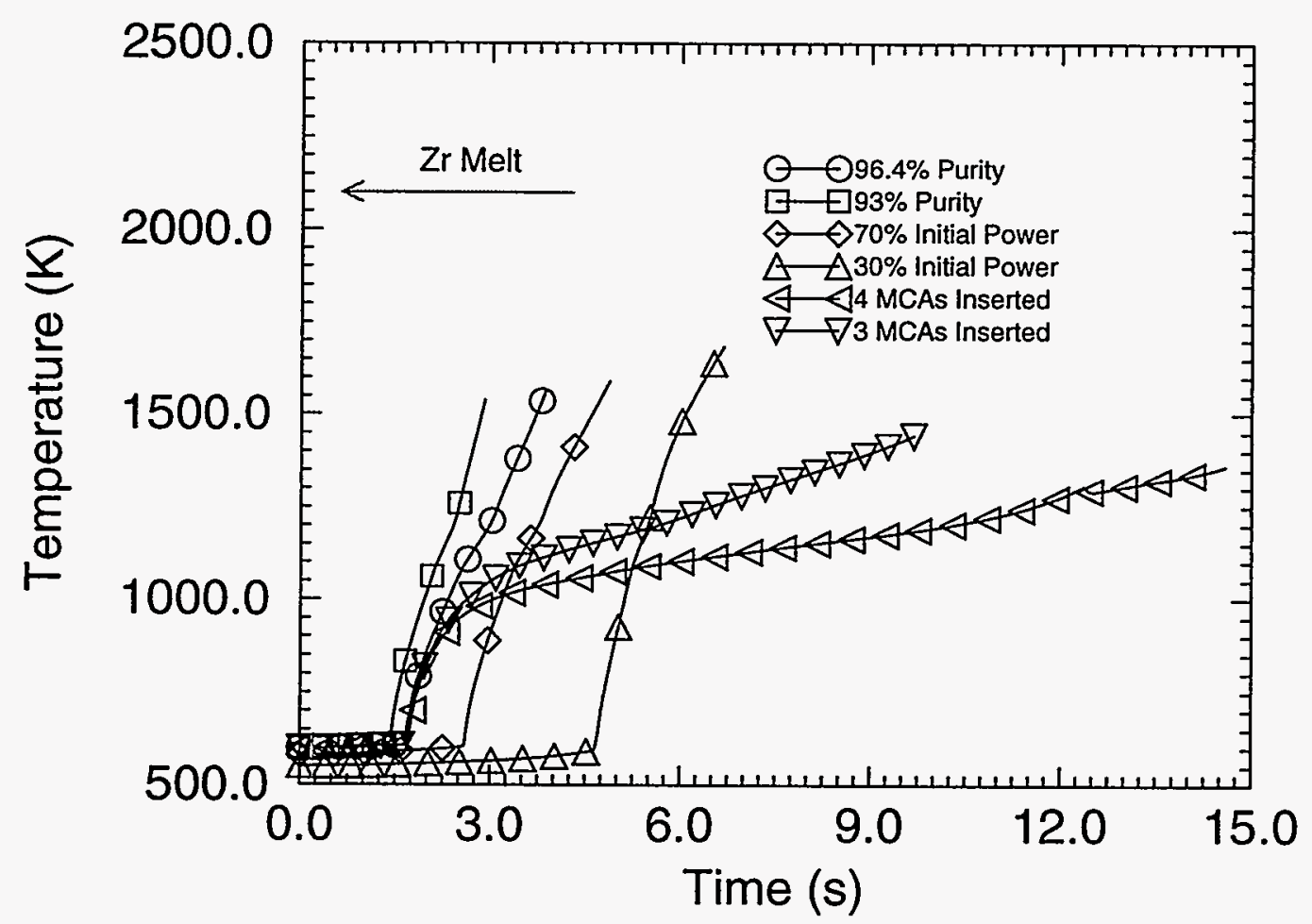

Figure 32. FUEL9 peak clad surface temperature for the large-break LOCA sensitivity calculations with failure to shutdown.

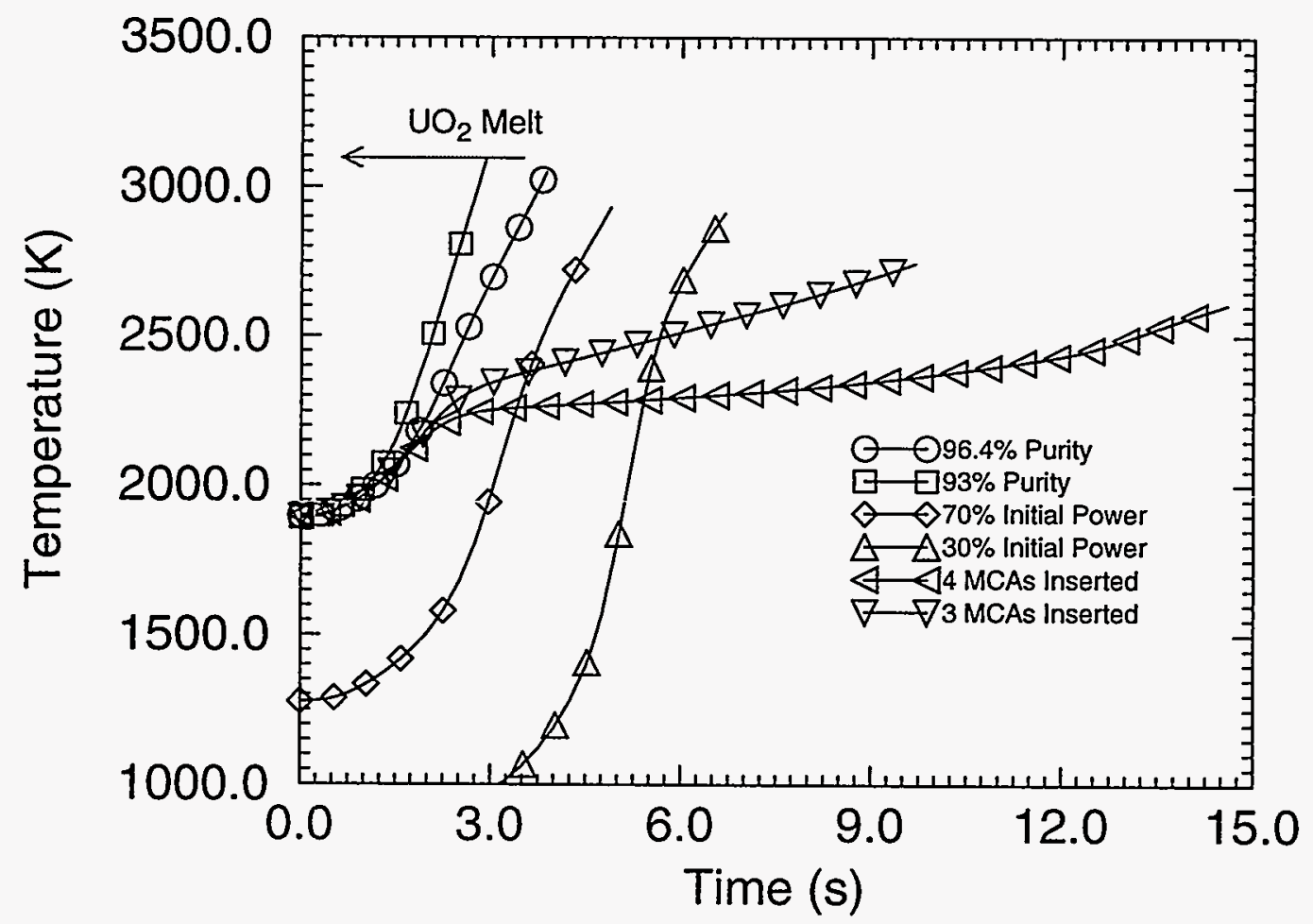

Figure 33. FUELl peak fuel centerline temperature for the large-break LOCA sensitivity calculations with failure to shutdown. 


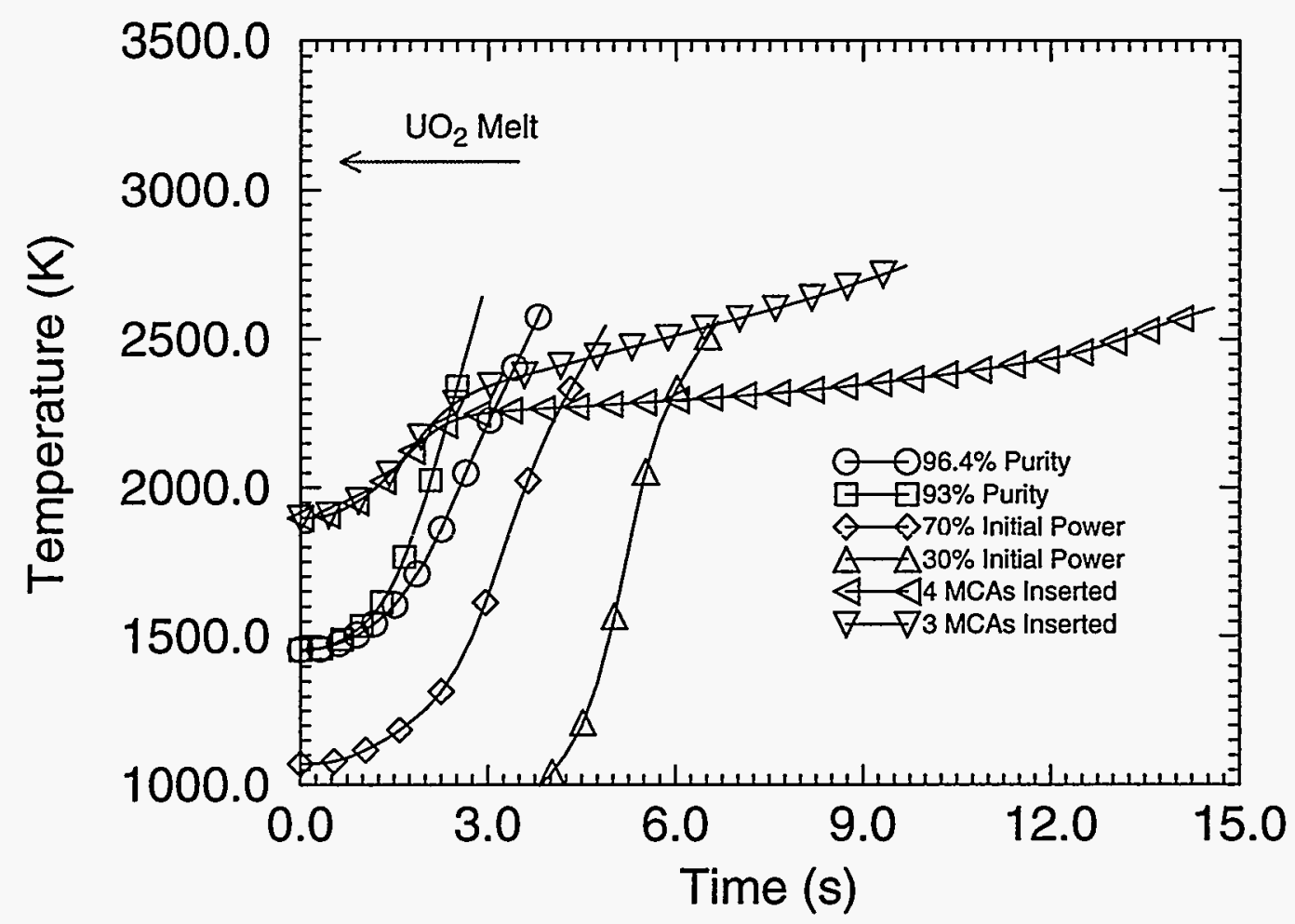

Figure 34. FUEL9 peak fuel centerline temperature for the large-break LOCA sensitivity calculations with failure to shutdown.

\subsection{Rod Bank Withdrawal Movement Transient}

The models and calculational sequence described in Section 3 were used to perform a bank withdrawal transient without scram and assess the performance of the core during these types of events. The reactor is initially at $103 \%$ full power with a $6 \%$ power tilt. Adjuster rods were used to simulate the rod movement in these calculations.

The models and calculational sequence described in Section 3 were used to perform an ATWS calculation and assess the performance of the core during this type of event. The reactor is initially at $103 \%$ full power with a $6 \%$ power tilt. The event was initiated with a withdrawal of six adjuster rods worth approximately $0.012 \Delta \mathrm{k} / \mathrm{k}$ (20 cents) of reactivity over a thirty second time span. This calculation was performed by not allowing any trips or relief valve operation to investigate the inherent response of the core to small positive reactivity insertions at full power.

The reactivity insertion was simulated by a series of instantaneous rod movements. The CERBERUS code system can only model reactivity devices positioned at mesh lines. This analysis assumed a thirty second withdrawal time which results in a speed of roughly $10 \mathrm{~cm} / \mathrm{second}$. This results in a rod movement approximately every three seconds during the simulation since the mesh width is $28.6 \mathrm{~cm}$ in the active fuel region of the model. Communication intervals of 250 milli-seconds were used throughout these calculations and resulted in 113 cycles through the code sequence shown in Figure 2. This interval was checked for adequacy by reducing it without producing any change in the results.

Figure 35 shows the normalized power of the core during the calculation. The power is still increasing at 27.7 seconds due to the fact that reactivity is still positive as shown in Figure 36 . Reactivity is still positive because the positive void and rod bank reactivity is greater than the negative fuel temperature reactivity feedback. The reduction in reactivity between 20 and 25 seconds appears to be primarily due to the reduction in the void formation rate during that period and slightly due to the increase 
in fuel temperature. The adjuster rods are almost completely withdrawn at 30 seconds. Figure 37 shows the behavior of the average void fraction in each of the 10 fuel channels. The void fractions increased initially due to the rapid power rise resulting from the rod withdrawal, then decreases as the fuel elements go into film boiling. After 25 seconds, almost all of the fuel channels have entered film boiling and the void formation rate begins to increase as power increases. Figure 38 shows the behavior of the peak cladding surface temperature during the transient. Critical heat flux (CHF) is exceeded in fuel channels 1 and 3 at 19 seconds, and all the other channels but 6 and 8 do so by 25 seconds into the transient. Figure 39 shows the behavior of the peak fuel centerline temperature during the transient.

If trips were allowed, the reactor would have tripped on an overpower trip at 1.937 seconds. This trip signal would result in SDS1 reaching the first row of fuel channels at 2.317 seconds and becoming fully inserted at 3.24 seconds thus terminating the transient.

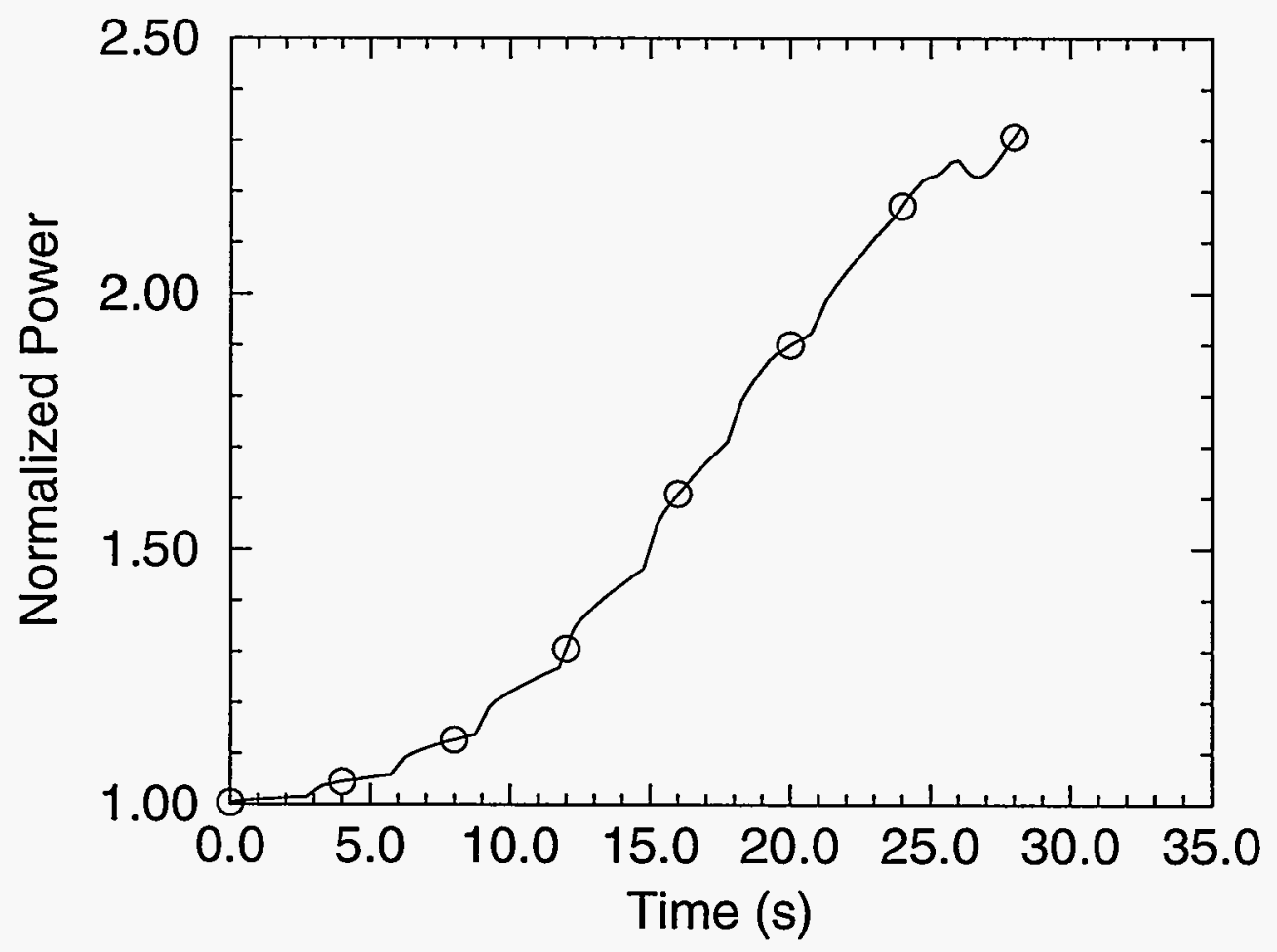

Figure 35. Normalized power for the rod bank withdrawal transient. 


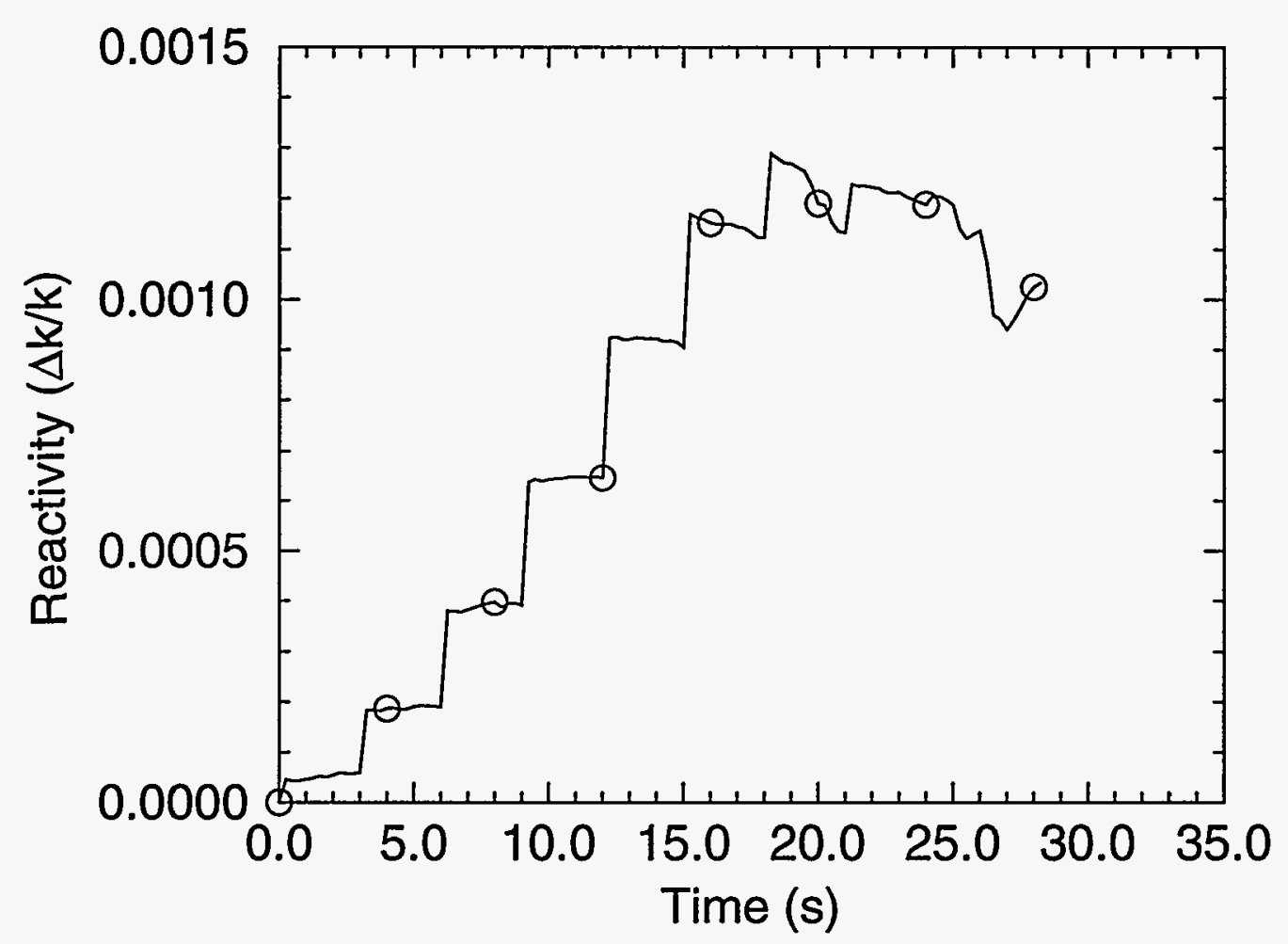

Figure 36. Reactivity for the rod bank withdrawal transient.

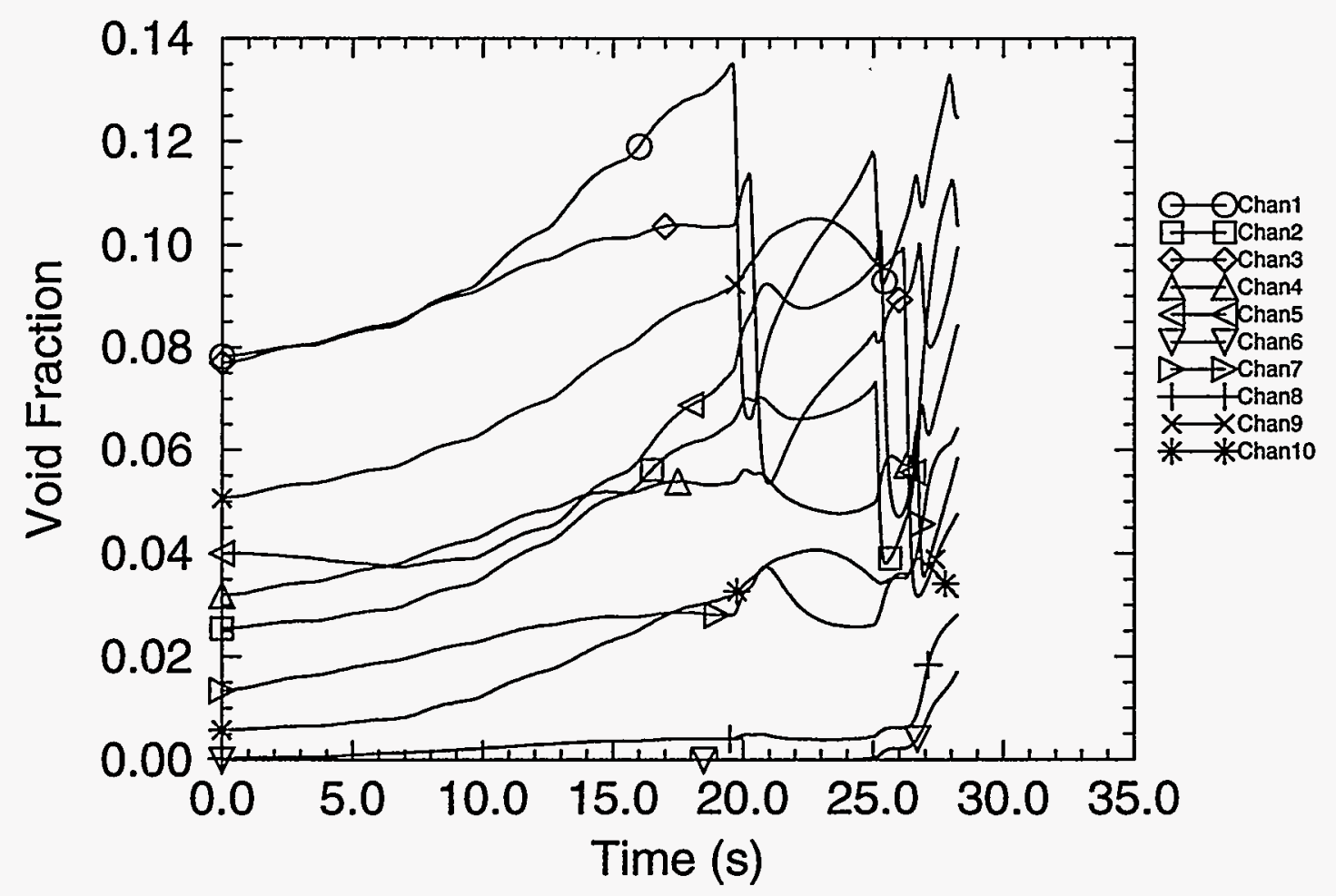

Figure 37. Channel average void fractions for the rod bank withdrawal transient. 


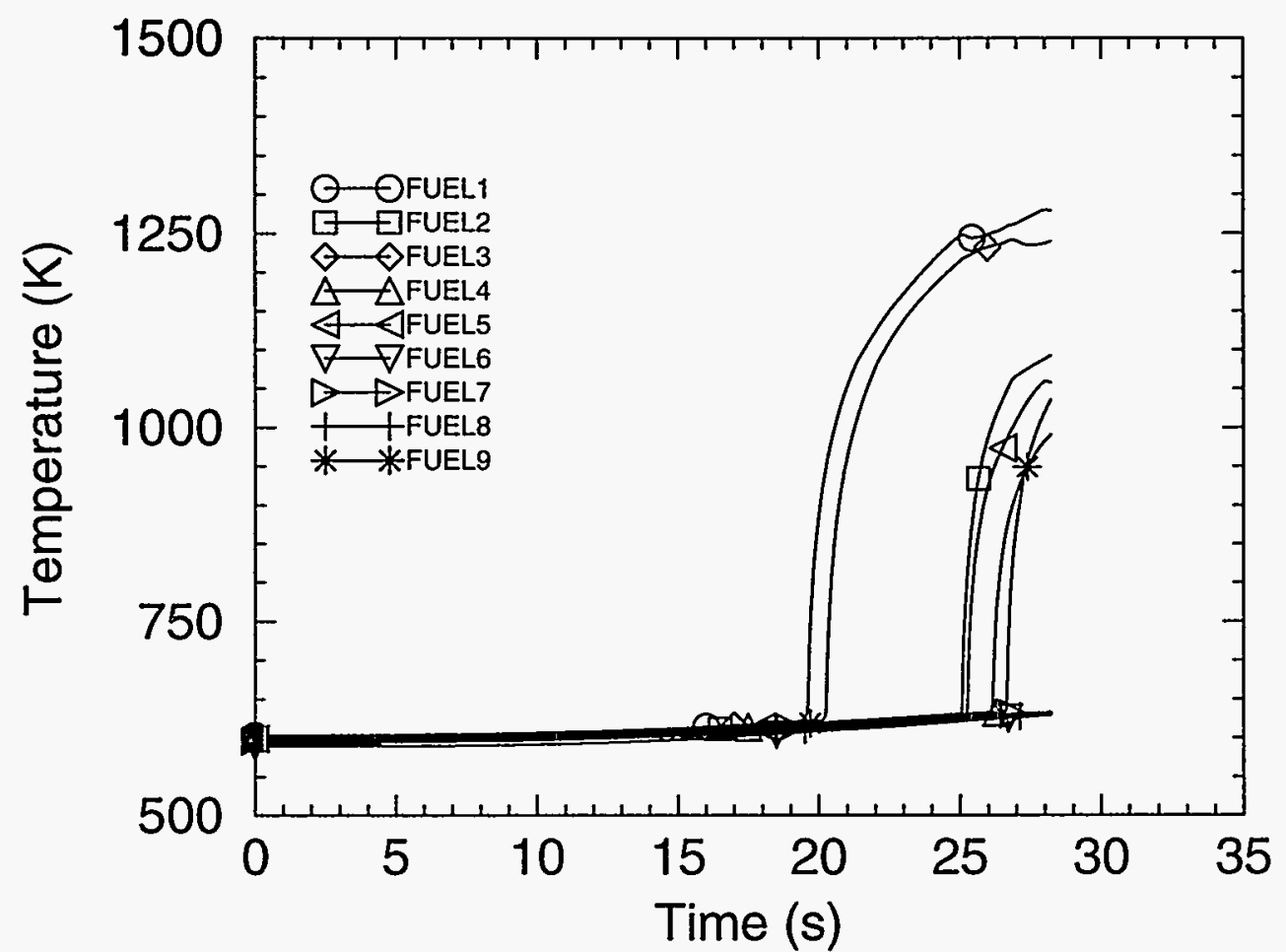

Figure 38. Channel peak clad surface temperatures for the rod bank withdrawal transient.

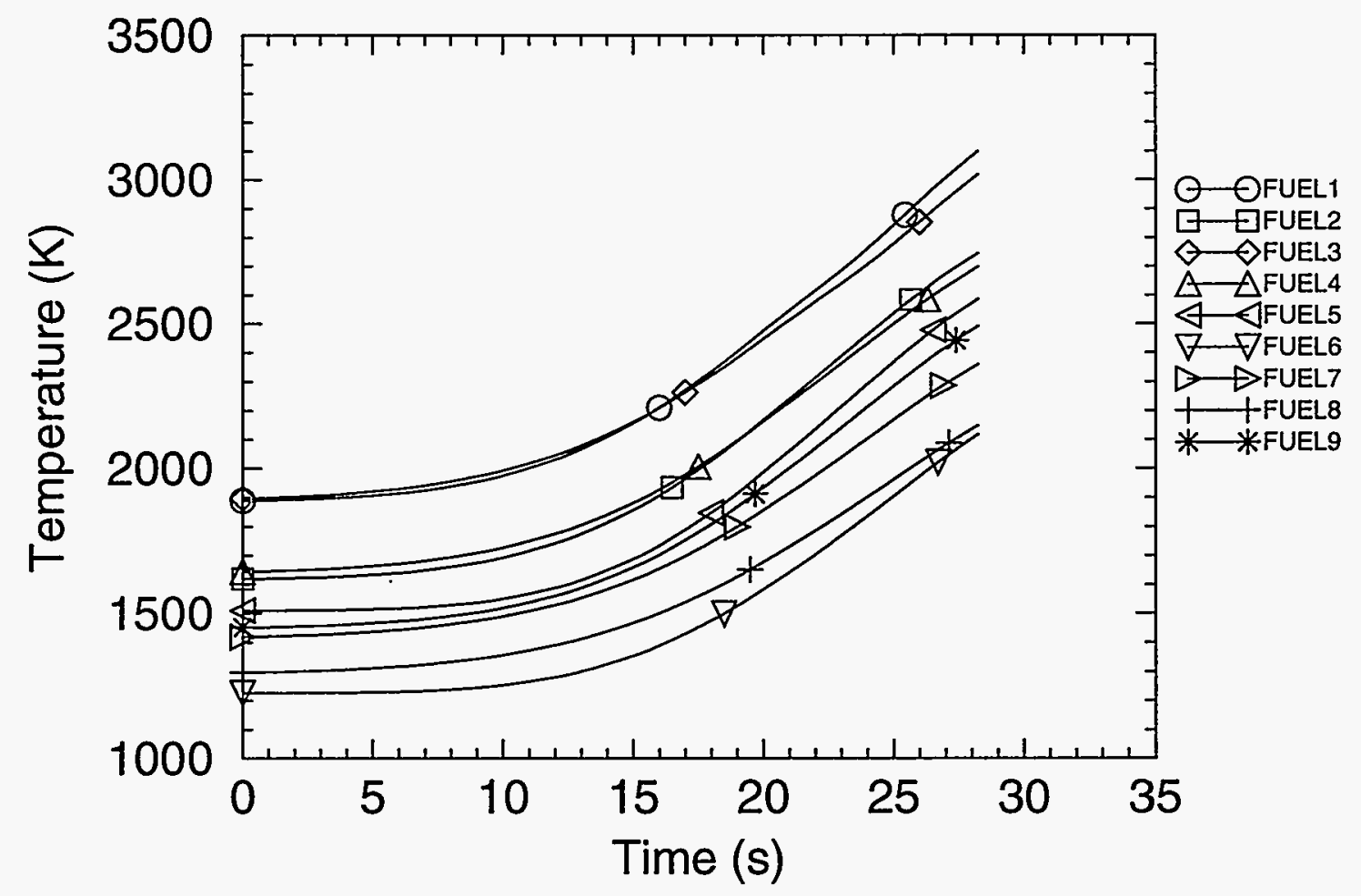

Figure 39. Channel peak fuel centerline temperatures for the rod bank withdrawal transient. 


\subsection{Loss-of-Off-Site-Power Transient}

The calculations performed in this study deal with a CANDU 3 loss of Class IV (off-site) power. The expected scenario is for the reactor to switch to 'island mode' when such an event occurs. Island mode control logic is designed to switch the reactor to local power within one second. Mechanical zone controllers and mechanical control absorbers ramp the power down to $60 \%$, and $10 \%$ of the generated steam is directed to the turbines to supply an in-house power load of 30 to $35 \mathrm{MW}(\mathrm{e})$. The remaining steam is dumped to the condenser.

The following analysis assumes the less likely possibility that power shifting to island mode fails and power to the main coolant pumps and feedwater pumps is not restored. Main pump coastdown causes a core flow decrease, a core void increase, and a resulting power increase. However, another set of 4 rods, the mechanical control absorber (MCA) rods begin a free fall into the core when power is lost. The clutches that hold the MCA in place above the core will release when clutch power is lost. Their $0.010 \Delta \mathrm{k} /$ $k$ of negative reactivity effectively scrams the reactor.

Loss of feedwater flow combined with a decrease in primary flow causes a reduction in the amount of energy removed from the primary loops. If the primary pressure exceeds a set value, liquid relief and/or vapor relief valves open. These valves are in piping between the pressurizer and the bleed condenser tank. The relief valve modeling is described in Section 3.5.

An important factor in a loss-of-off-site-power event is the coastdown of the primary pumps because of the effect of core flow rate on core void reactivity. The pump parameters were left just as provided in the original AECL CATHENA input model. The pump had a mechanical efficiency of 0.885 . Other pump statistics are shown in Table 9.

Table 9. Primary pump parameters.

\begin{tabular}{||l|l||l|l||l|l||}
\hline \multicolumn{1}{|c||}{ Parameter } & \multicolumn{1}{|c||}{ Value } & \multicolumn{1}{|c|}{ Parameter } & \multicolumn{1}{|c||}{ Value } & \multicolumn{1}{|c||}{ Parameter } & Parameter \\
\hline Pump Type & ANC & $\begin{array}{l}\text { Rated Density } \\
(\mathrm{kg} / \mathrm{m} 3)\end{array}$ & 857 & $\begin{array}{l}\text { Stopped } \\
\text { Resistance } \\
\text { 'K' }\end{array}$ & 20 \\
\hline $\begin{array}{l}\text { Rated Head } \\
(\mathrm{m})\end{array}$ & 227 & $\begin{array}{l}\text { Rated Speed } \\
(\mathrm{RPM})\end{array}$ & 1800 & $\begin{array}{l}\text { Moment of Inertia } \\
(\mathrm{kg} \cdot \mathrm{m} 2)\end{array}$ & 1500 \\
\hline $\begin{array}{l}\text { Rated Volumetric } \\
\text { Flow } \\
\left(\mathrm{m}^{3} / \mathrm{s}\right)\end{array}$ & 1.553 & $\begin{array}{l}\text { Operating speed } \\
(\text { RPM })\end{array}$ & 1800 & $\begin{array}{l}\text { Mechanical } \\
\text { Torque } \\
(\text { N.m) }\end{array}$ & 49870 \\
\hline
\end{tabular}

The calculations are reported in increasingly challenging steps by varying three parameters: pressure relief, shutdown and mechanical control absorbers. In all cases, it is assumed that SDS2 is not actuated. The five cases are:

1. With relief, with SDS1 and with MCA.

2. With relief and SDS1 but no MCA.

3. With relief, no SDS but with MCA.

4. With relief, no SDS, and no MCA.

5. No relief, no SDS, and no MCA.

Rather than discussing the results from each of the transient cases individually, the results are presented by phenomena. The differences in the cases are discussed for each phenomena. The SDS1 system trip is based on three trip setpoints; low core flow, high outlet header pressure, and neutron flux trip 
setpoints. The latest trip was used in order to be conservative. Cases 1 and 2 tripped last on the high outlet header pressure trip. Cases 3, 4, and 5 assume that SDS1 and SDS2 systems are inoperable. Table 10 shows the times at which the various trip parameter setpoints were reached during each of the cases. Only in cases 1 and 2 are the shutdown systems allowed to activate. The trip times for the other cases is given for comparison purposes only. Cases 1 and 3 model the insertion of the MCAs and this insertion is not based on a trip signal. The MCAs are assumed to begin their insertion into the core following a 380 millisecond delay from the loss of power.

Table 10. SDS1 trip times for the various cases.

\begin{tabular}{|c|c|c|c|c|c|}
\hline \multirow{2}{*}{ Trip Parameter } & \multicolumn{5}{|c|}{ Time to Reach Trip Setpoint (s) } \\
\hline & Case 1 & Case 2 & Case 3 & Case 4 & Case 5 \\
\hline Outlet Header 1 Pressure & 2.95 & 2.40 & 2.95 & 2.40 & 2.40 \\
\hline Outlet Header 2 Pressure & 2.87 & 2.33 & 2.87 & 2.33 & 2.32 \\
\hline HTS Flow Channel 1 & 2.29 & 2.03 & 2.29 & 2.03 & 2.03 \\
\hline HTS Flow Channel 2 & 2.32 & 2.07 & 2.32 & 2.07 & 2.07 \\
\hline HTS Flow Channel 3 & 2.15 & 2.11 & 2.15 & 2.11 & 2.11 \\
\hline HTS Flow Channel 4 & 2.16 & 2.13 & 2.16 & 2.13 & 2.13 \\
\hline HTS Flow Channel 5 & 2.44 & 1.97 & 2.44 & 1.97 & 1.97 \\
\hline HTS Flow Channel 6 & 2.55 & 2.25 & 2.55 & 2.25 & 2.25 \\
\hline HTS Flow Channel 7 & 2.24 & 2.26 & 2.24 & 2.26 & 2.26 \\
\hline HTS Flow Channel 8 & 2.21 & 2.20 & 2.21 & 2.20 & 2.20 \\
\hline HTS Flow Channel 9 & 2.30 & 2.17 & 2.30 & 2.17 & 2.16 \\
\hline HTS Flow Channel 10 & 2.37 & 2.25 & 2.37 & 2.25 & 2.25 \\
\hline Neutron Flux Level & a & 0.88 & $\mathbf{a}$ & 0.88 & 0.88 \\
\hline High Log Rate & a & 1.52 & a & 1.52 & 1.52 \\
\hline Trip Time Used to Trip SDS1 & 2.95 & 2.40 & $\begin{array}{l}\text { No Trip } \\
\text { Assumed }\end{array}$ & $\begin{array}{l}\text { No Trip } \\
\text { Assumed }\end{array}$ & $\begin{array}{l}\text { No Trip } \\
\text { Assumed }\end{array}$ \\
\hline
\end{tabular}

a. Neutron flux level and high log rate trips not used since the MCAs are inserted for these cases.

\subsubsection{Pump Coastdown and Core Flow}

The four primary pumps begin an inertial coast down from an initial speed of $1800 \mathrm{rpm}$. The five transients were short enough that pump speed versus time for each transient is very similar. The results from Case 1 for pump1 and pump2 are shown in Figure 40. Pumpl drives flow through one-quarter of the core to outlet header $1(\mathrm{OH} 1)$ and pump2 forces flow through another quarter to $\mathrm{OH} 2$. Pump coastdown rates are not identical. Flow resistances between inlet and outlet headers are different and the pressurizer is connected to $\mathrm{OH} 2$. The pressurizer gives increased fluid capacitance in loop 2. 
The core flow response to the loss-of-off-site-power is dominated by the pump speed. However, core flow is altered somewhat by the power history, boiling mode, and relief valve opening. Figure 41 shows the core flow decay for all 10 channels for Case 1. Note that the channel 9 and 10 each represent a quarter of the core and their flow mass flow rates have been divided by 10 to scale them into the plot.

Increased power generation can cause core flow to decrease if the core remains in nucleate boiling because increased voids leads to increased two-phase wall friction. In film boiling, the rod heat flux is less and void generation is less. Transition to film boiling can result in a reduced two-phase wall friction and increased flow. Figure 42 shows a core flow increase and a subsequent flow oscillation for Case 4 and 5 at the time the critical heat flux (CHF) was exceeded and channel 1 experienced film boiling. The phenomena gets complicated because multiple events are occurring simultaneously. The liquid relief valve (LRV) begins to open at about the same time CHF is reached. Without SDS1 or MCA action (Case 4 and 5), the power escalation resulted in fuel temperatures above the fuel melting point $(3100 \mathrm{~K})$ and the transient was terminated at about 9 seconds for both cases. All the channels connected to $\mathrm{OH} 2$ show a flow increase and channels 9 and 10 experienced a flow decrease at the same time.

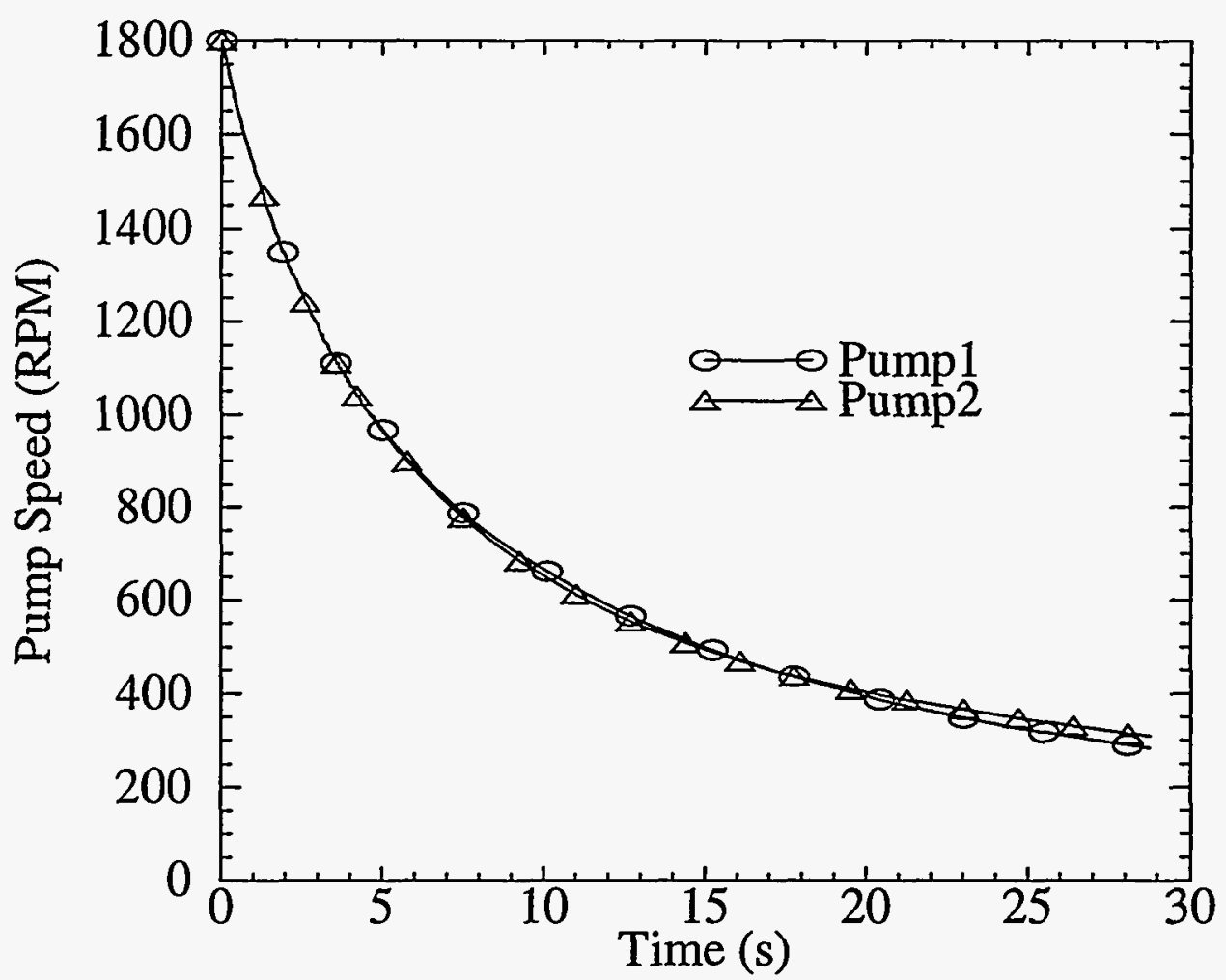

Figure 40. Case 1 pump speed. 


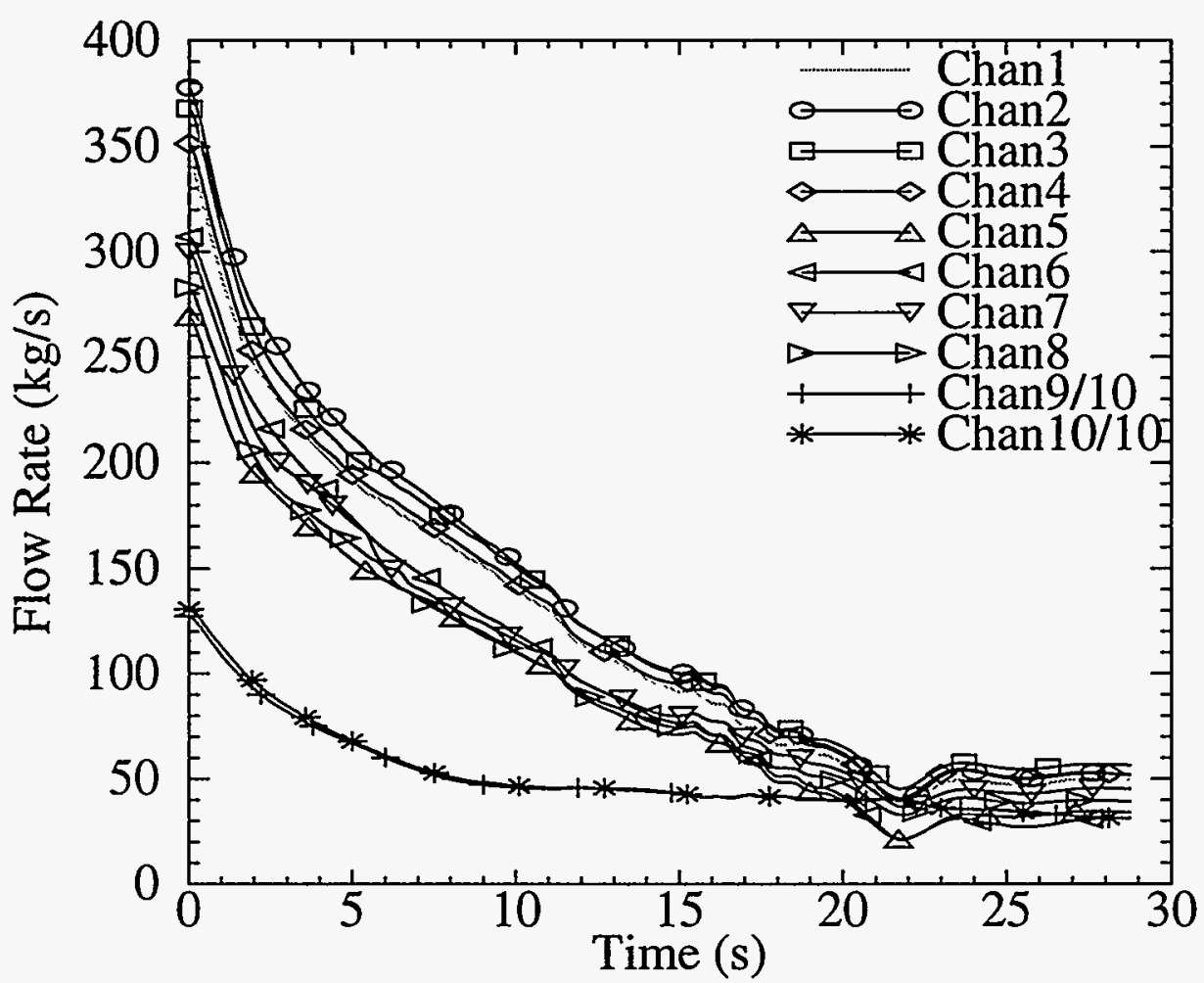

Figure 41. Core flow for all case 1 channels.

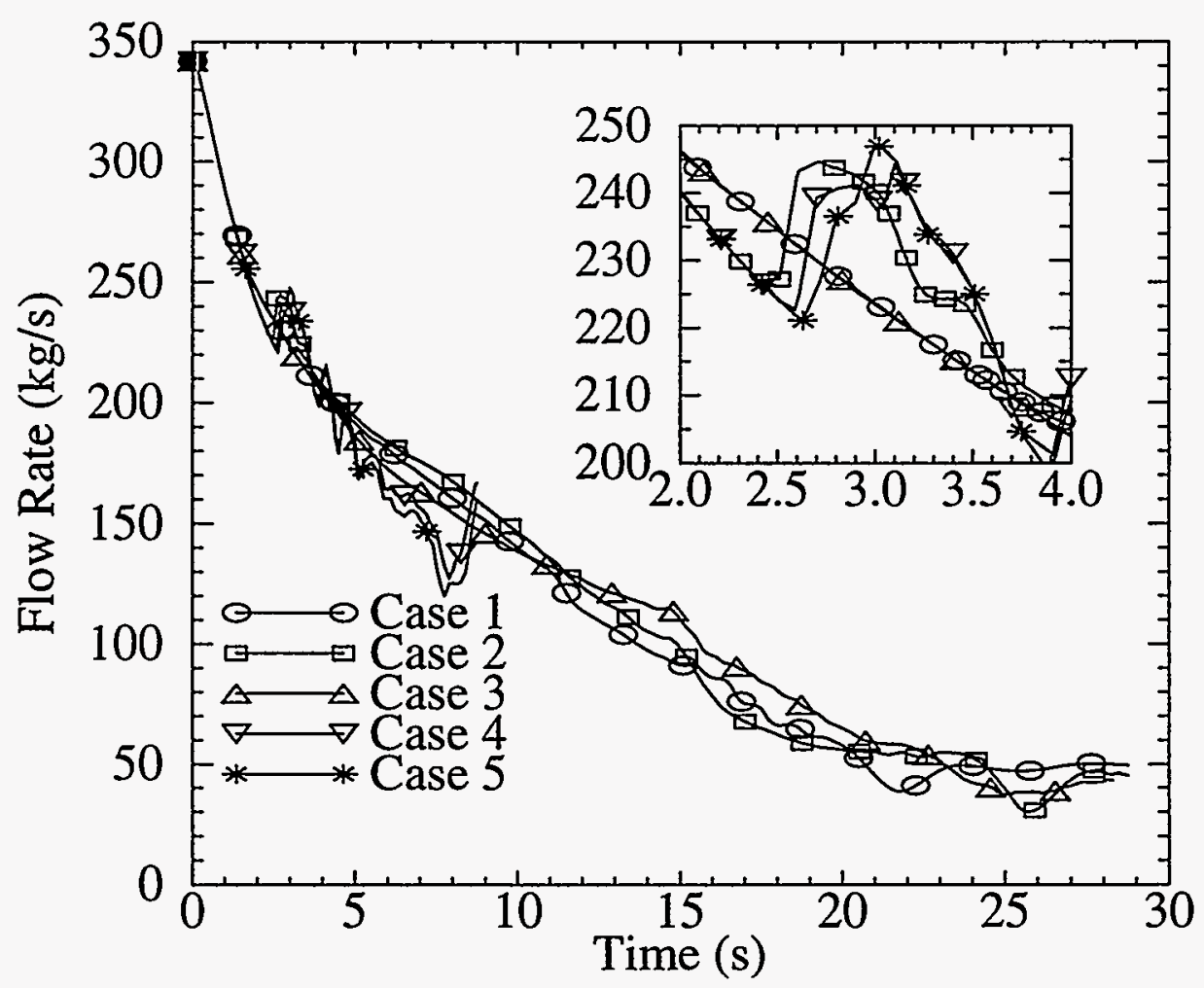

Figure 42. Chanl core flow for five cases. 


\subsubsection{Core Power, Voids and Reactivity}

Initially power increased for Case 1 as the flow decreased and the void fraction increased but at 0.38 seconds the MCA began their 3 second fall and power was quickly reduced. The 0.38 seconds delay is the estimated time for the clutches holding the $4 \mathrm{MCA}$ rods to release. Another power reduction is caused by the insertion of the 22 SDS1 rods that begins at 3 seconds. These rods trip on high flux, low core flow or high outlet header pressure. The latest trip was used to be conservative. The pressure trip on an $\mathrm{OH} 1$ pressure of 10.55 MPA at 2.954 seconds was used (See Table 10). The calculated power history is given in Figure 43.

Figure 44 shows the changes in the channel average void fractions as the Case 1 transient progresses. Inserting the rods made the void fractions decrease but as the core flow got lower the voids increased again.

Reactivity is the driving parameter for power and is shown.in Figure 45. The basic components of reactivity for Case 1 are void reactivity, MCA worth, and SDS1 worth. Since the MCAs reach the active fuel region 0.38 seconds after the loss of power, they insert sufficient negative reactivity to more than compensate for the positive void reactivity during the transient.

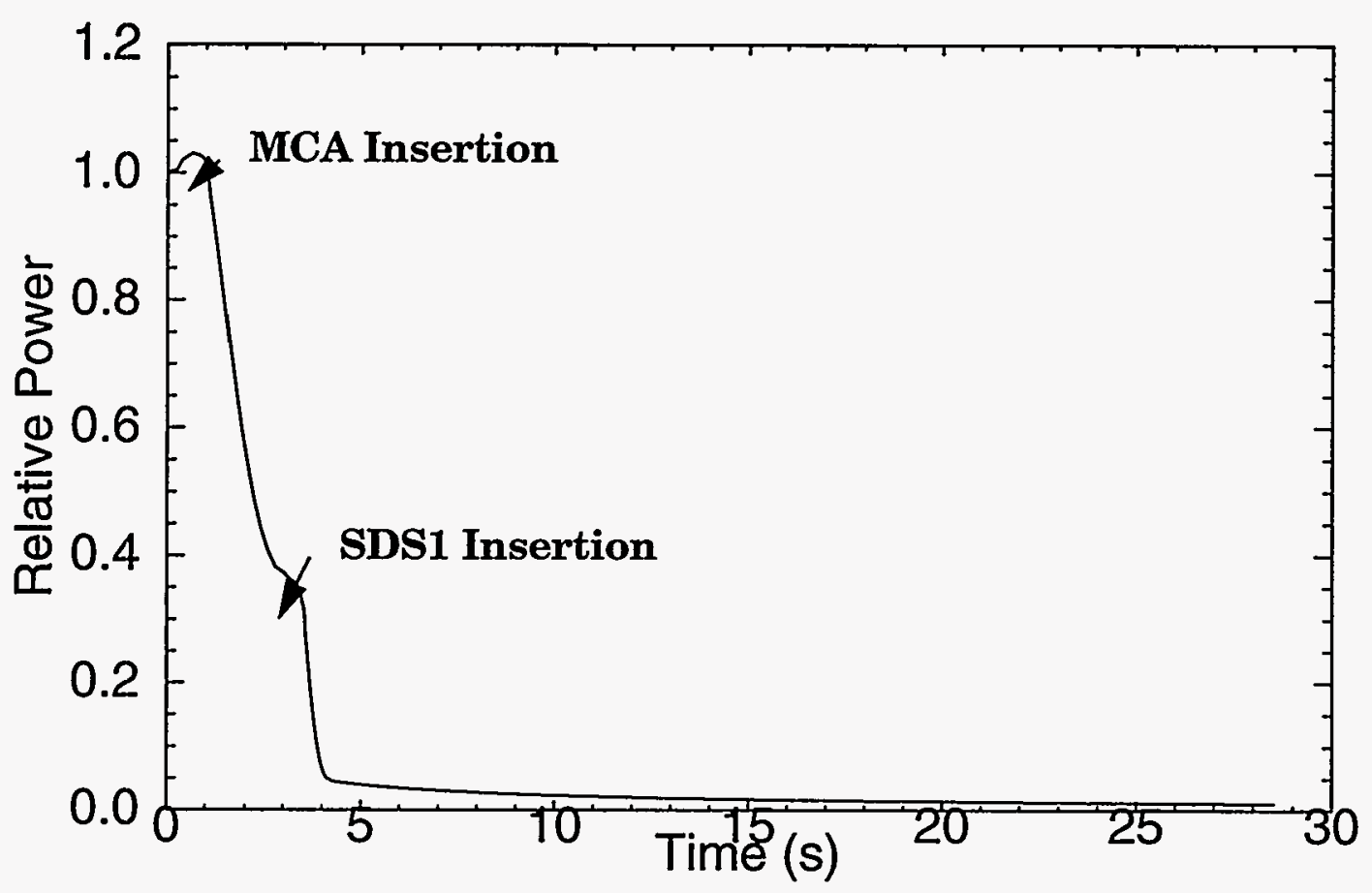

Figure 43. Case 1 reactor power. 


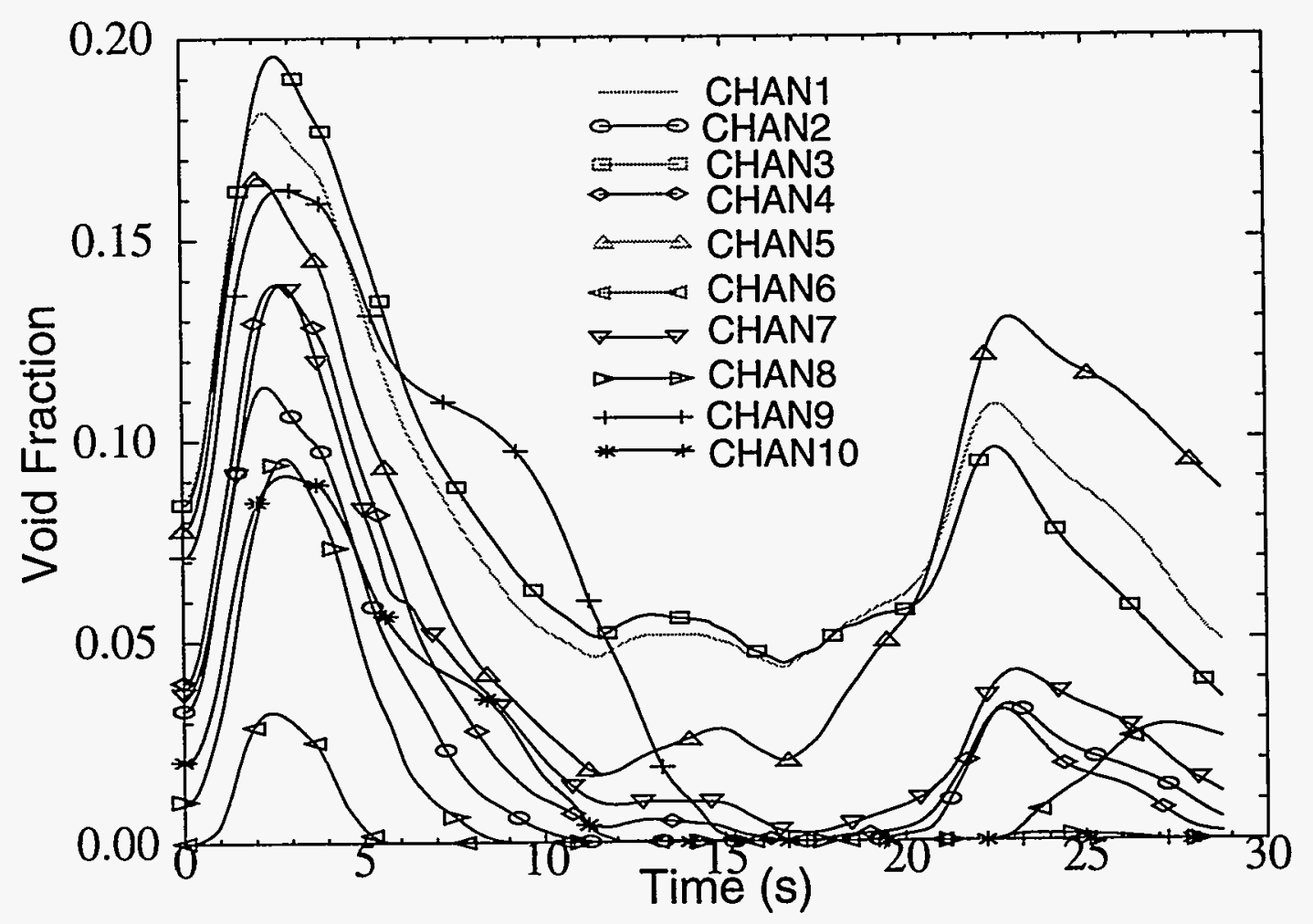

Figure 44. Case 1 core voids.

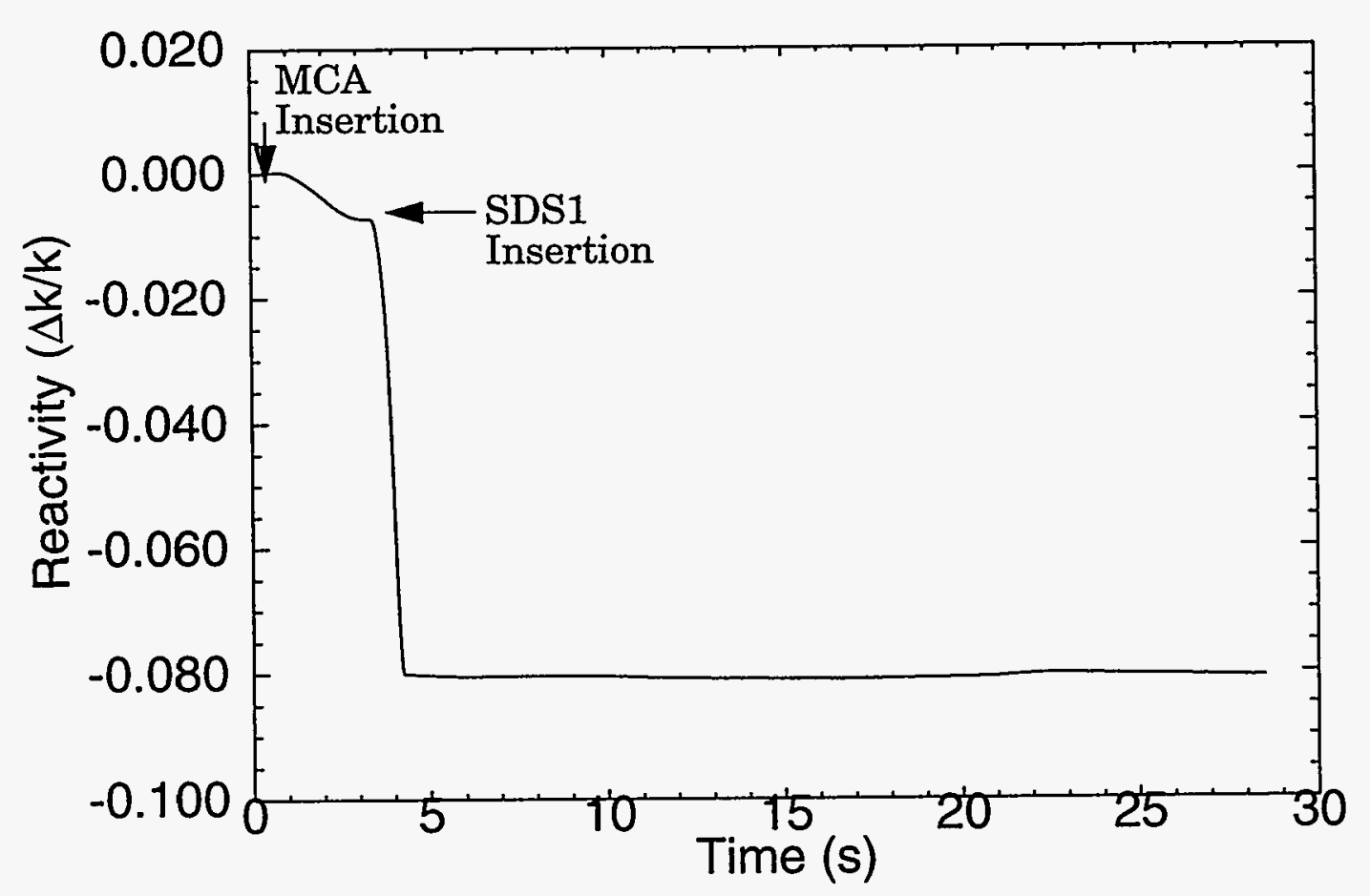

Figure 45. Case 1 reactivity. 
Cases 4 and 5 (see Figure 46) have very similar power curves because the calculational time window is too short for the relief valve opening in Case 4 to have much of an effect on core voids and power. Thus the five cases yield only 4 different types of curves.

The void profiles also show 4 different types. Figure 47 shows the channel average void fraction versus time for Chan 1 for all five cases and Figure 48 shows the channel exit values. Note that the initial channel exit void fraction is above $40 \%$. Also note in Figure 47 and Figure 48 that the behavior of the void fraction in channel 1 (and the rest of the core) is very similar to the power history. The void formation rate in the core is dependent on the power to flow ratio. Since the flows in each case are roughly the same with time, the void formation rate will follow the core power. fraction.

Figure 49 illustrates that the reactor reactivity is dominated by the control rod position and void

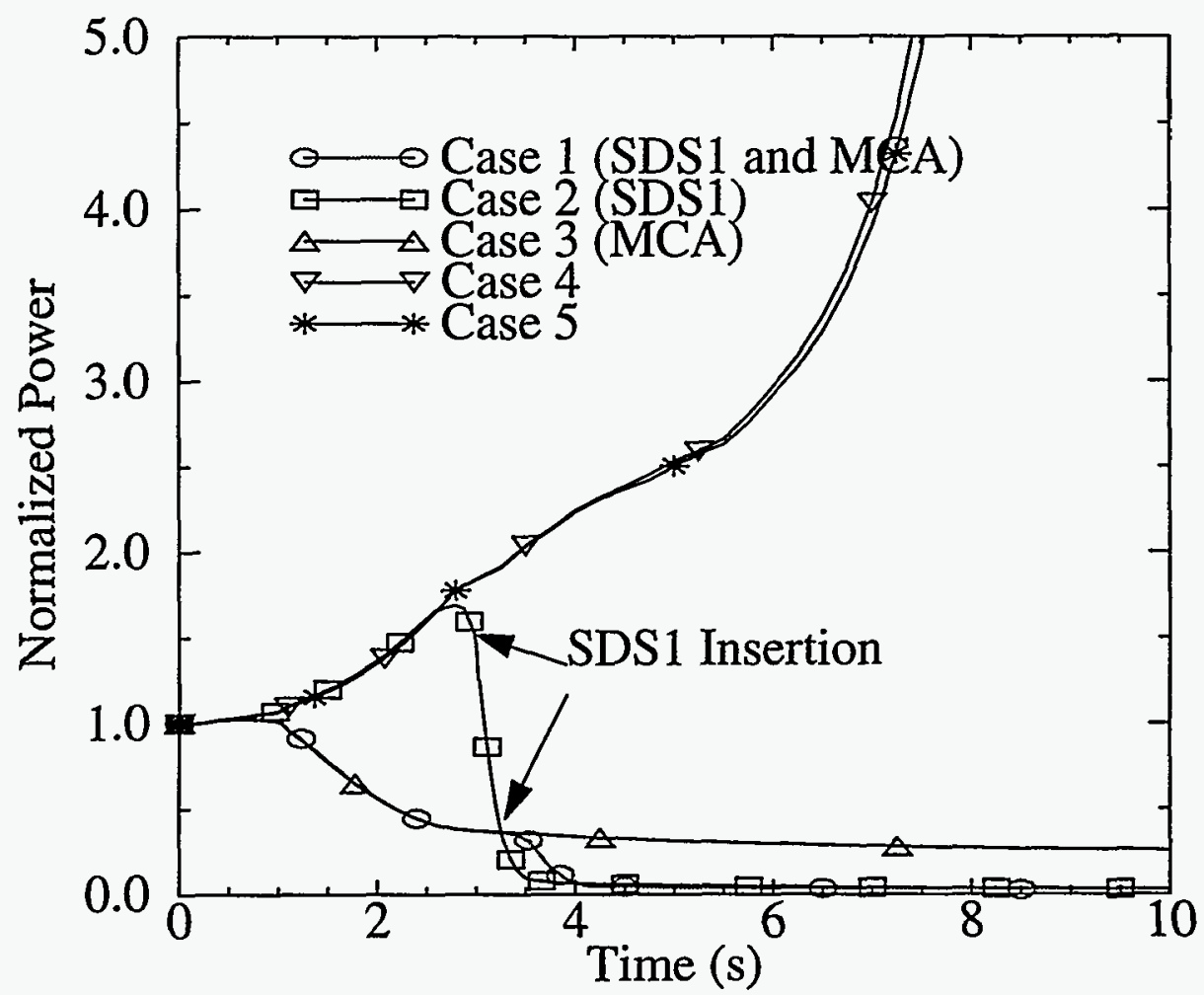

Figure 46. Power for all cases. 


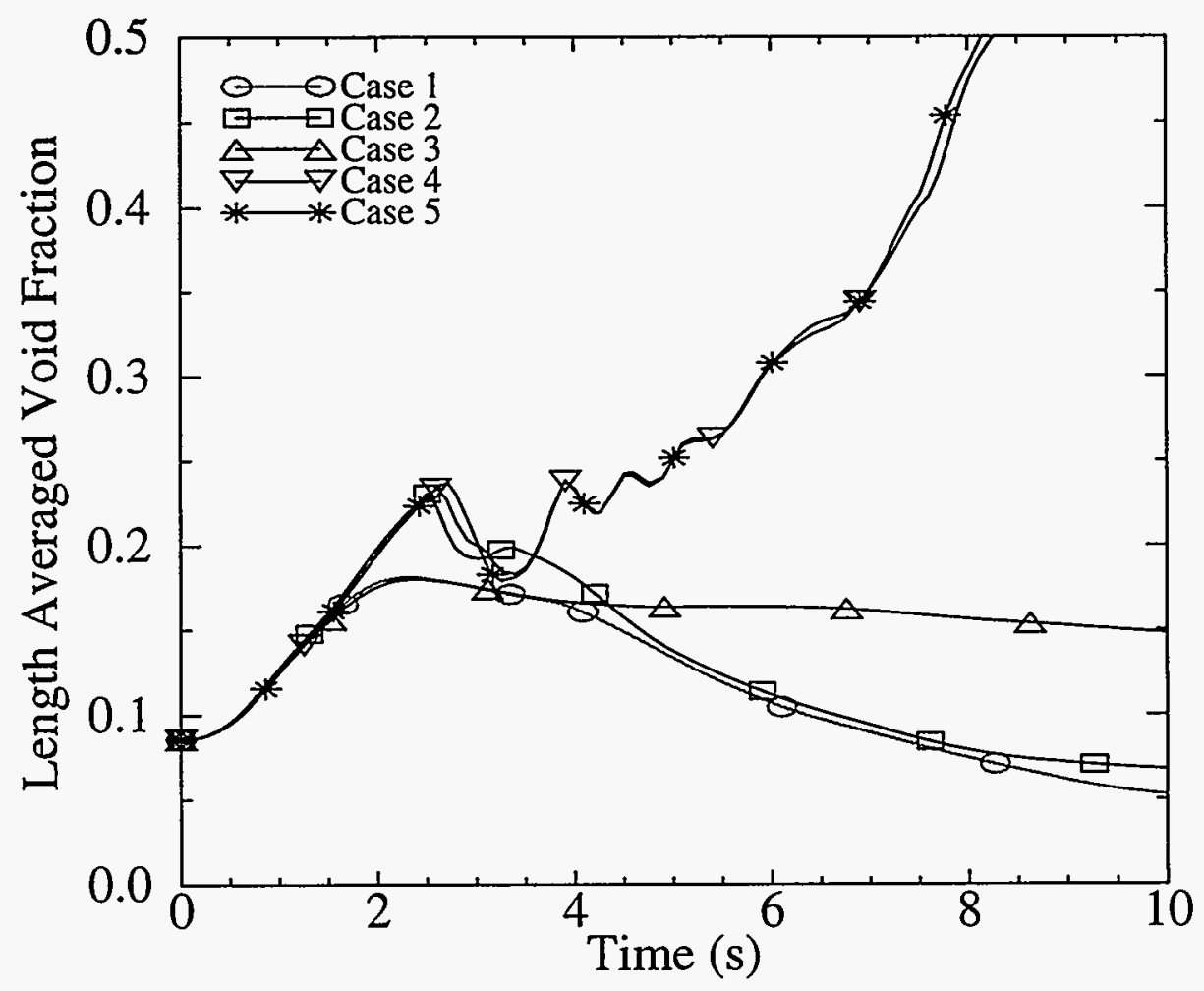

Figure 47. Chan 1 average void fraction for all cases.

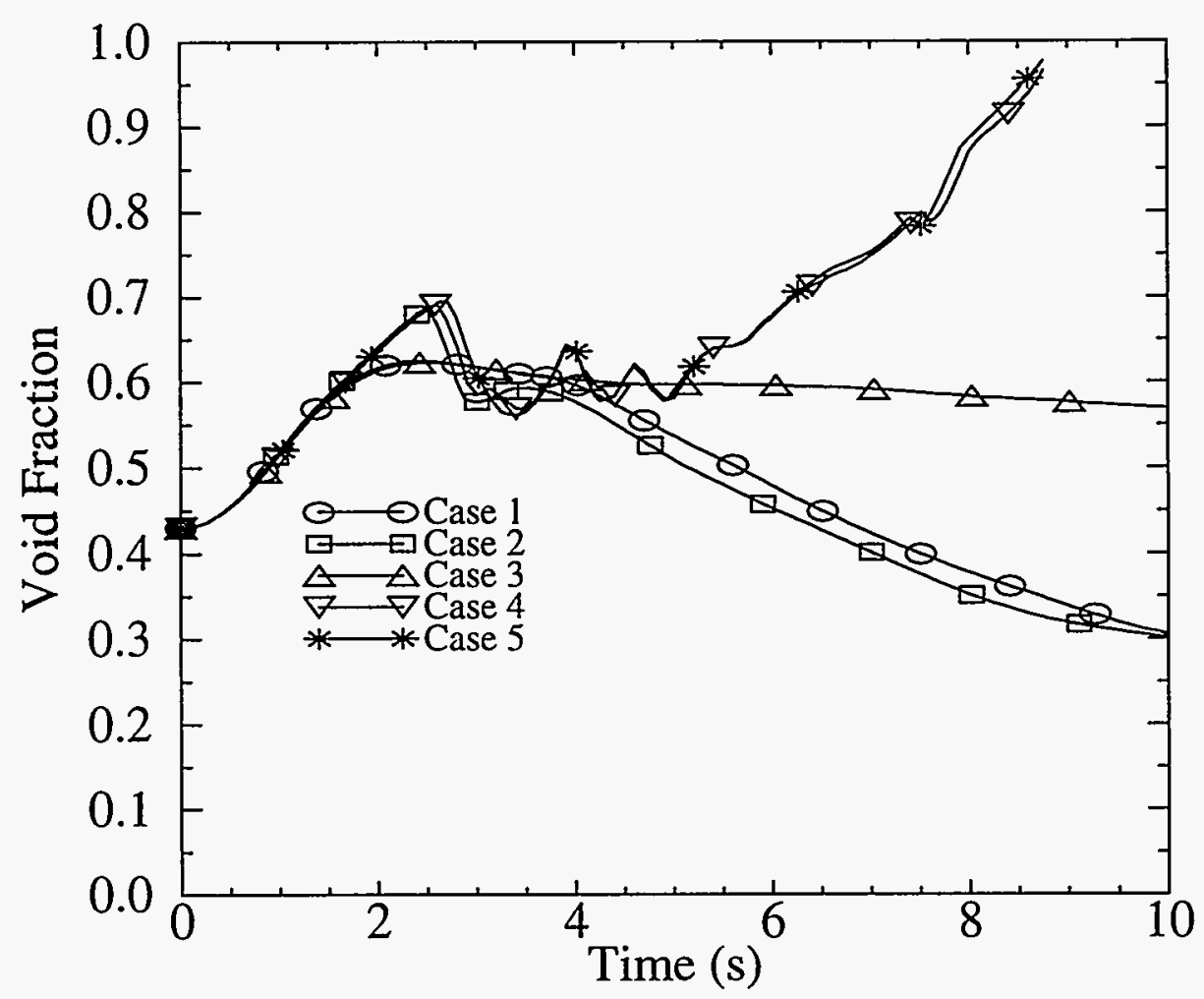

Figure 48. Chan 1 exit void fraction. 


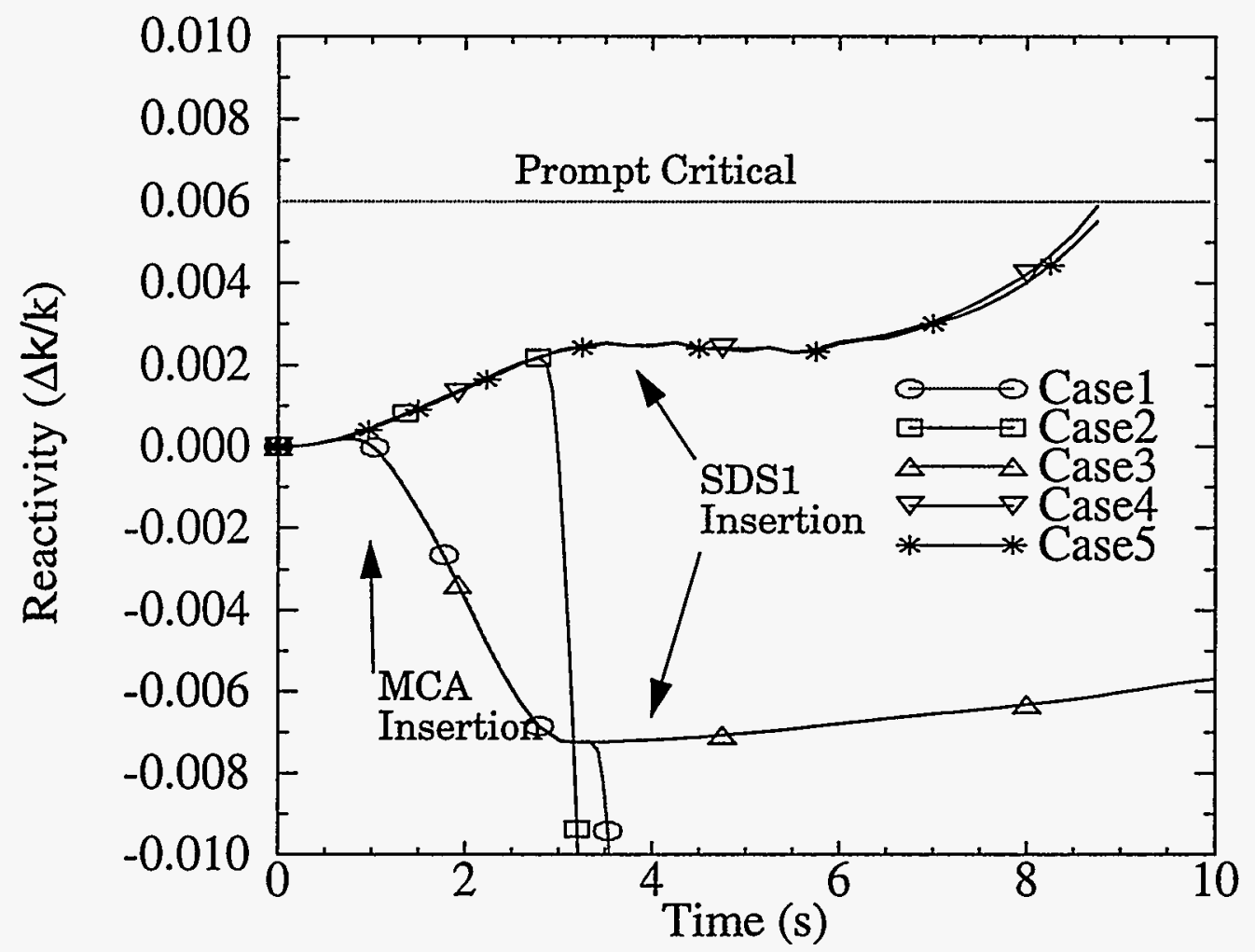

Figure 49. Reactivity for all cases.

\subsubsection{Fuel and Cladding Temperatures}

For the cases where the power is ramped down the fuel and rod cladding temperatures quickly approach the fluid temperatures. This is illustrated for Case 1 fuel and cladding temperatures in Figure 50 and Figure 51, respectively.

Maximum fuel temperatures for Chan1 for all cases are shown together in Figure 52. Figure 53 shows the cladding temperatures. The critical heat flux was exceeded at some point in fuel channel 1 for all cases except Case 1 . 


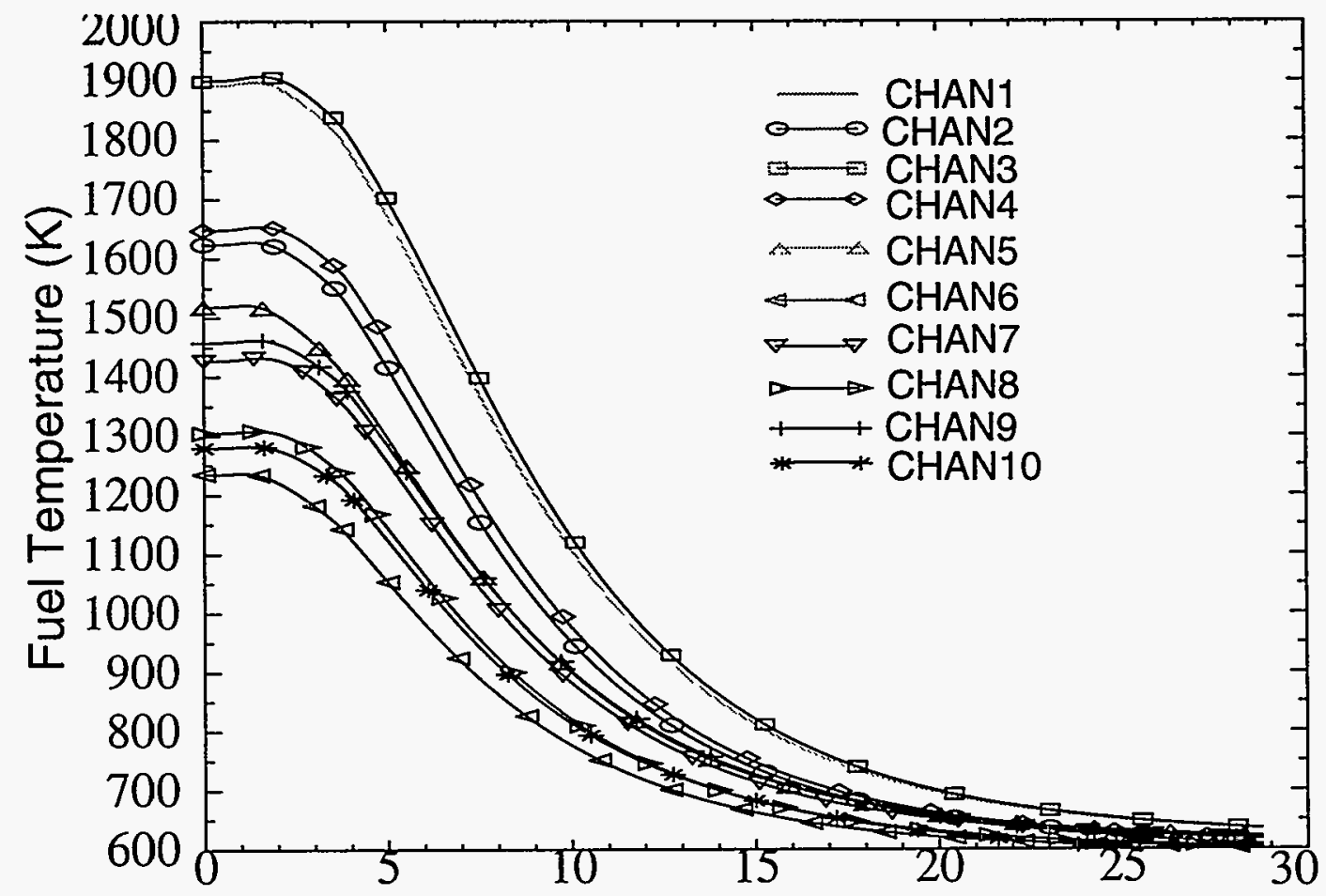

Figure 50. Case 1 fuel temperatures.

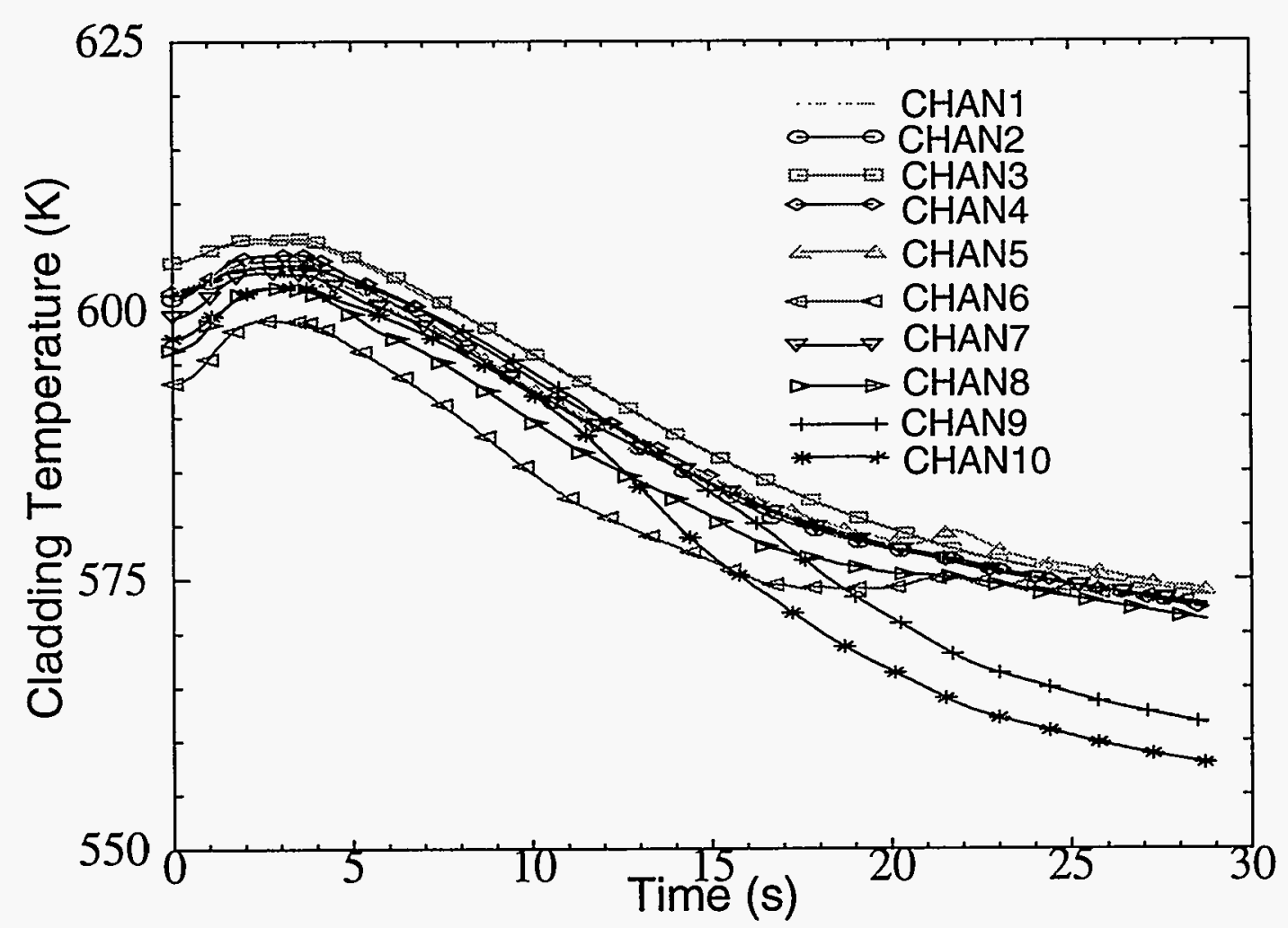

Figure 51. Case 1 cladding temperatures. 


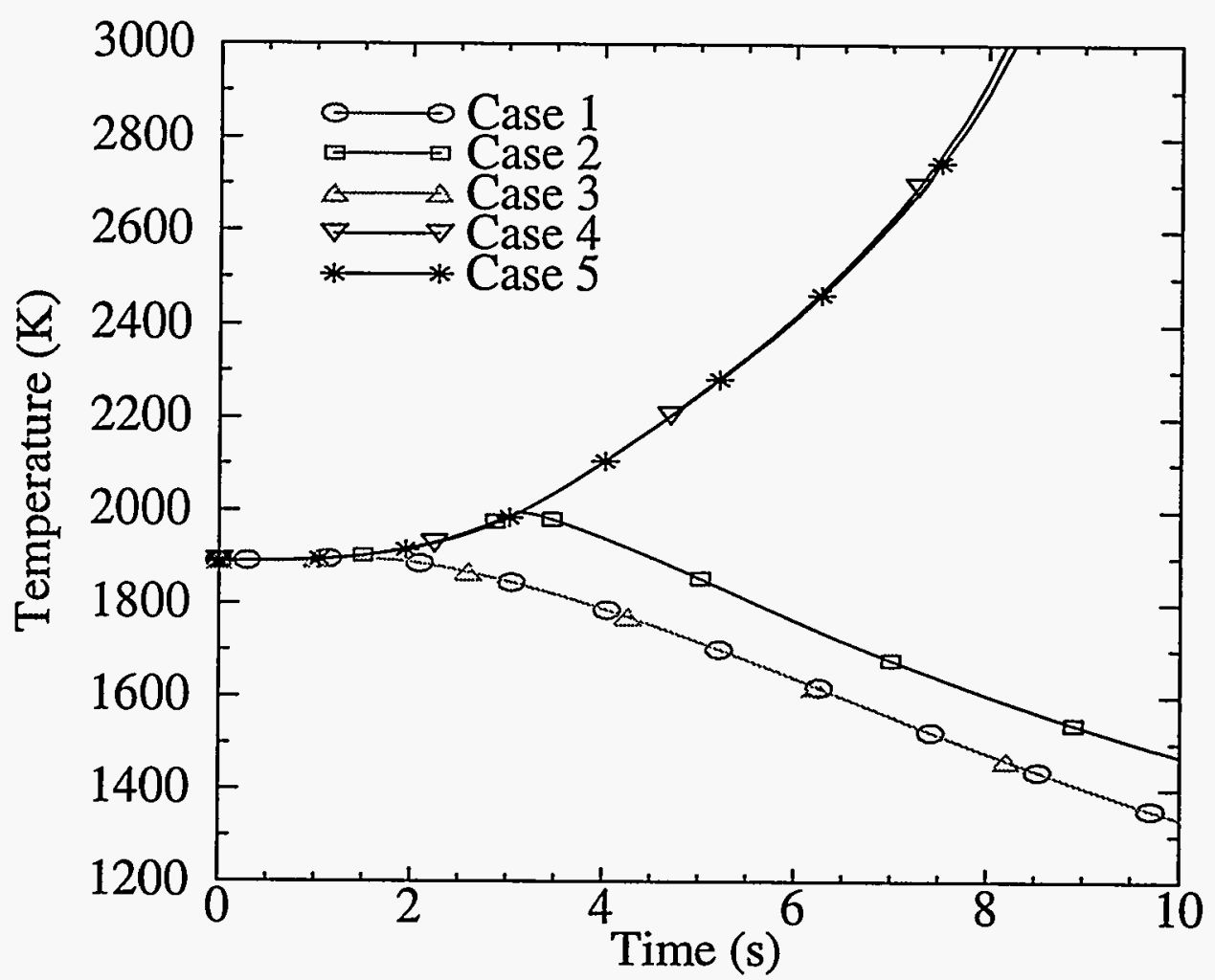

Figure 52. Chan 1 maximum fuel temperature for all cases.

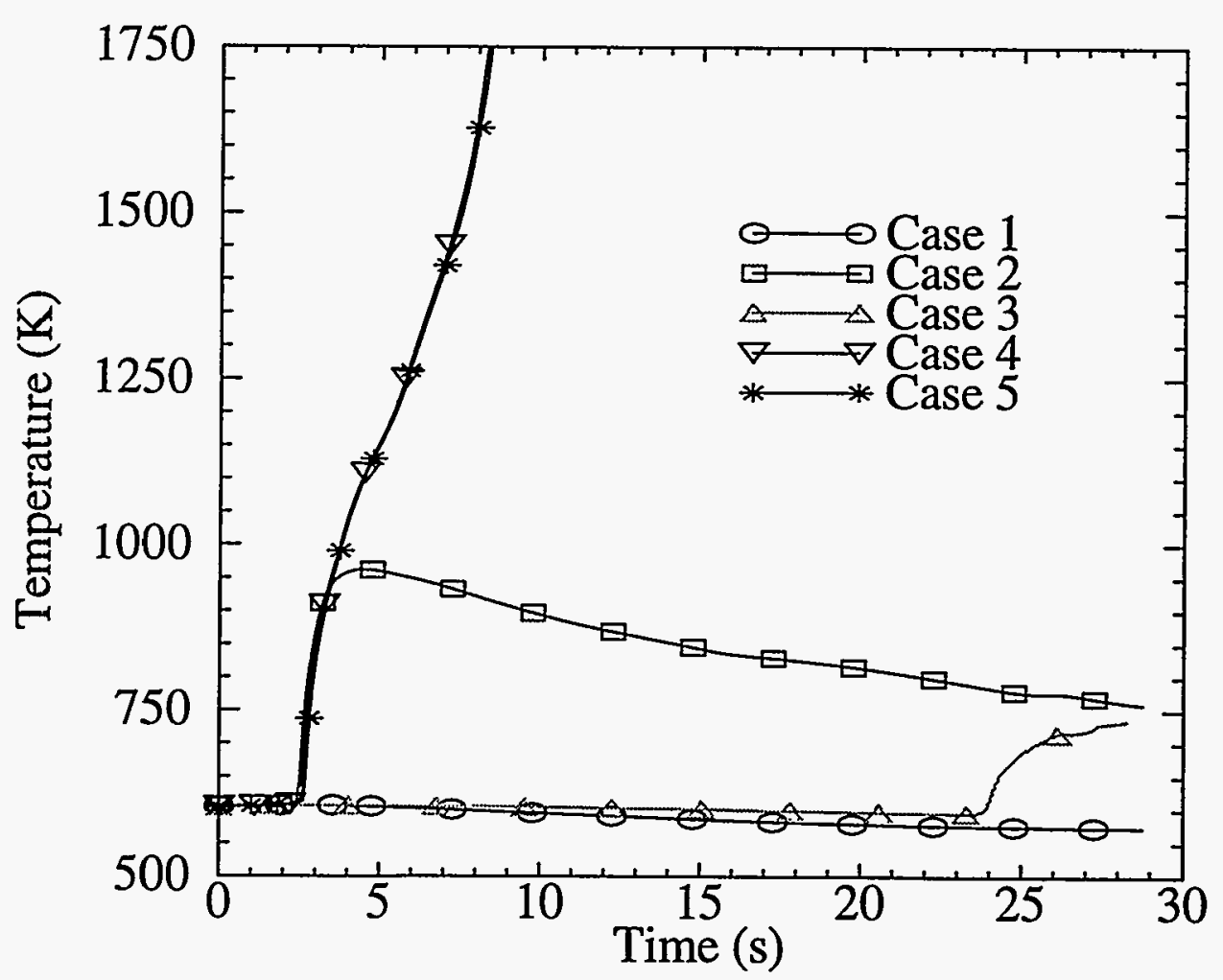

Figure 53. Chan 1 cladding temperature all case. 


\subsubsection{Primary Pressure}

The initial pressure difference between the inlet headers and the outlet headers is about $1.5 \mathrm{MPa}$ (200 psid). As the four pumps coast down this difference collapses as shown in Figure 54 for Case 1. The pressure in outlet header 2 for all five cases is shown in Figure 55. Relief valves opening helps to control the pressure rises for Cases 1-3. The pressure rise without scram would cause pressure tubes to rupture. Steam discharging into the calandria tank would cause a power decrease due to the negative void coefficient in the moderator tank. Pressure tube ruptures were not modelled in CATHENA.

\subsubsection{Pressurizer and Relief Valves}

During Case 1 the liquid relief valve (LRV) opened to about $60 \%$ and the vapor relief valve (VRV) did not open. Figure 56 shows various parameters relative to the performance of the valves. Note that the pressure in the pipe (P2LRV) on the upstream side of the LRV had a much lower pressure than the pressurizer (PSR3) did when fluid was escaping through the valve. If the valve open position were governed by this pressure, valve area oscillations could be expected. At the maximum valve open position, the flow rate reached about $200 \mathrm{~kg} / \mathrm{s}$.

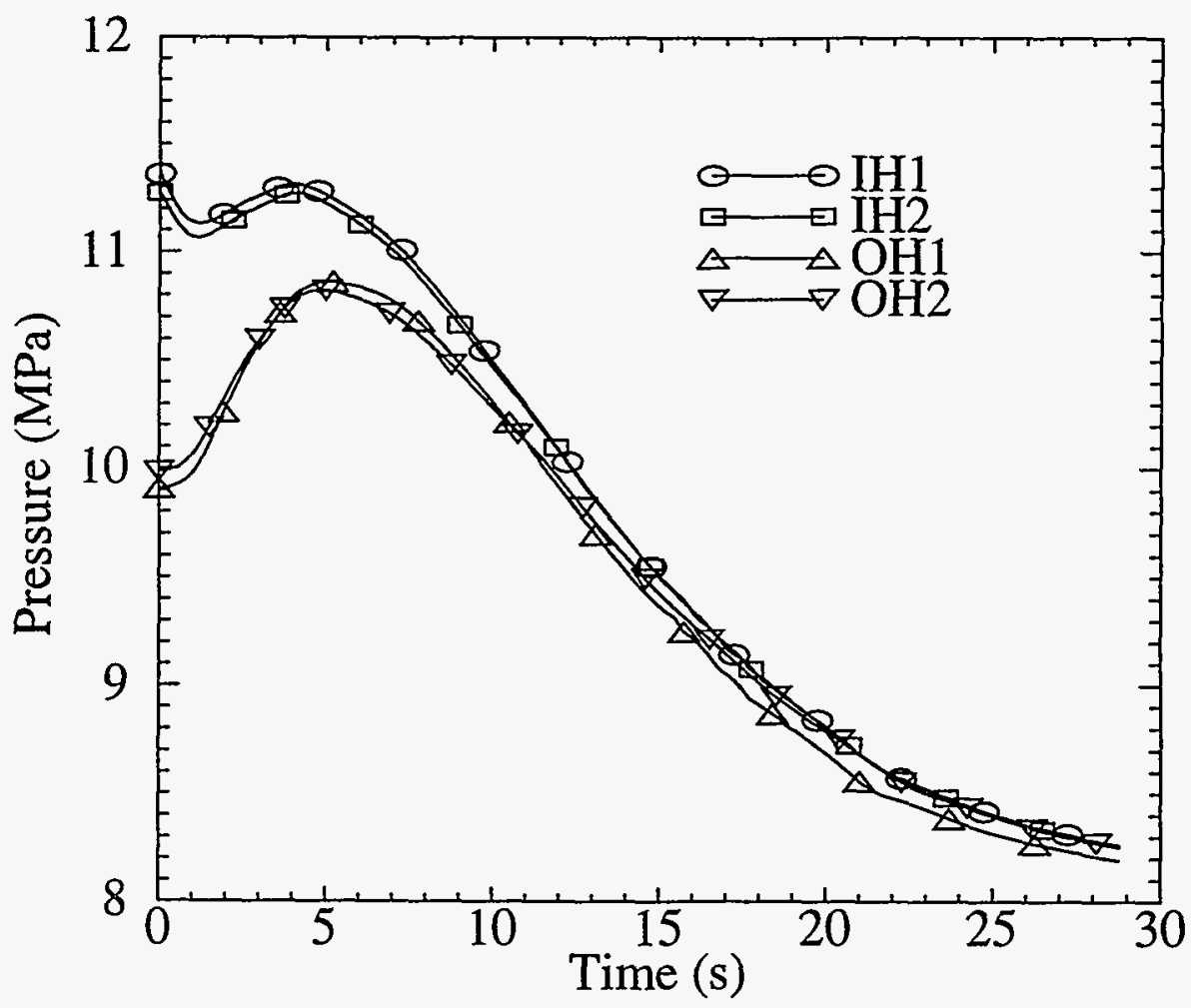

Figure 54. Inlet and outlet header pressures for case 1. 


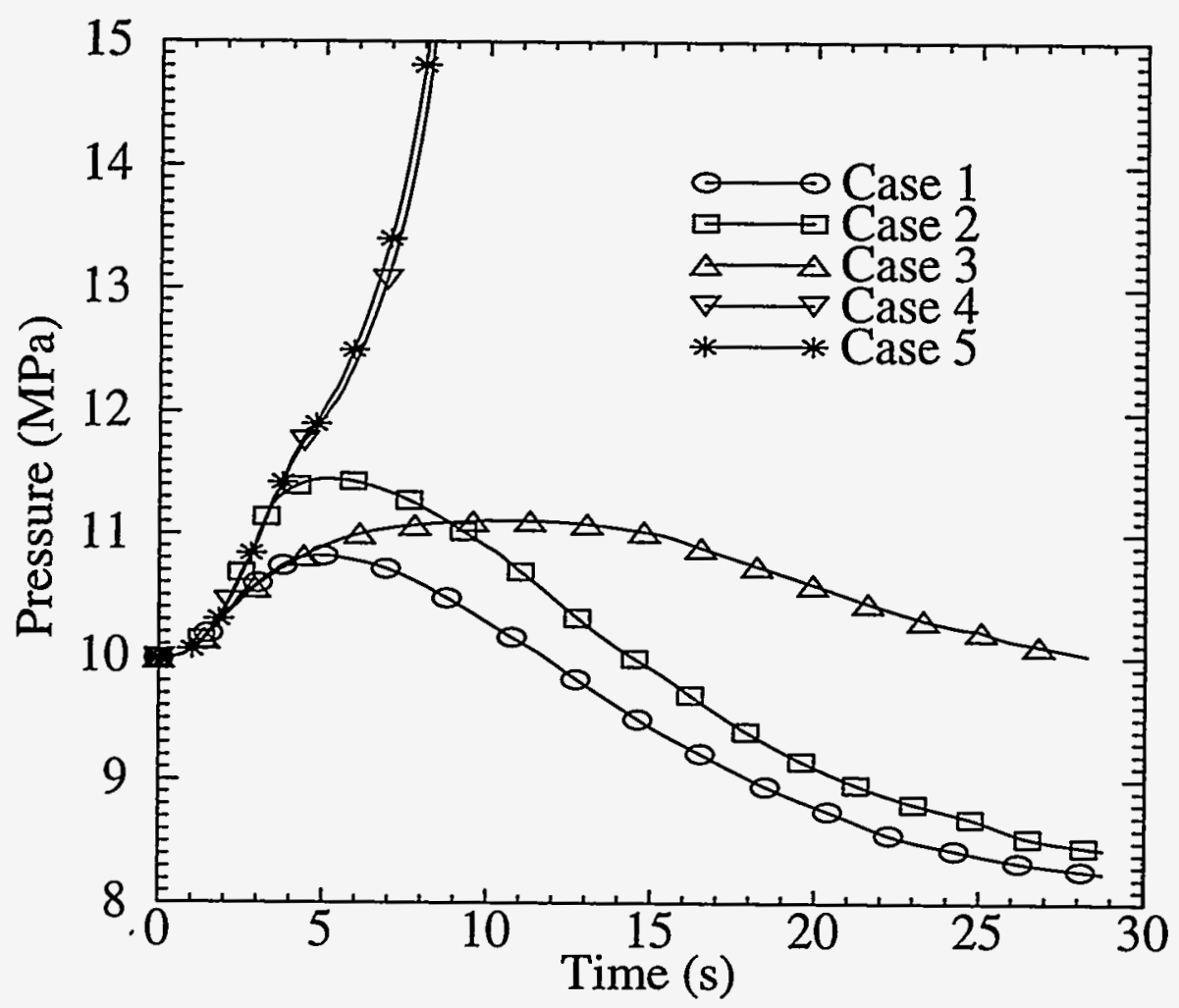

Figure 55. $\mathrm{OH} 2$ pressure for all cases.

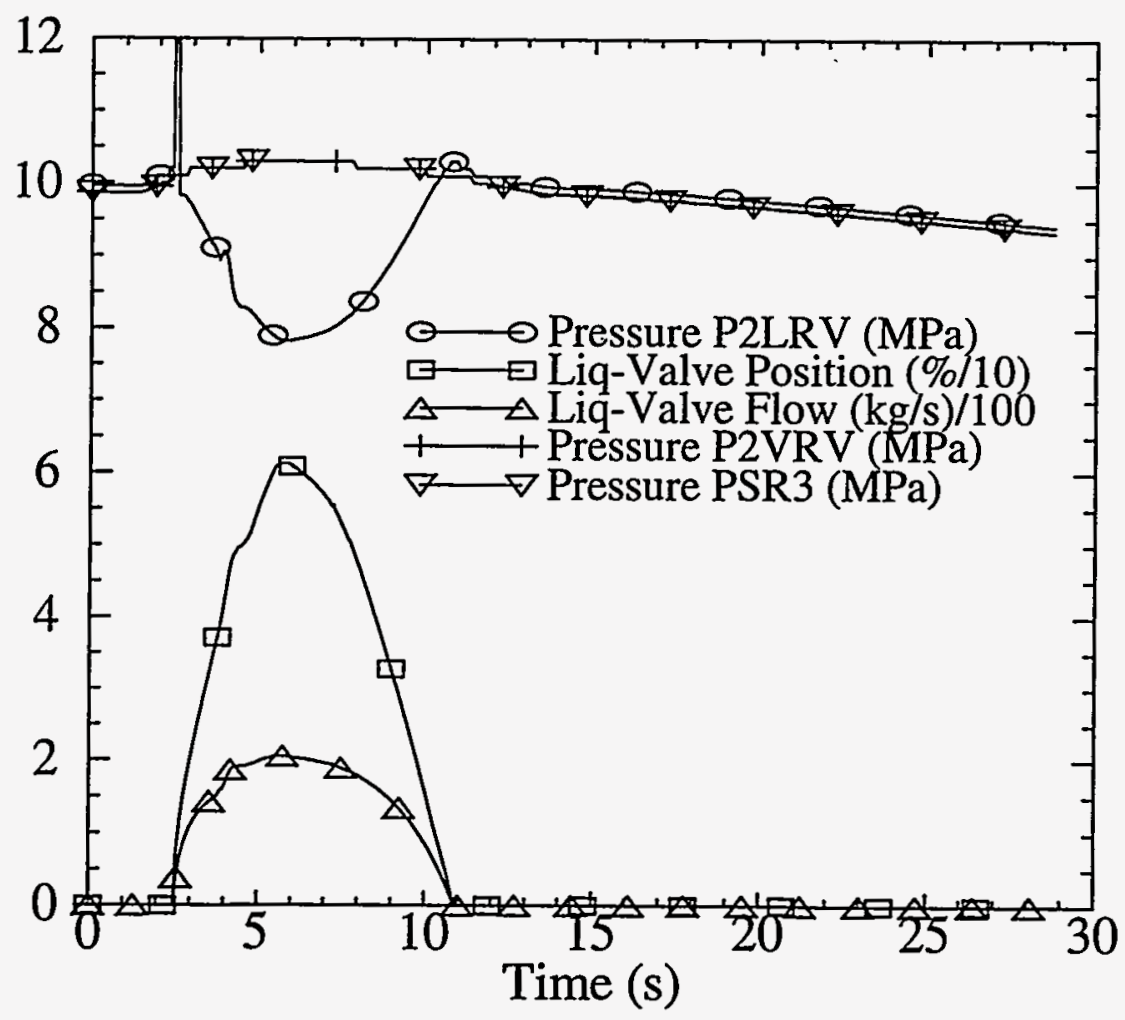

Figure 56. Relief valve parameters for case 1. 
The P2LRV pressure spike shown in Figure 56 at about 2.5 seconds was caused by water-packing when the valve initially opened then closed, because the water temperature in the pipe between the pressurizer and the valve was set to a low value initially. A test was run with hot (saturated) water in the pipe and the pressure spike did not occur. Evidently the initial flow surge was softened by flashing when hot water was specified. The spike is not expected in the plant for two reasons even though the water will be below saturation. The reasons are that valve is controlled by the outlet header (OH2) pressure and the valve has an opening time constant which was not modelled. The water-packing problem described results from the improper initial coolant conditions in the liquid relief valve line, however the current model is believed to yield adequate results for this study.

LRV opened completely only for Case 4 as shown in Figure 57. The LRV was open longer during Case 3 than in the other cases, however, the pressurizer liquid level changed only slightly because liquid is entering the pressurizer from the outlet header through the surge line.

The VRV opened completely for Case 4 and slightly for Cases 2 and 3 (see Figure 58).

During all cases the pressurizer pressure lags the outlet header pressure because of the flow resistance of the surge line. The increasing pressure difference is shown in Figure 59 for Case 4. The actual relief valve open position is a function of the pressure in the outlet header and thus, the amount of the relief calculated here may be pessimistic.

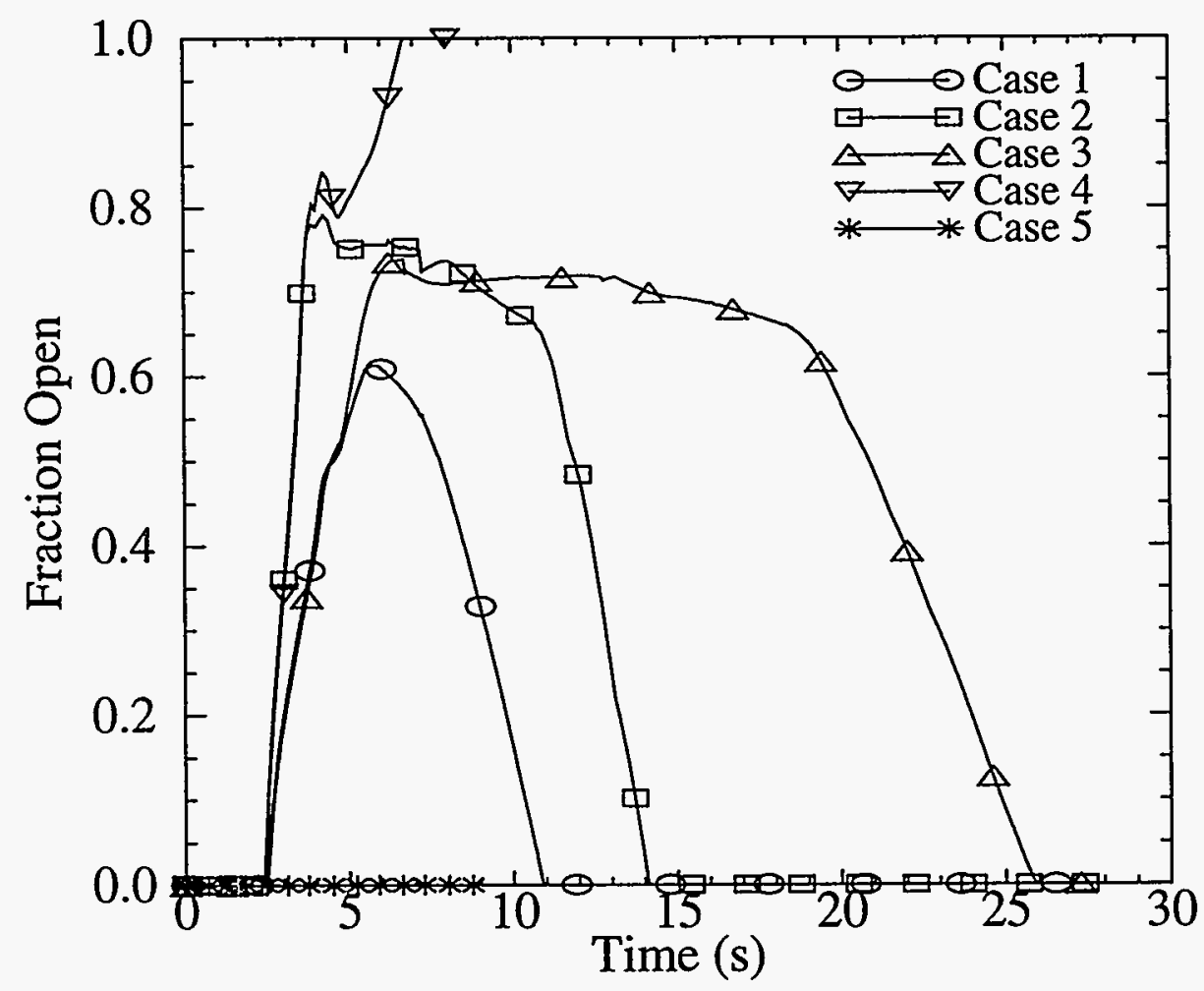

Figure 57. LRV position for all cases. 


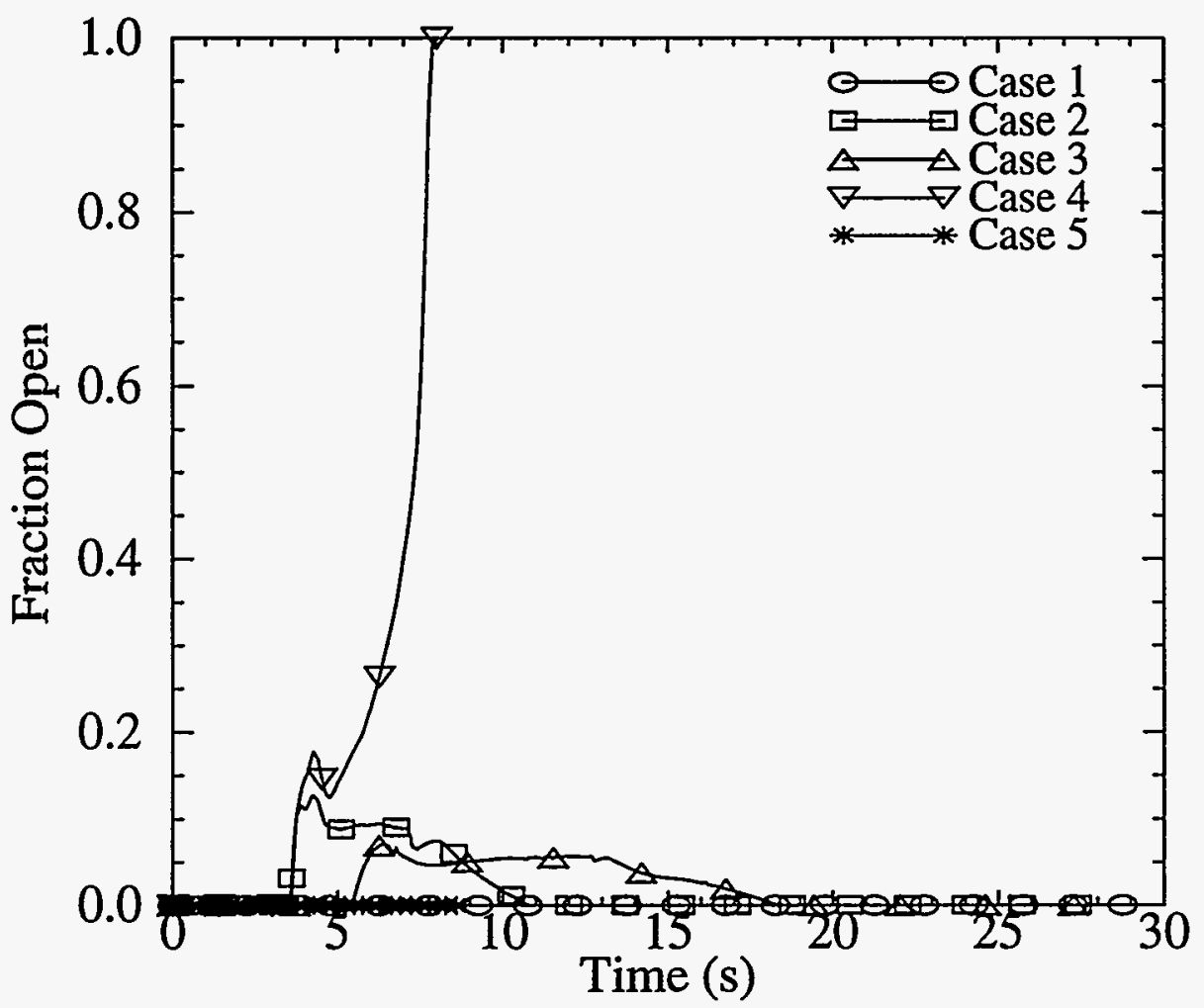

Figure 58. VRV open position for all cases.

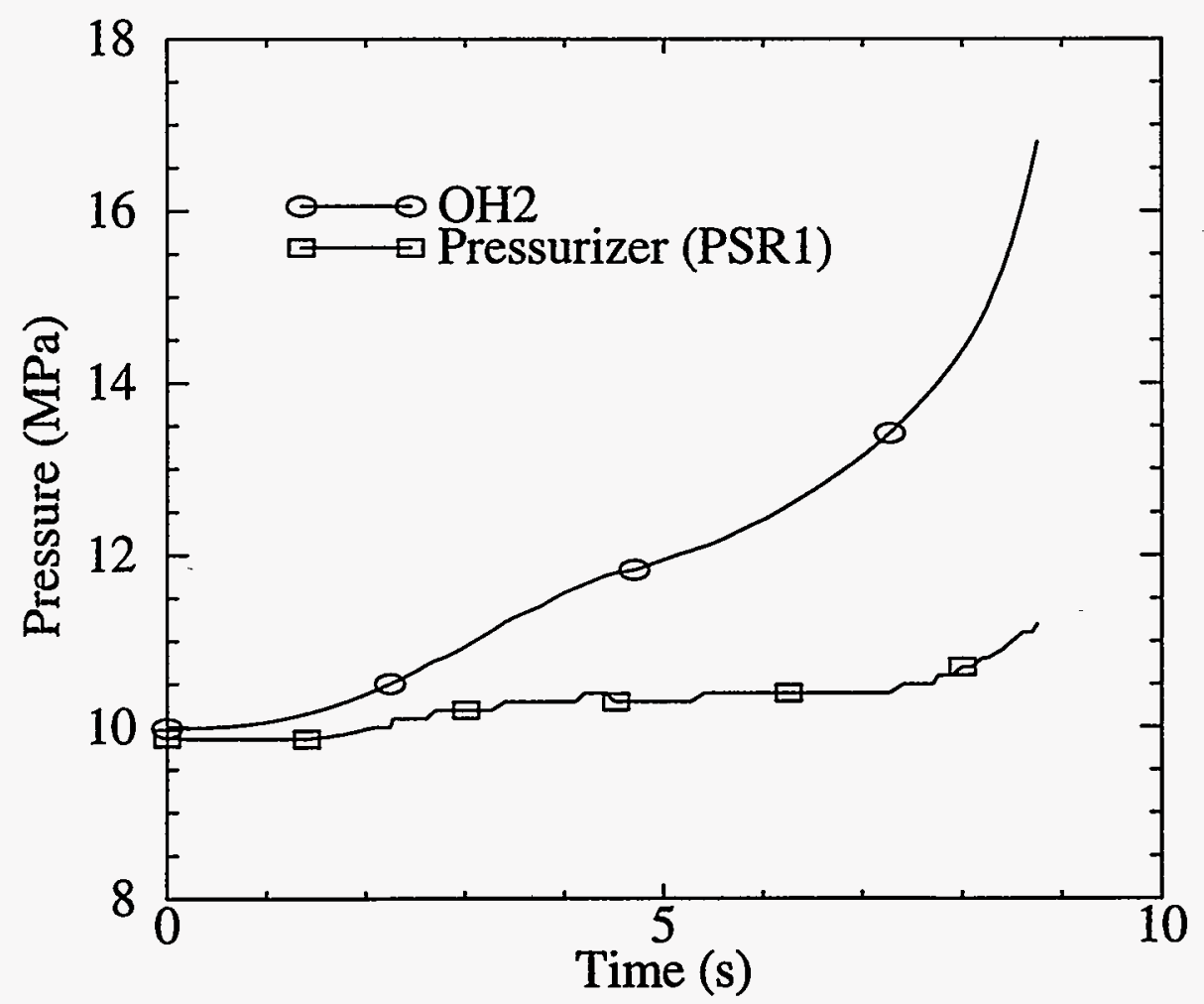

Figure 59. $\mathrm{OH} 2$ and pressurizer pressure for case 4. 
60.

The pressure difference forcing flow from $\mathrm{OH} 2$ to the pressurizer for Case 3 is shown in Figure

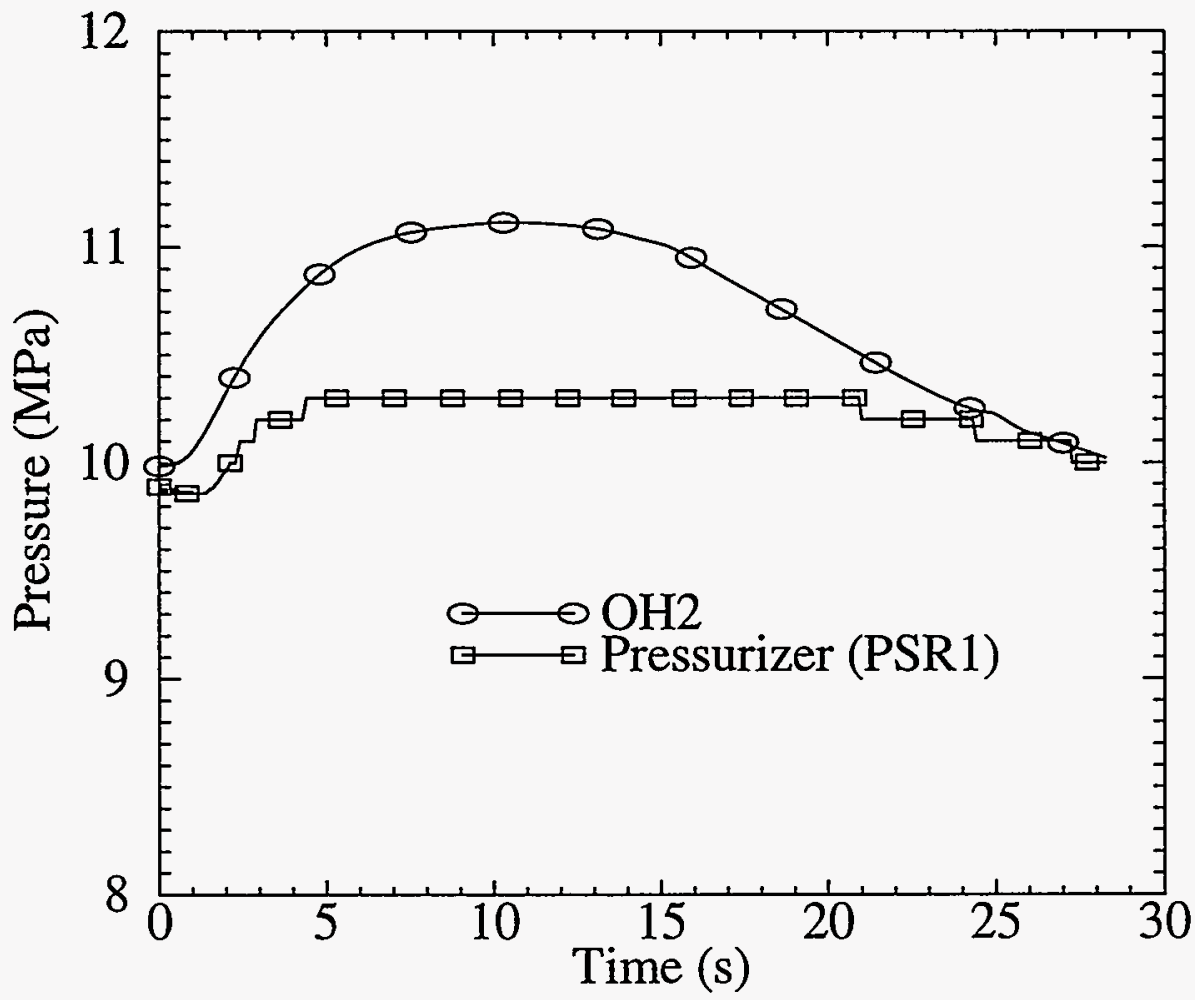

Figure 60. Case $3 \mathrm{OH} 2$ and pressurizer pressure.

Since the valve area and discharge coefficients are not known at this time and the operation of the relief valve was not modelled exactly, a valve modeling sensitivity study should be done when the exact valve area, discharge coefficients, and operational parameters (i.e. valve time constants and pressure setpoints) are available.

\subsubsection{Secondary Side}

The CATHENA secondary side model was not changed from the original LOCA model except that the feedwater flow was ramped to zero in two seconds. The turbine trip signal is a low secondary pressure. Upon failure to enter 'island mode', when a loss-of-off-site-power transient occurs, the secondary may not behave just as modelled here but the time span of the calculation is short enough that secondary changes would not be noticed in the primary side. As will be shown the steam generator (boiler) liquid inventory did not substantially change during these cases.

The steady state feedwater flow rate was $358 \mathrm{~kg} / \mathrm{s}$ to each boiler. Figure 61 shows the flow ramping to zero in two seconds. The primary flow reduction caused by the pump trip reduces the rate at which steam is being produced in the boilers. The resulting boiler pressure reduction is shown in Figure 62. 


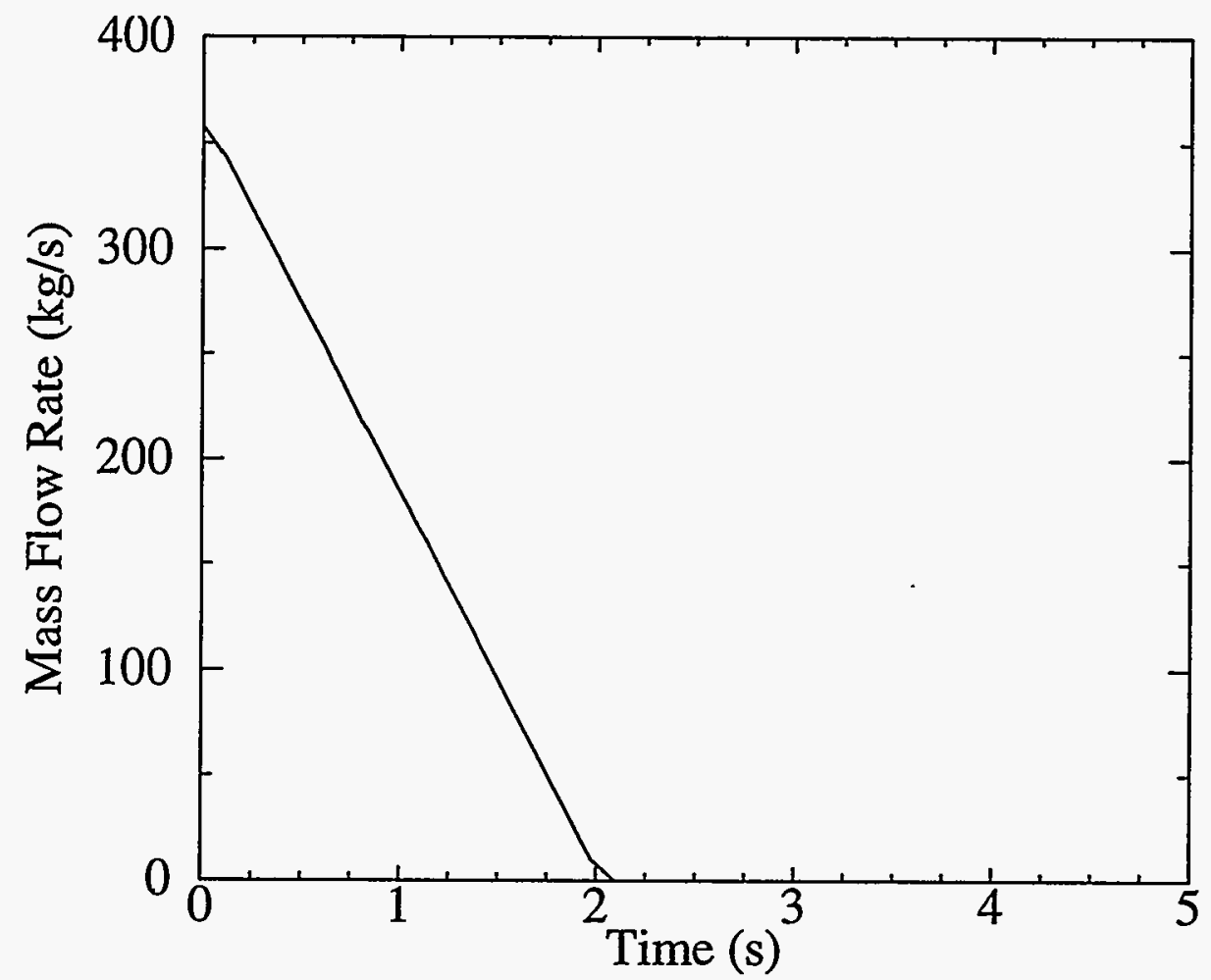

Figure 61. Feedwater flow rate.

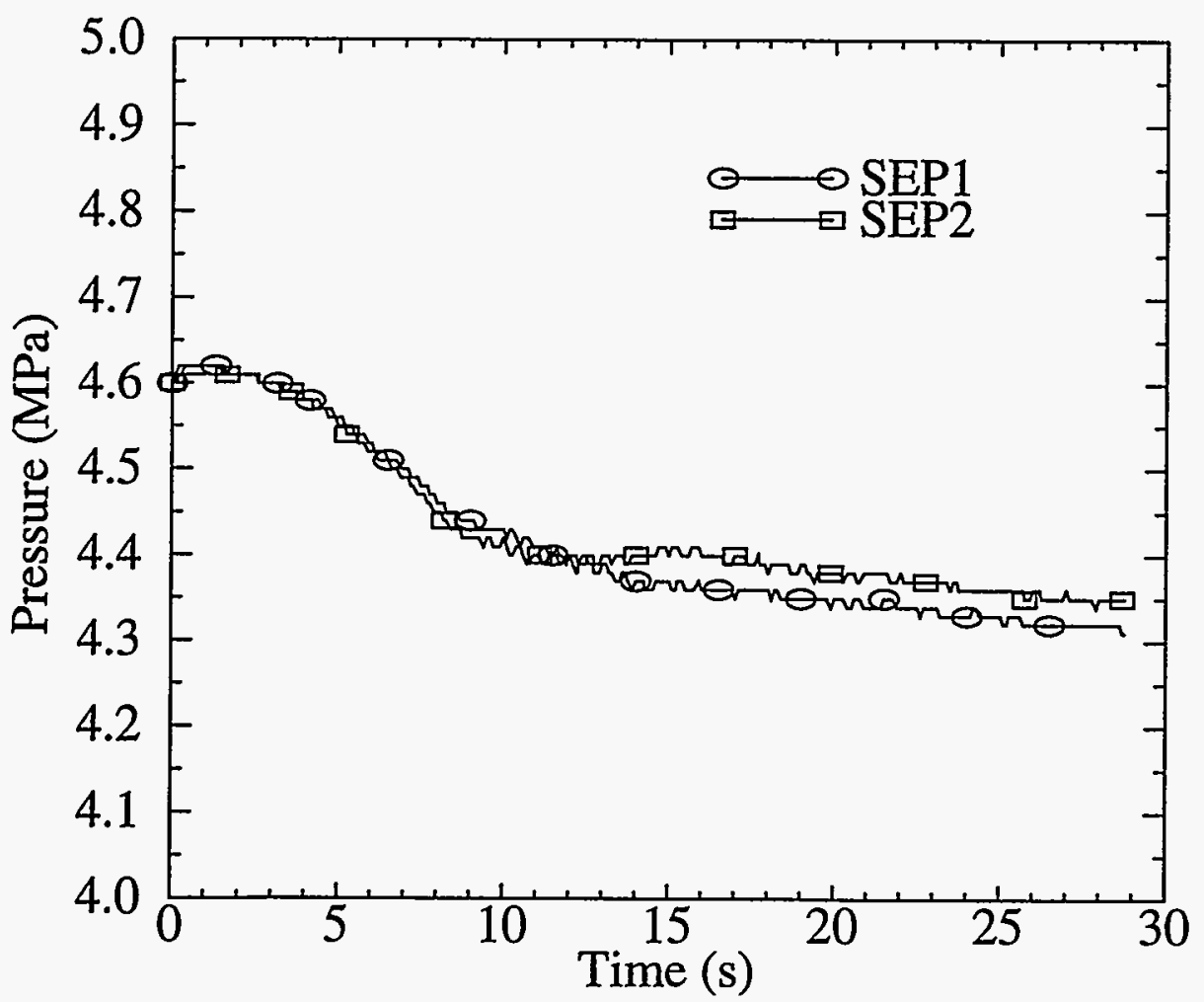

Figure 62. Boiler pressure. 
The reduction in the feedwater flow causes a reduction in boiler liquid inventory but the rate of energy delivery from the primary is also decreasing because the primary flow is coasting down. The total liquid inventory decreases about $10 \%$ during the 28 second transient (see Figure 63).

The initial value of flow to the turbines is equal to the feedwater flow rate $(358 \mathrm{~kg} / \mathrm{s})$. When the boiler pressure falls below $95 \%$ of $4.7 \mathrm{MPa}$ a control variable begins to ramp the flow down. It reaches zero flow below a boiler pressure of $90 \%$ of $4.7 \mathrm{MPa}$. Figure 64 shows the turbine flow for Case 1 . The turbine flow for the other cases is similar to Case 1.

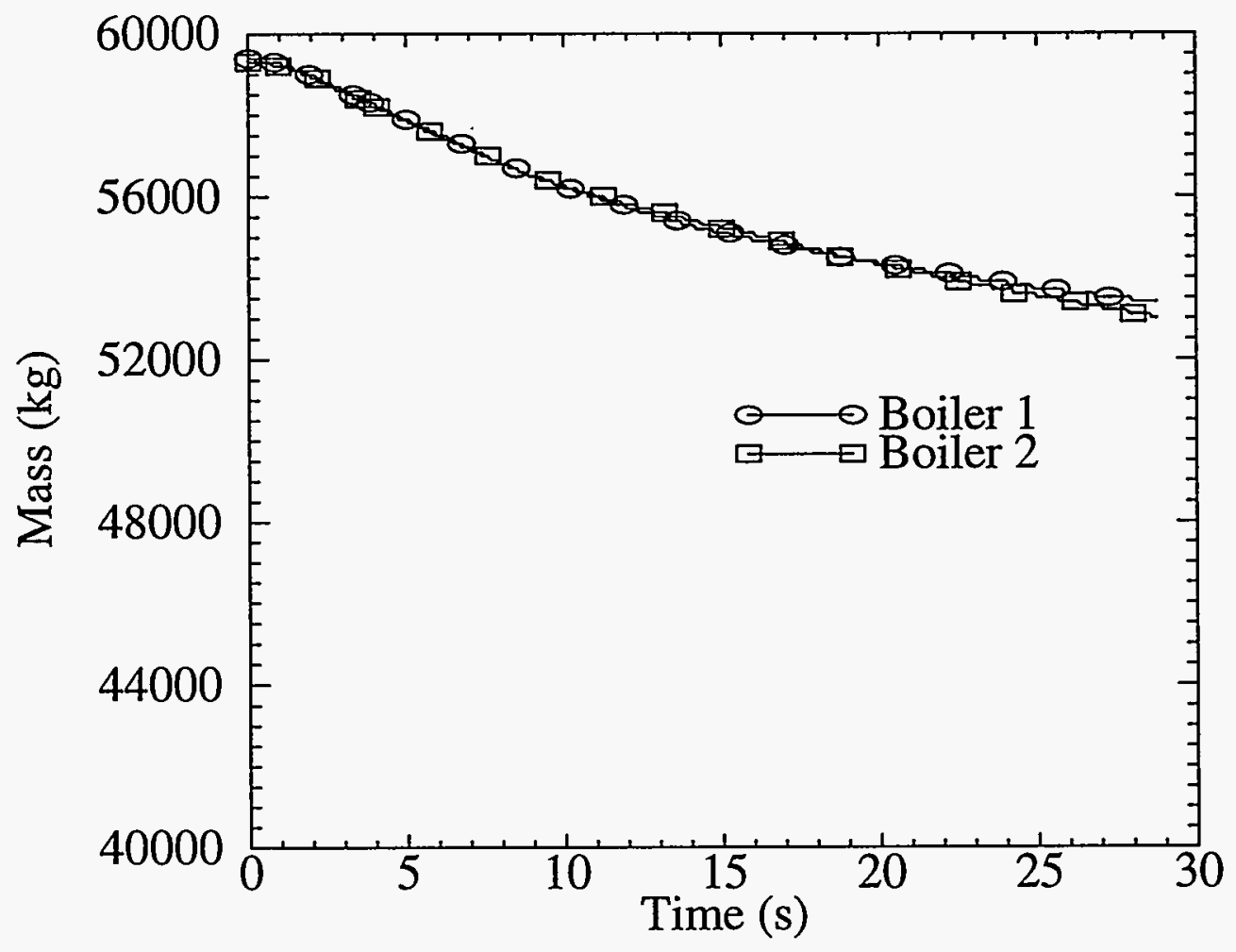

Figure 63. Boiler inventory case 1 . 


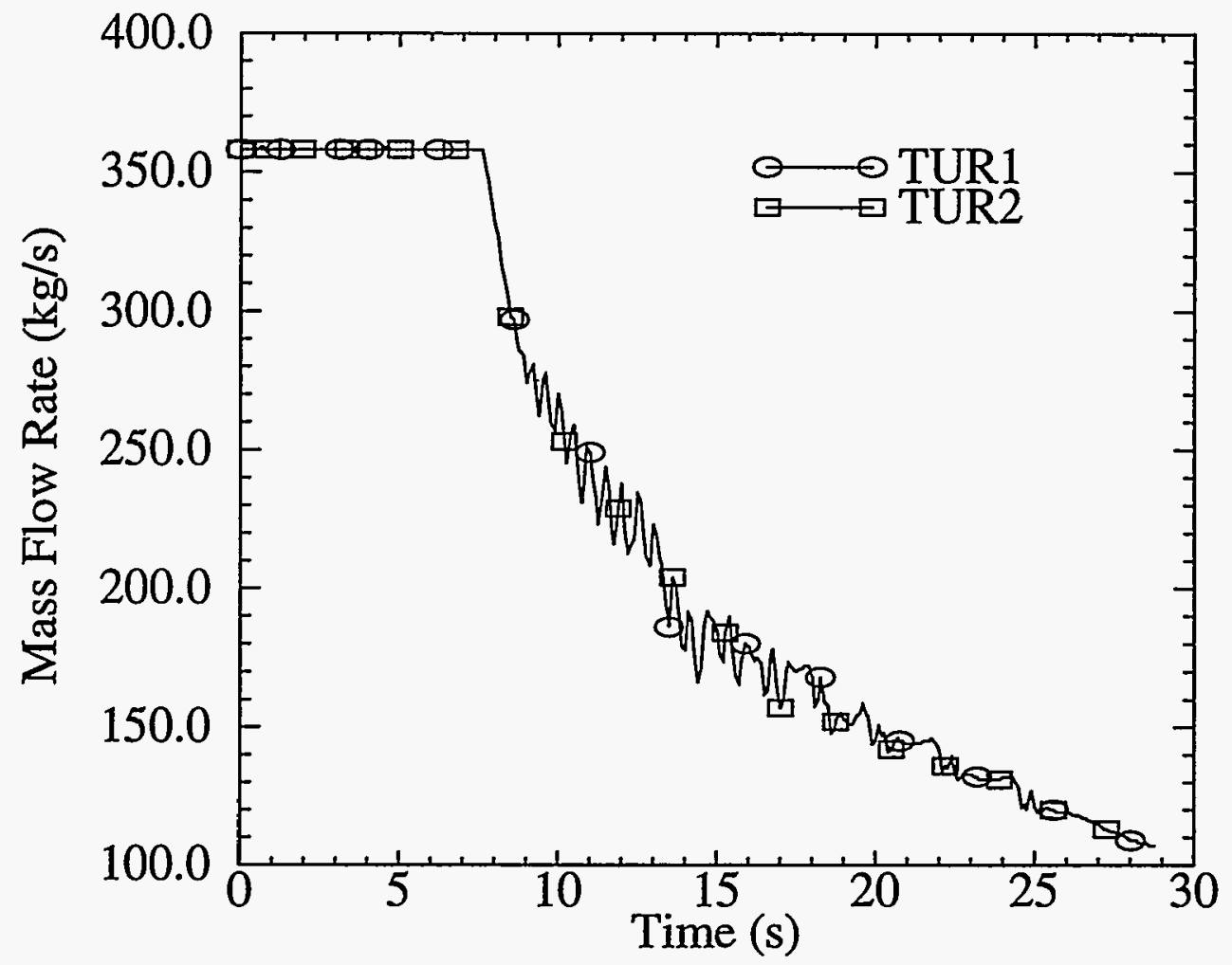

Figure 64. Flow to turbines for case 1. 


\subsection{Baseline Calculations}

To ensure that the CATHENA code had been installed correctly on the INEL and NRC computers, and that it was running properly, two baseline calculations were performed that could be compared with similar calculations performed by AECL. One large-break LOCA (LBLOCA) and one small-break LOCA (SBLOCA) were selected for this purpose, and the comparative AECL calculations can be found in References 3 and 11. In addition, the availability of the complete results of the calculations provided much more information on the CANDU 3 transient response than was available in the references.

Both the LBLOCA and the SBLOCA were modeled to occur on an inlet header. The Emergency Core Cooling system described in Section 3.4 was modeled for these events. The 232 fuel channels were modeled as four equal fuel channels. Table 11 shows the equivalent fuel channel groupings for the basic 10 channel model shown in Figure 3 and the four channel CATHENA model used in this section. All other aspects of the four channel model are identical to the 10 channel model. Each of the four channels modeled two groups of fuel rods. The fuel rod group on the bottom of the channel has 19 rods and the top fuel rod group has 18 rods. The total power of $1421 \mathrm{MW}$ was divided evenly among the four channels. The large calandria moderator tank surrounding the fuel channels is not included in the model. The break location is, again, modeled in inlet header number 2.

Table 11. Relationship between the ten and four channel models.

\begin{tabular}{|c|c|}
\hline Channel Number in Four Channel Model & Channel Number in Ten Channel Model \\
\hline 1 & 9 \\
\hline 2 & $1,3,5,7$ \\
\hline 3 & 10 \\
\hline 4 & $2,4,6,8$ \\
\hline
\end{tabular}

Calculations presented below involve only the CATHENA code. Since rapid shutdown of the reactor is assumed for these two LOCAs, stand-alone calculations could be done with CATHENA without coupling the code to the reactor kinetics models. To run the CATHENA calculation, a power history that had been developed earlier by AECL and accounted for decay heat was specified in the CATHENA input file.

When the outlet header pressure falls to $6 \mathrm{MPa}$ a LOCA signal trip occurs which results in turbine unloading, steam dump valves opening and activation of the ECC system. Turbine unloading is modeled by ramping up the flow resistance in the steam line. The MSSV opening lowers the saturation temperature of the secondary side of the two steam generators and causes more rapid cooling of the primary fluid. The MSSV opening time is 30 seconds. Low primary pressure causes rupture discs to break in the ECC lines. The discs are modeled between cells 2 and 3 in both the inlet and outlet header ECC lines. When the pressure in cell 3 is $0.35 \mathrm{MPa}$ less than the pressure in cell 2 the rupture discs fail.

\subsection{1 $100 \%$ Inlet Header Break with Scram and ECCS}

The power history used for this LBLOCA calculation is essentially the same as that presented in Section 4.1.1 for the base case.

The flow rate out of the break peaks at over $7000 \mathrm{~kg} / \mathrm{s}$ at 0.6 seconds although this is not shown clearly in Figure 65. Break flow reaches a minimum at about 100 seconds and then rises again as the primary loop fills with emergency core coolant. 
Pressure at outlet and inlet header number 2 are given in Figure 66. Initially there is about a 1.3 $\mathrm{MPa}$ pressure difference between the inlet and the outlet headers. The outlet header pressure falls to 6 $\mathrm{MPa}$ at about 11 seconds causing the LOCA signal to be sent to the MSSVs and the ECC system.

The void fraction for all six headers in given in Figure 67. CATHENA modelled the headers with a homogenous flow regime. Since the void fraction is above $50 \%$ for relatively long periods of time, the core temperatures would be higher than shown in these results if stratified conditions existed. Some of the fuel channels would be fed steam instead of the average header mixture.

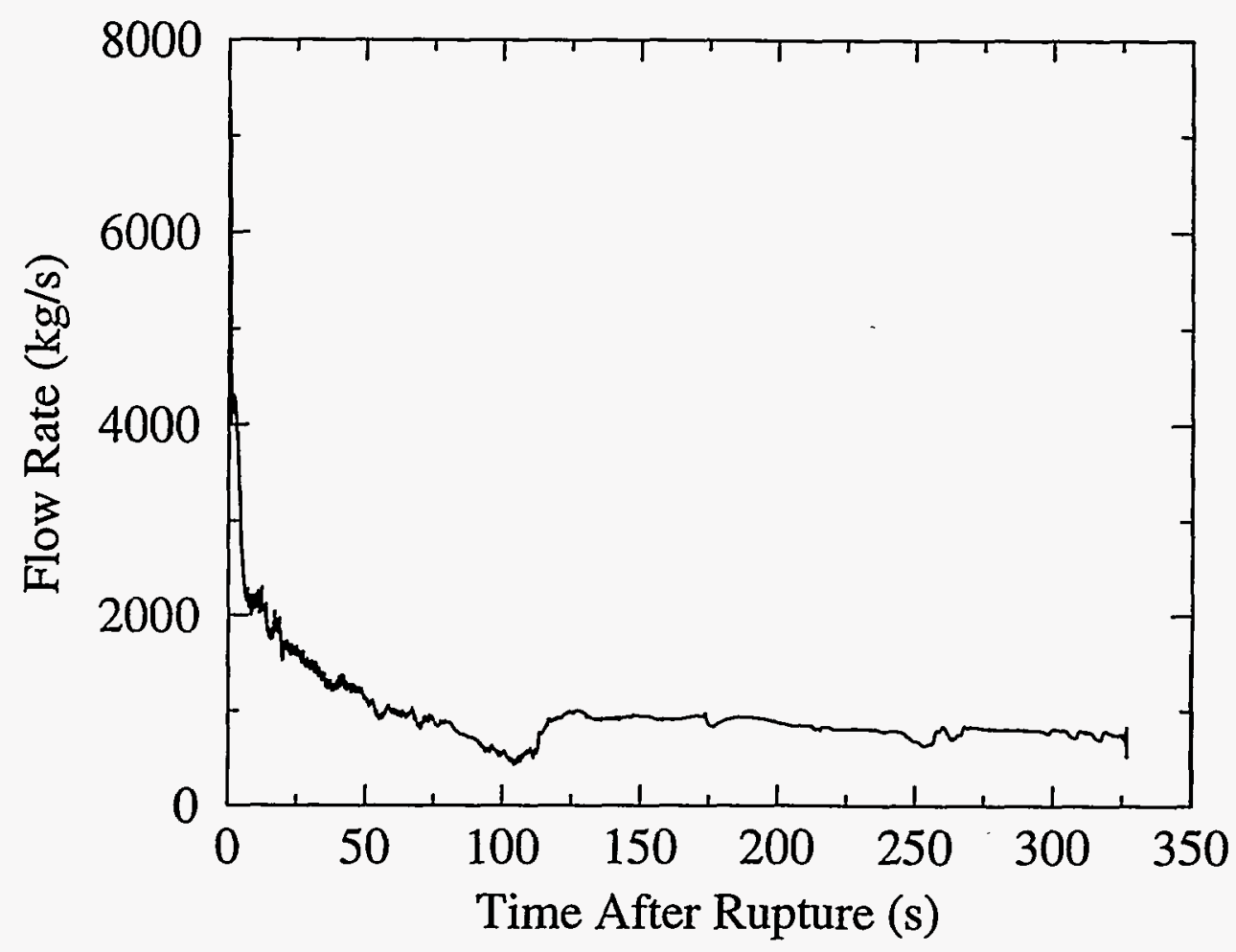

Figure 65. LBLOCA break flow rate. 


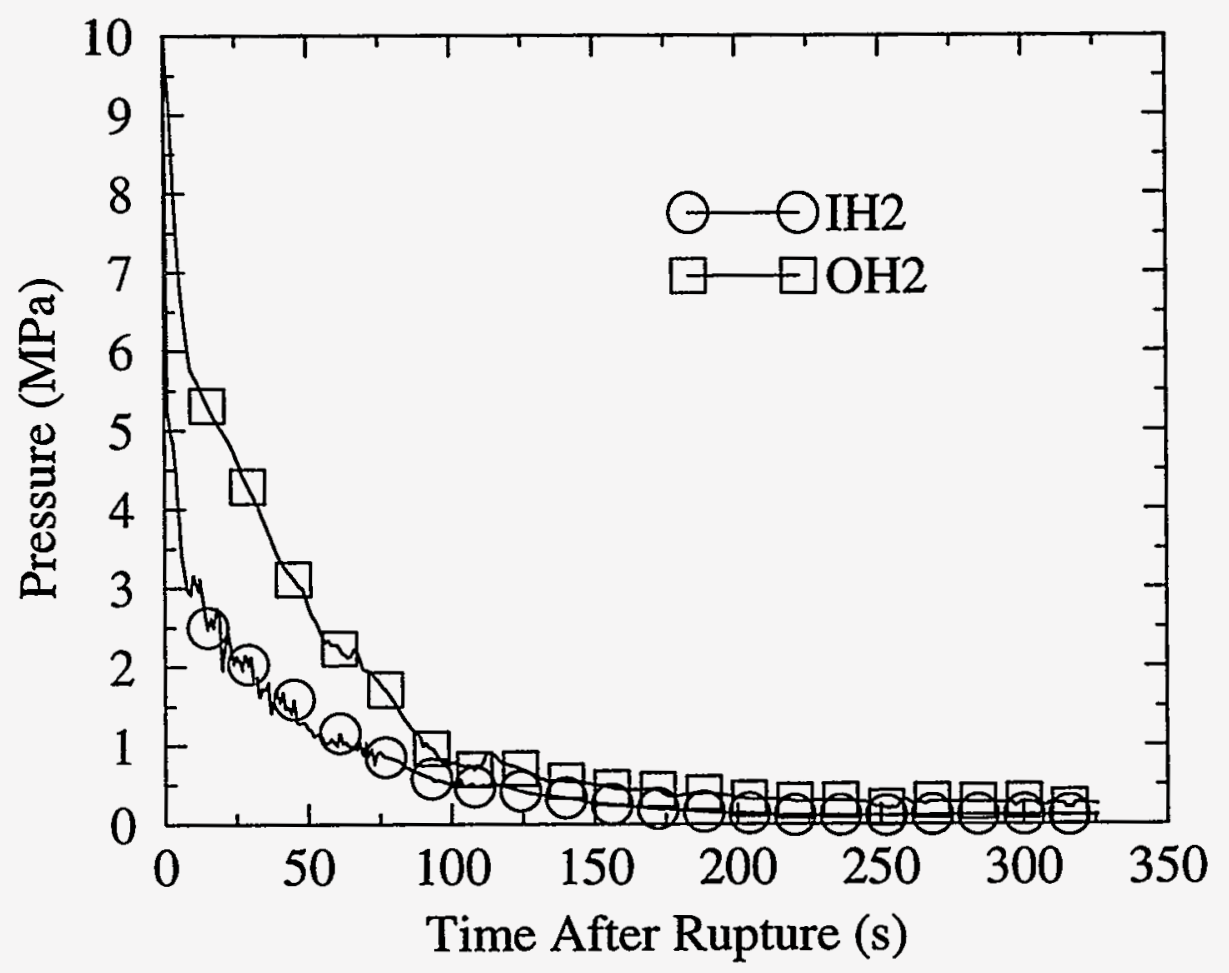

Figure 66. LBLOCA pressure in inlet and outlet header 2 .

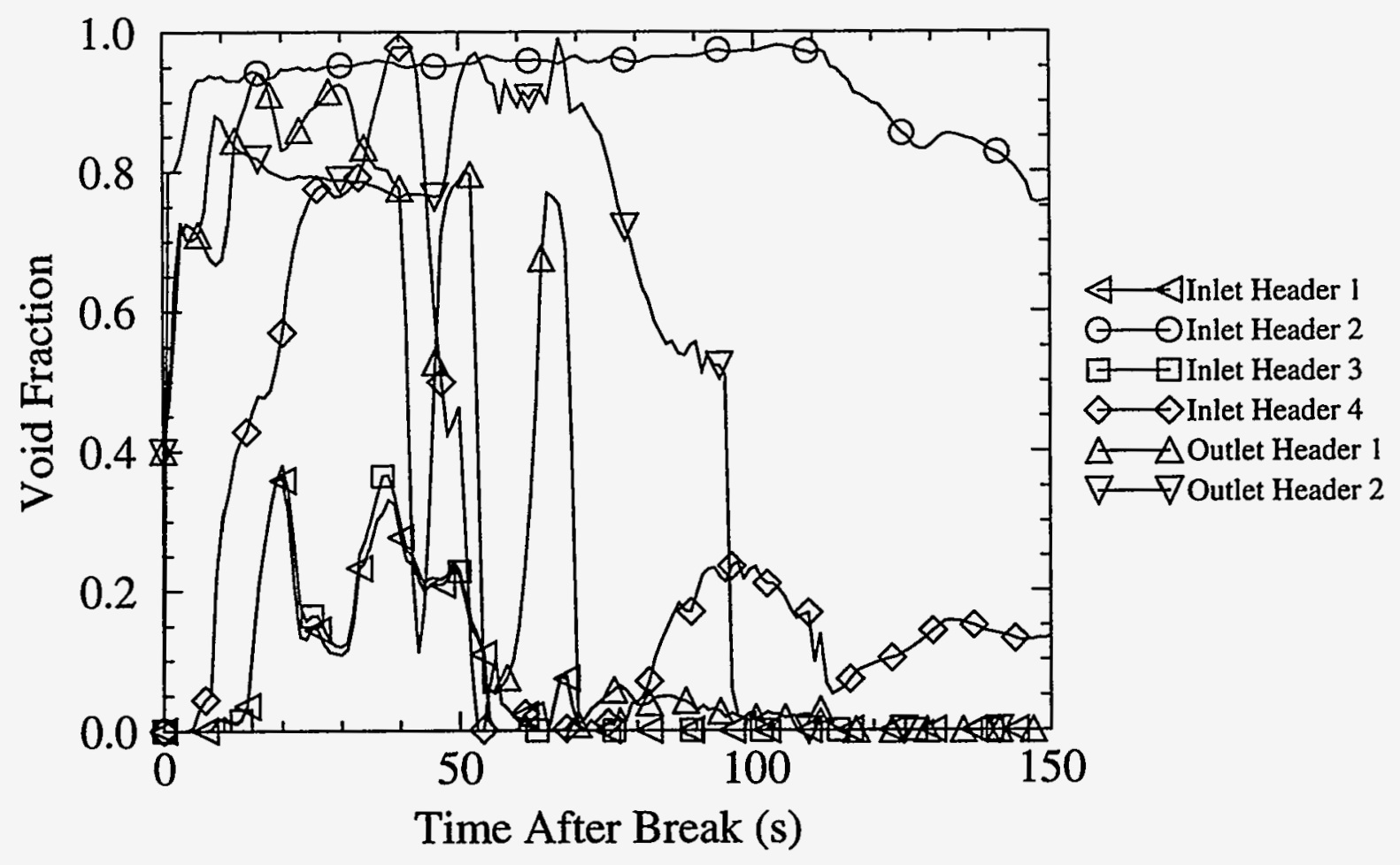

Figure 67. LBLOCA void in inlet and outlet headers. 
Coolant flow reversed through the fuel channel 2 immediately following the break. The reverse flow was large enough to keep the fuel from heating up. Forward flow was also large enough in channel 1 and 3 to keep the fuel in nucleate boiling. However, the flow in channel 4 almost stagnated at about 20 seconds for about 50 seconds and a heatup occurred; see Figure 68. The temperatures are plotted in Figure 69. Only channel 4 has a departure from nucleate boiling to film boiling for about 50 seconds. Figure 70 shows the channel void fraction behavior. Channel 4 has the highest void fraction, but all the voids have collapsed by 120 seconds into the transient.

The pressurizer has a considerable water inventory which backflows to outlet header 2 immediately following rupture. The discharge of pressurizer water probably is a contributing factor to channel 4 flow stagnation. The volume in the pressurizer is about 20 times more than the volume in an outlet header. Figure 71 shows the flow rates. The accumulator flow began at 14 seconds and terminated at 322 seconds. The valve from the low pressure ECC line opened at 261 seconds and this system was delivering $585 \mathrm{~kg} / \mathrm{s}$ at the time of problem termination.

The main steam safety valves begin to open when the LOCA signal is received at about 11 seconds. Figure 72 shows the mass flow rate exiting both steam lines. The peak mass flow rate is about $150 \mathrm{~kg} / \mathrm{s}$.

All of the above results are in good agreement with AECL calculations of the same transient as reported in References 3 and 11.

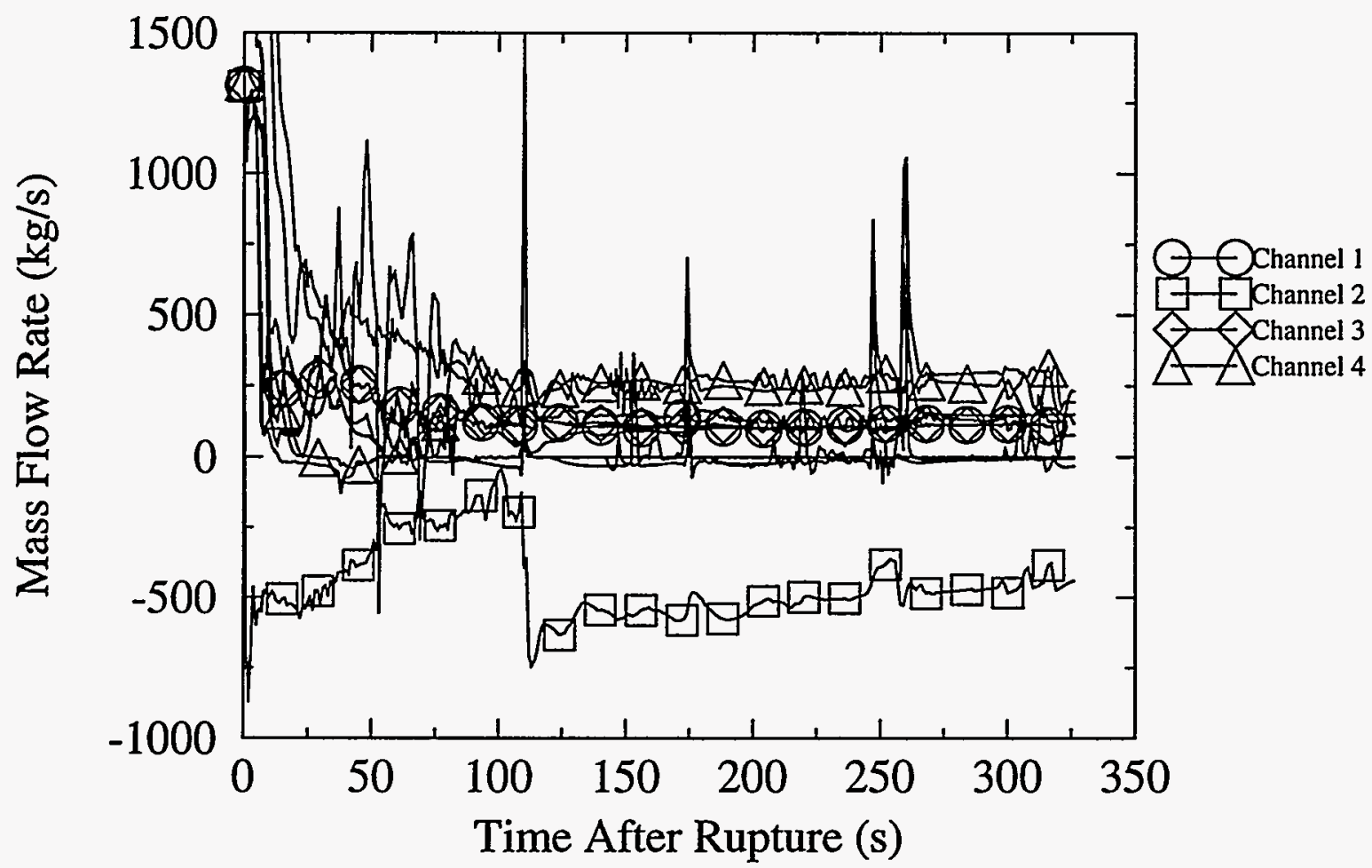

Figure 68. LBLOCA channel flow rates. 


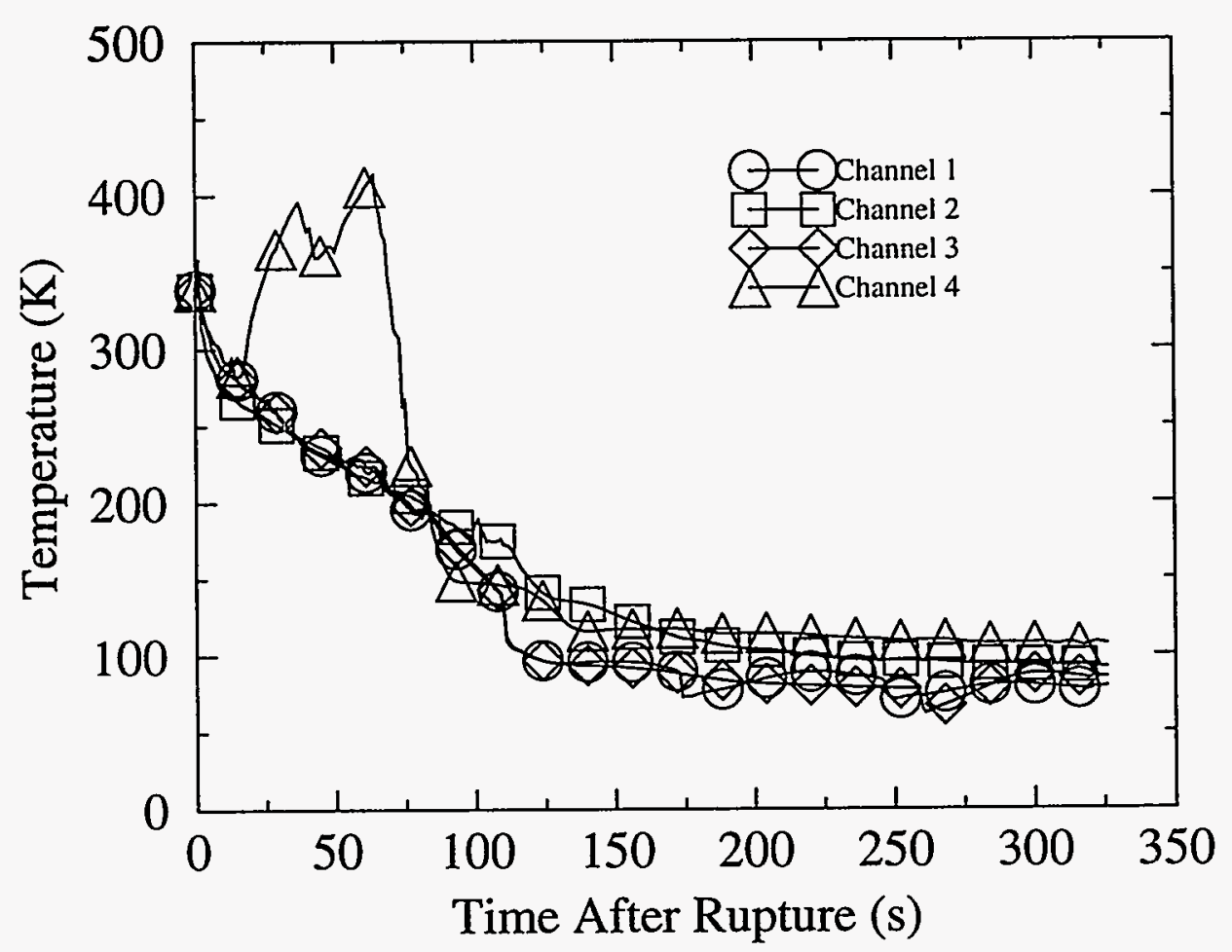

Figure 69. LBLOCA maximum cladding temperatures.

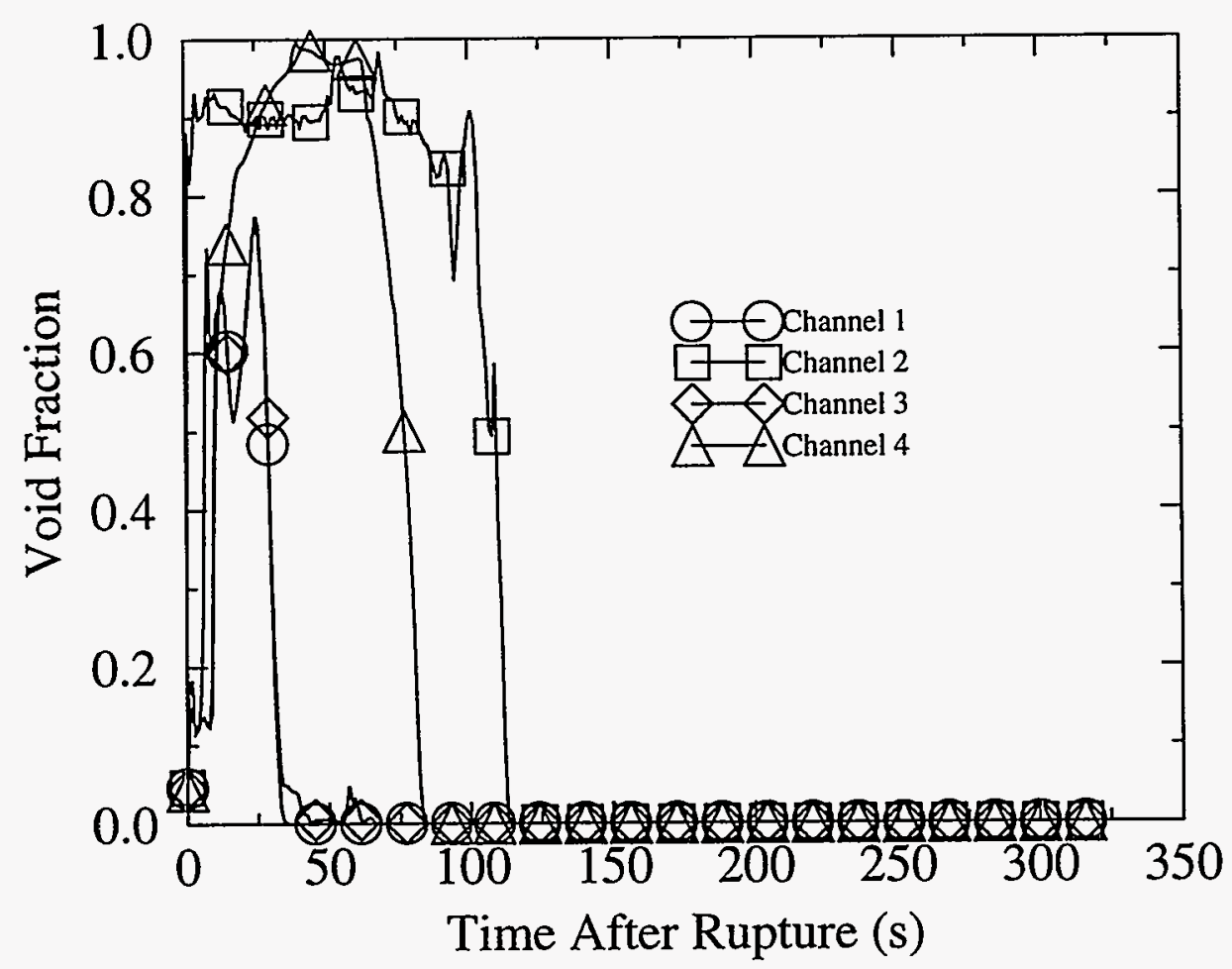

Figure 70. LBLOCA channel average void fractions. 


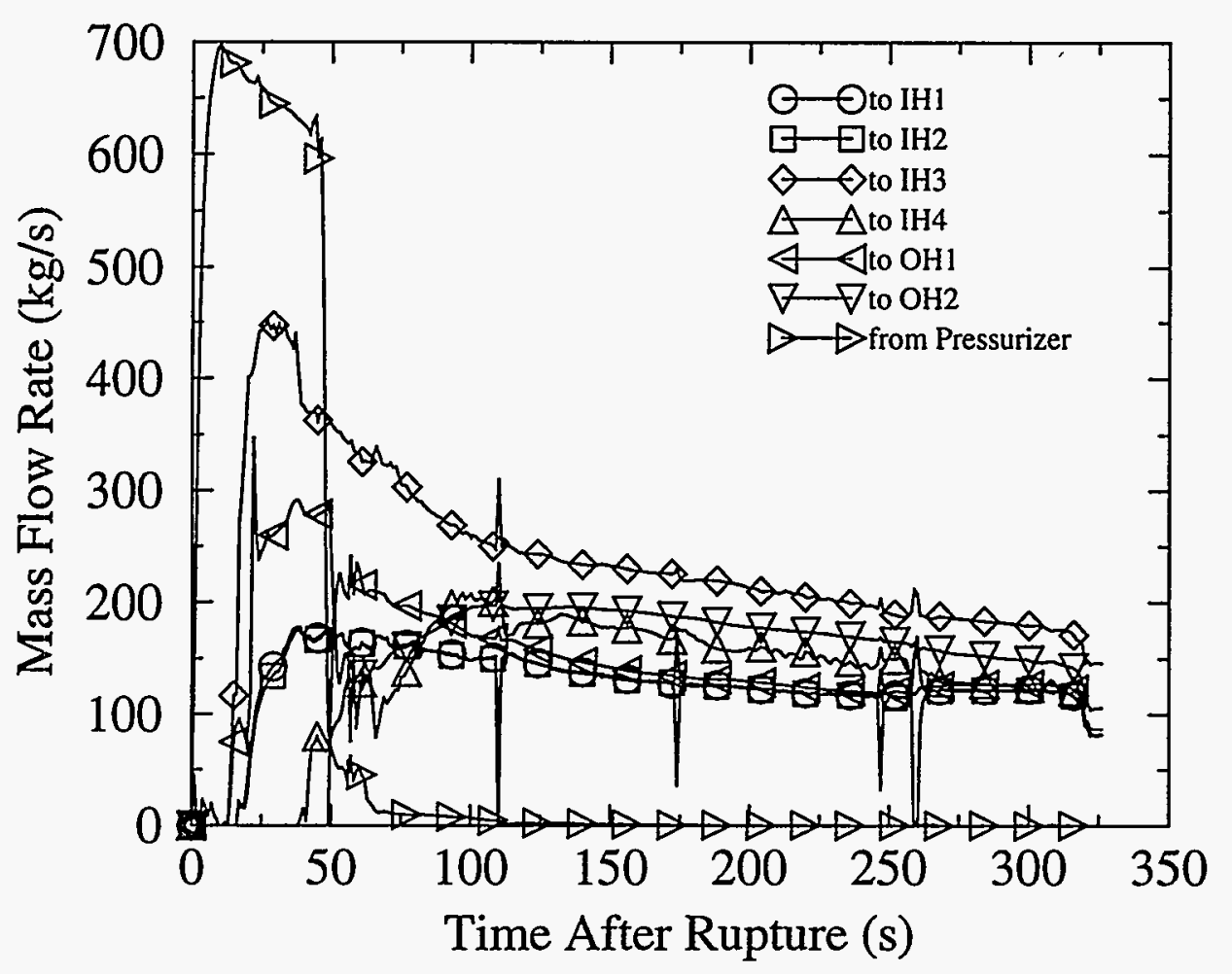

Figure 71. LBLOCA pressurizer and ECC flow to headers.

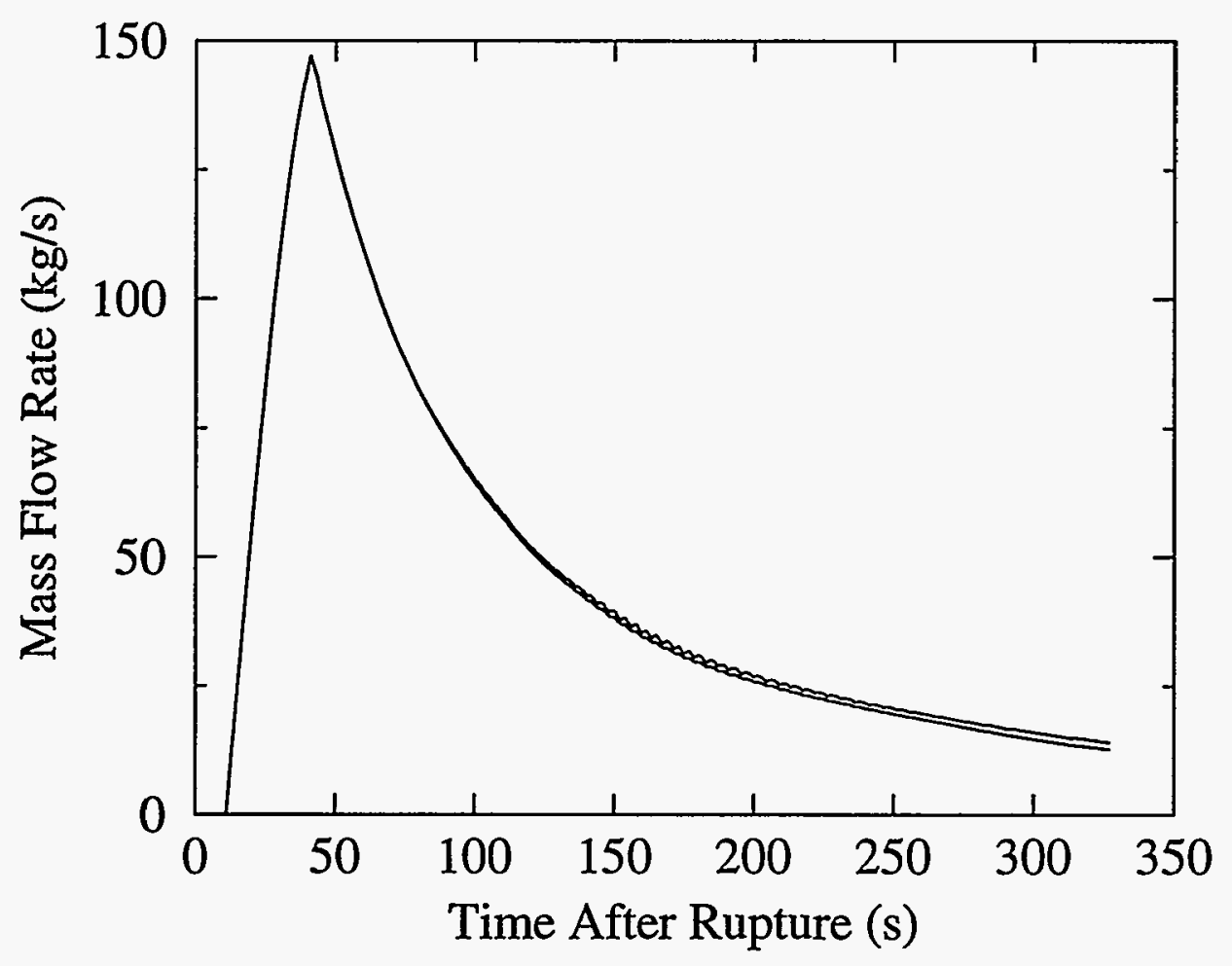

Figure 72. LBLOCA MSSV flow rate. 


\subsection{2 $0.76 \%$ Inlet Header Break with Scram and ECCS}

The SBLOCA was assumed to result in a loss of class IV power (LCIVP). The input file used for this calculation appears to be the same as the one used for the $100 \%$ calculation except for the break size, the power history and loss of class IV power logic.

For a small break LOCA (SBLOCA) trip events are spread out over long periods of time. Table 12 shows the trips and the trip times. A reactor trip signal was received at about 177 seconds and power decay began. The specified power curve does not have an initial rise because rapid core voiding does not occur.

Table 12. Small break trip information.

\begin{tabular}{|l|l|l|l|l|}
\hline Trip Identifier & \multicolumn{1}{|c|}{ Variable Monitored } & \multicolumn{1}{|c|}{ Criteria } & \multicolumn{1}{|c|}{$\begin{array}{c}\text { Time } \\
\text { Delay } \\
(\mathrm{s})\end{array}$} & \multicolumn{1}{|c|}{$\begin{array}{c}\text { Time Reached } \\
\text { Including Delay } \\
(\mathrm{s})\end{array}$} \\
\hline LOWP & Outlet Header Pressure & $<9.3 \mathrm{MPa}$ & 0.17 & 125.7 \\
\hline PSRLVL & Pressurizer Level & $<8.99$ feet & 0.17 & 176.8 \\
\hline RTRIP & LOWP and PSRLVL & $\begin{array}{l}\text { Both are } \\
\text { TRUE }\end{array}$ & 0 & 176.9 \\
\hline MAINPMPS & Steam Generator Pressure & $<4.46 \mathrm{MPa}$ & 0 & 187.8 \\
\hline LOCASIG & $\begin{array}{l}\text { Sustained Low Pressure in } \\
\text { Outlet Header 2 }\end{array}$ & $<5.4 \mathrm{MPa}$ & $240 .(4$ \\
\hline RUPI & $\begin{array}{l}\text { Inlet Header ECC Line Rup- } \\
\text { ture Disc Differential Pressure }\end{array}$ & $>0.35 \mathrm{MPa}$ & 0 & 484.3 \\
\hline RUP0 & $\begin{array}{l}\text { Outlet Header ECC Line Rup- } \\
\text { ture Disc Differential Pressure }\end{array}$ & $>0.35 \mathrm{MPa}$ & 0 & 488.3 \\
\hline
\end{tabular}

Break flow rate greatly decreases when the inlet header void fraction rises above 10 percent at about 450 seconds. Transition from single phase to two-phase flow began to occur at about 350 seconds. Following ECC injection initiation at about 500 seconds the inlet header pressure and void fraction oscillate causing the break flow rate to oscillate; see Figure 73.

Primary loop fluid losses cause the pressurizer level to fall. Upon reaching a combination of a pressurizer liquid elevation below $2.74 \mathrm{~m}$ (8.99 feet) and outlet header pressure below $9.3 \mathrm{MPa}$, a reactor trip set point is reached which results in control rod scram, turbine unloading, loss of class IV power, primary loop pump coastdown and MSSV opening. Figure 74 shows that the pressurizer drains and then partially refills following ECC injection.

Figure 75 shows a steady drop in the primary loop pressure and a sudden drop after reactor trip. Main pumps tripped at 187.7 seconds and stopped at about 530 seconds. When the pump head was lost the inlet and outlet header pressures became similar as shown in Figure 75. After the ECC came on there was a dip in the pressure caused by condensation.

Outlet headers have an initial void fraction of about $40 \%$. As the transient progress their void fraction increases until the pumps trip. The inlet header void fraction stays at about zero until just before ECC injection begins. Inlet header number 2 almost voids for a few seconds before it refills. The void fractions are shown in Figure 76. 


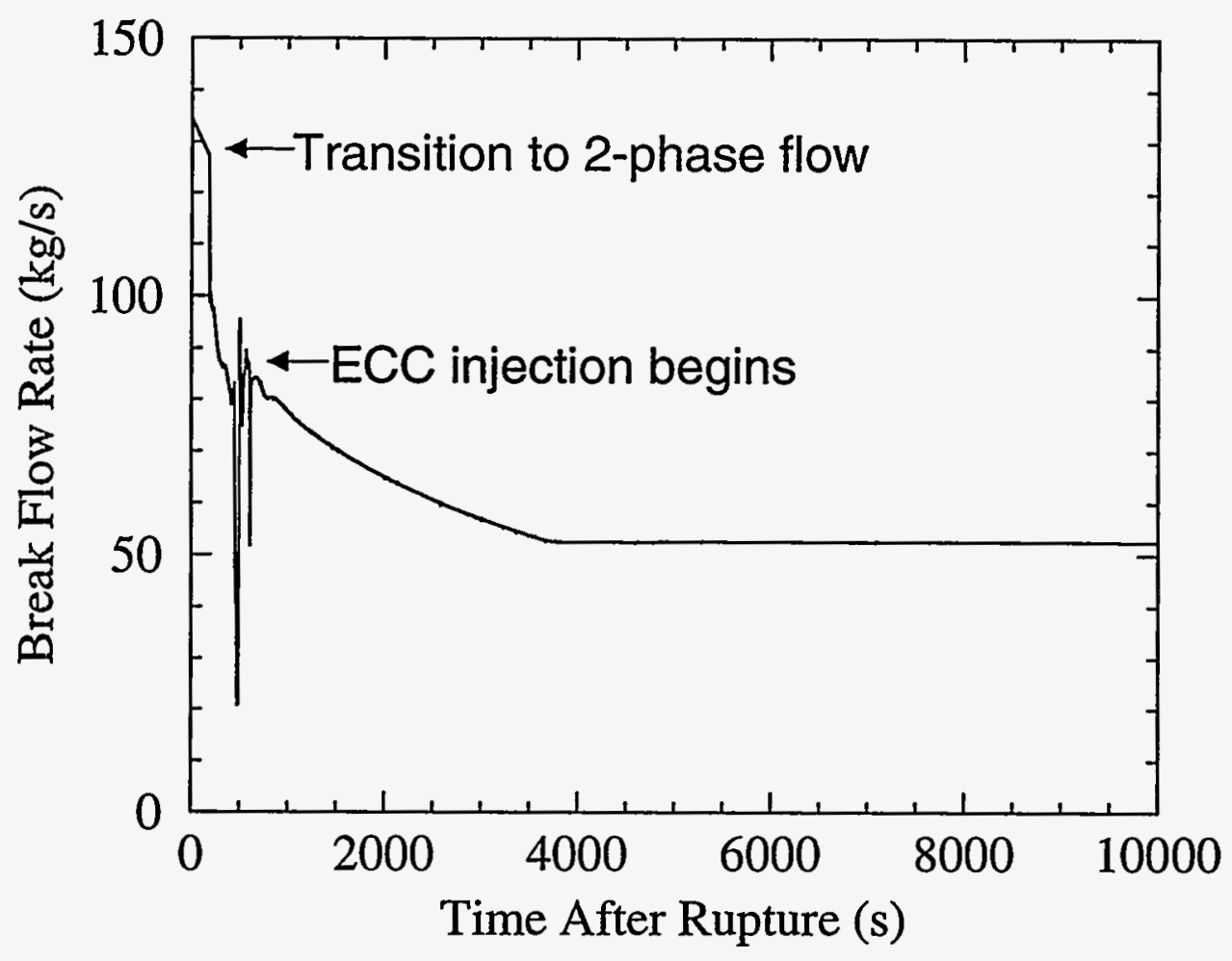

Figure 73. SBLOCA break flow.

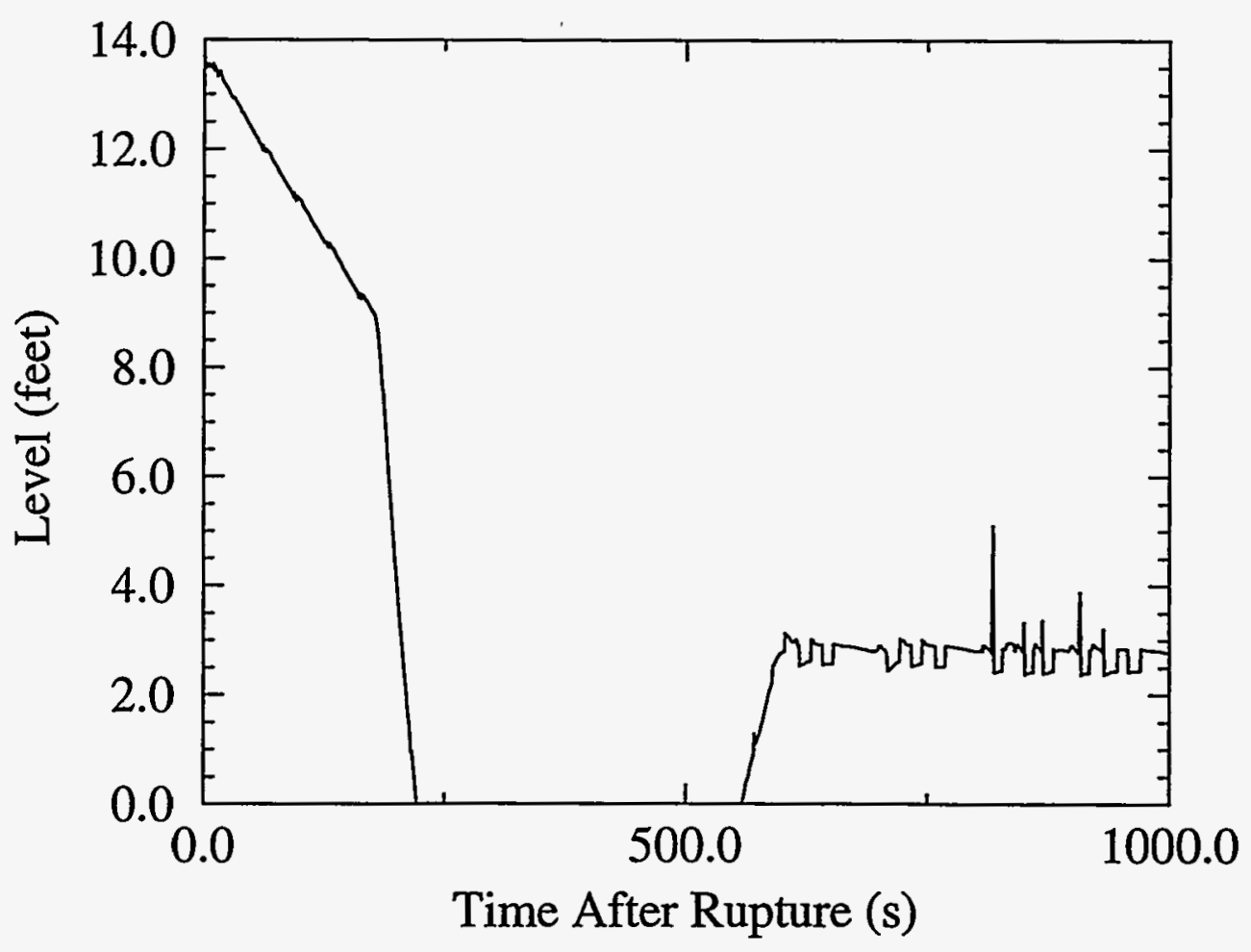

Figure 74. SBLOCA pressurizer level. 


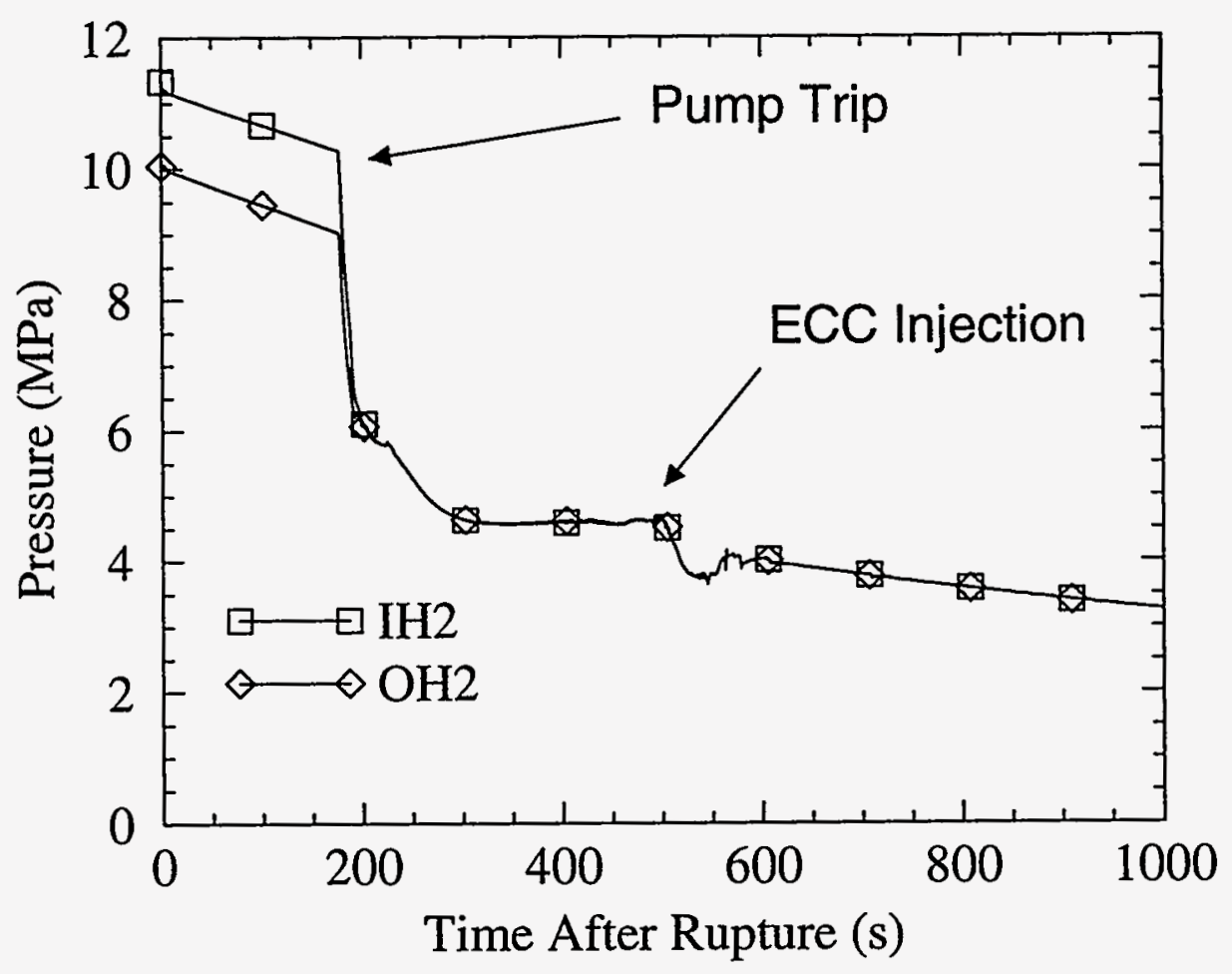

Figure 75. SBLOCA header pressures.

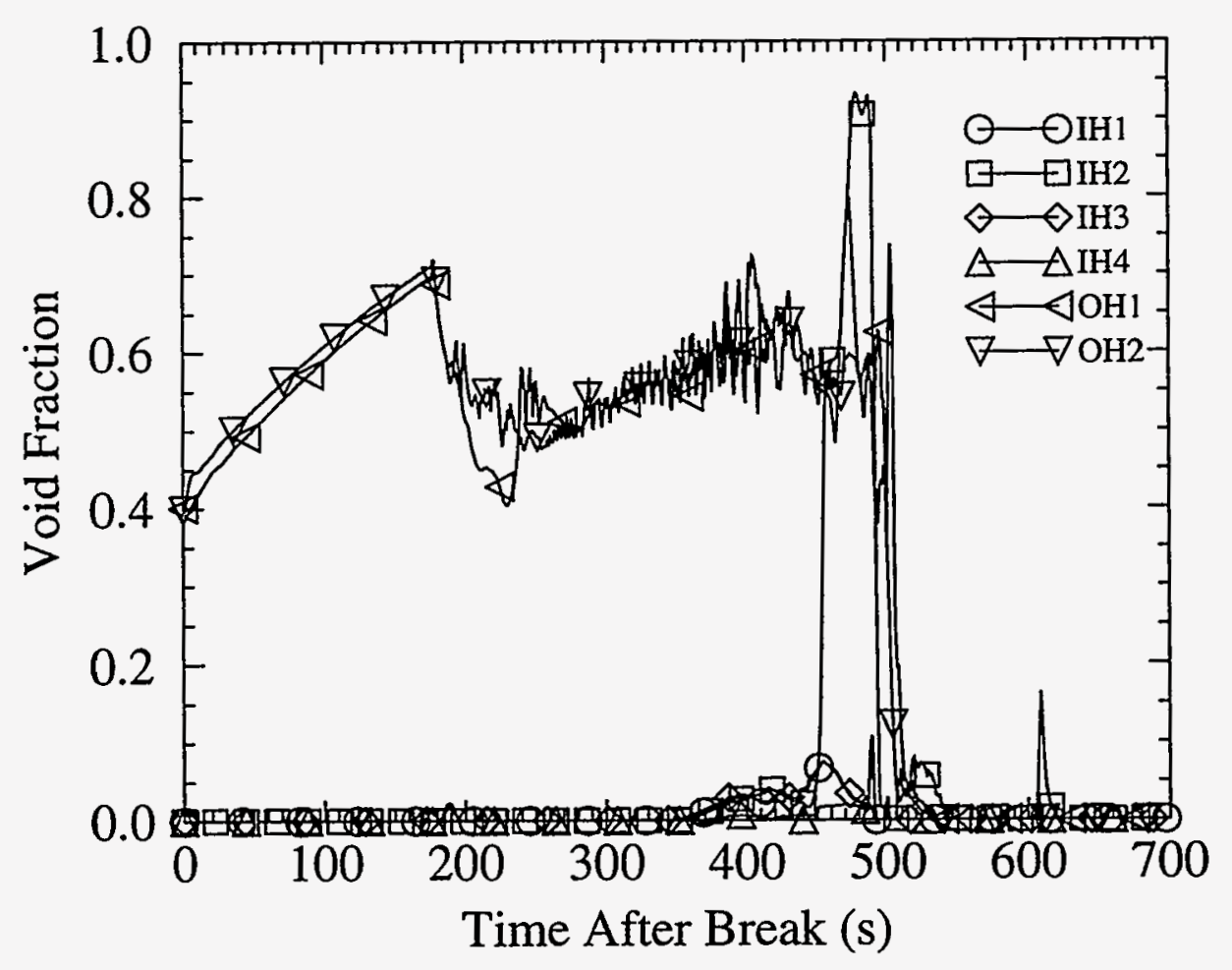

Figure 76. SBLOCA header void fraction. 
Flow through the fuel channels stays large and positive until the pumps trip. Thus the fuel temperatures follow the saturation temperature until the channel flow approaches zero. Figure 77 gives the flow rates and Figure 78 shows the cladding temperatures. The fuel temperatures only rose about 100 degrees before ECC water returned the fuel surfaces to nucleate boiling and forced convection to liquid. Channel 2 has the lowest flow rate and highest temperature because of the break in inlet header 2 . The flow rate in channel 2 is negative after about 500 seconds.

The pressurizer unloaded its inventory slowly as the primary pressure fell until the pumps tripped, then it emptied rapidly. An ECC trip signal was received at 486.4 when the trip logic detected the required pressure differential across the simulated rupture discs. Some backflow into the pressurizer occurred following ECC injection. The flow rates are shown in Figure 79.

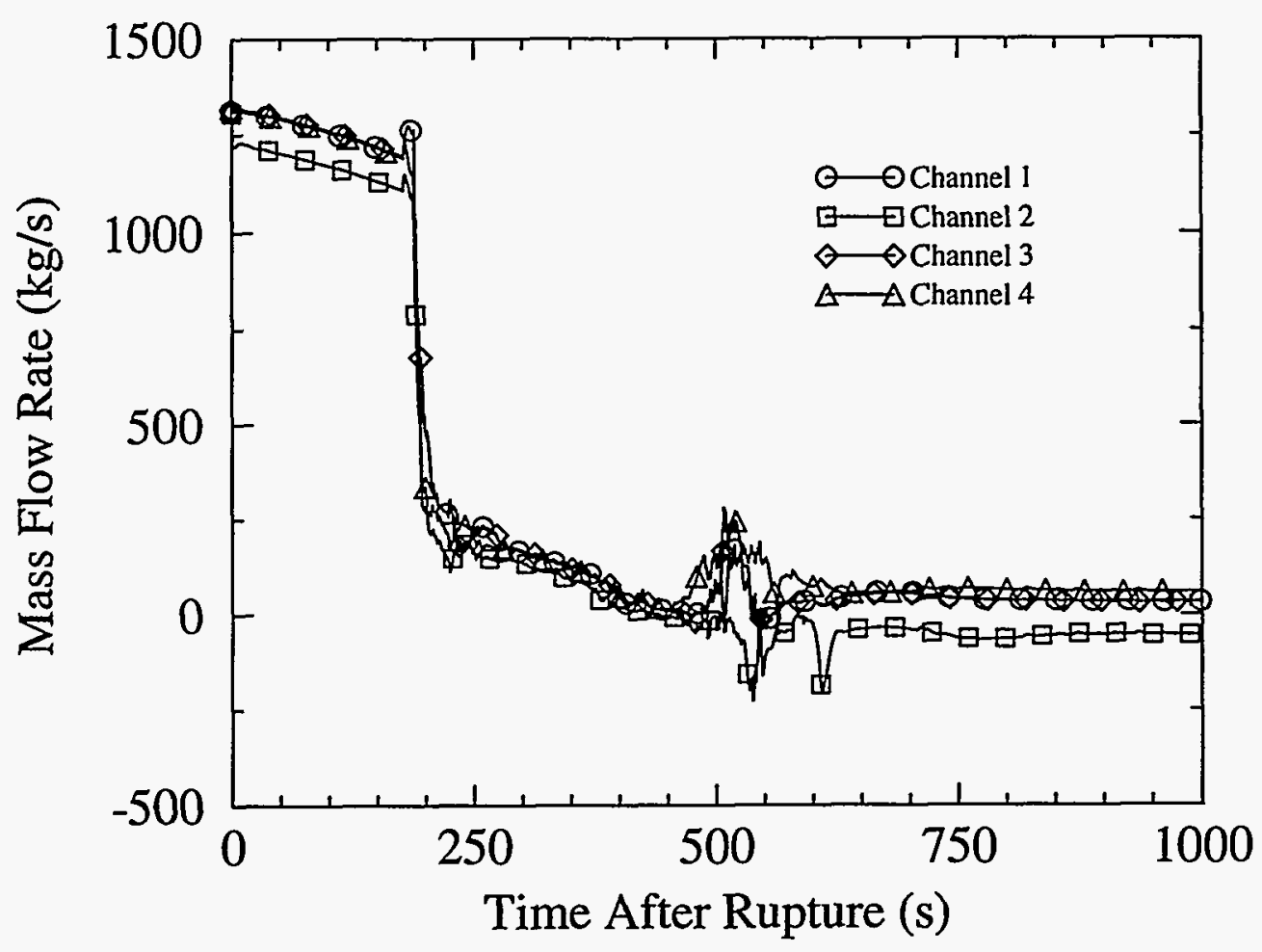

Figure 77. SBLOCA fuel channel flow rates. 


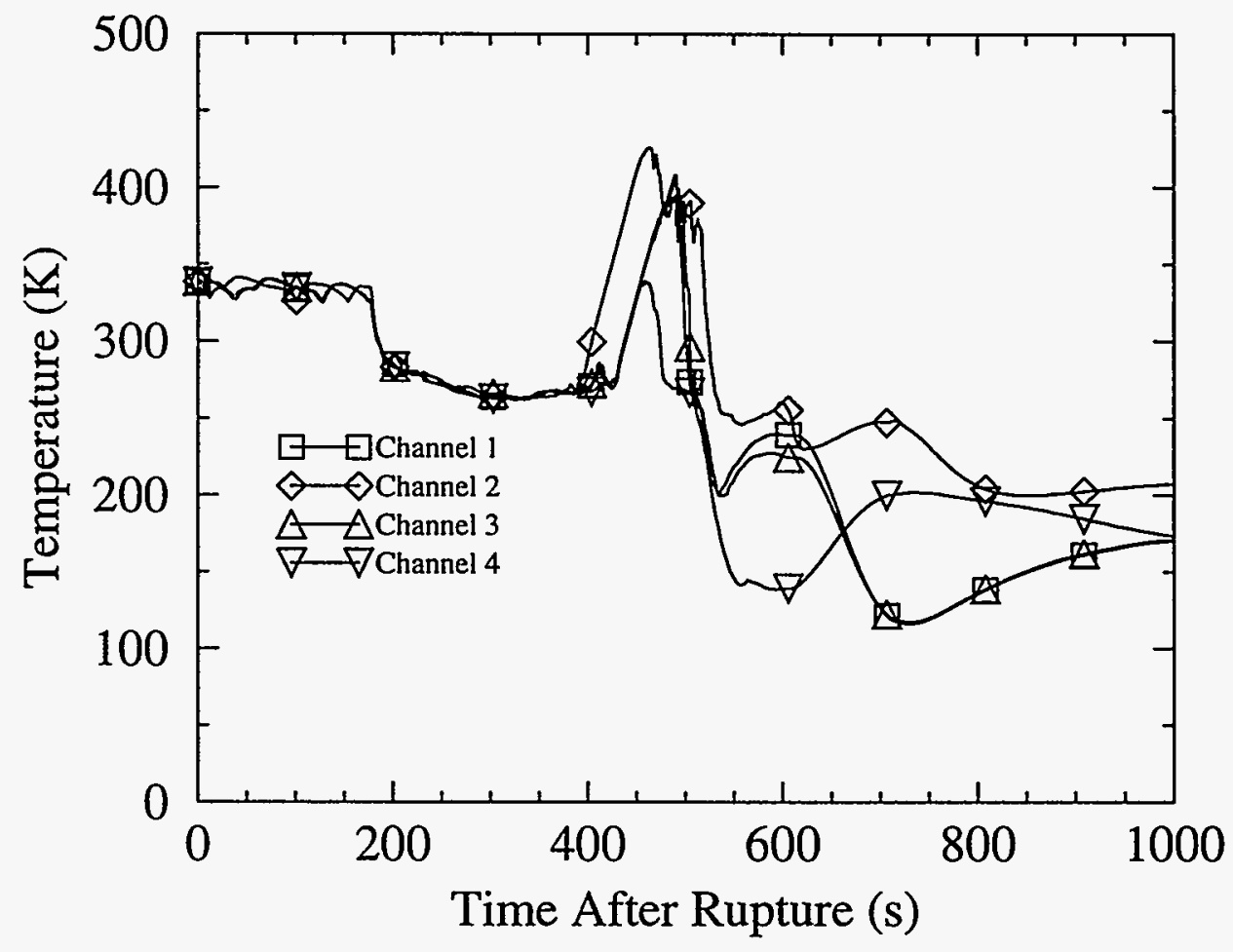

Figure 78. SBLOCA maximum cladding temperatures.

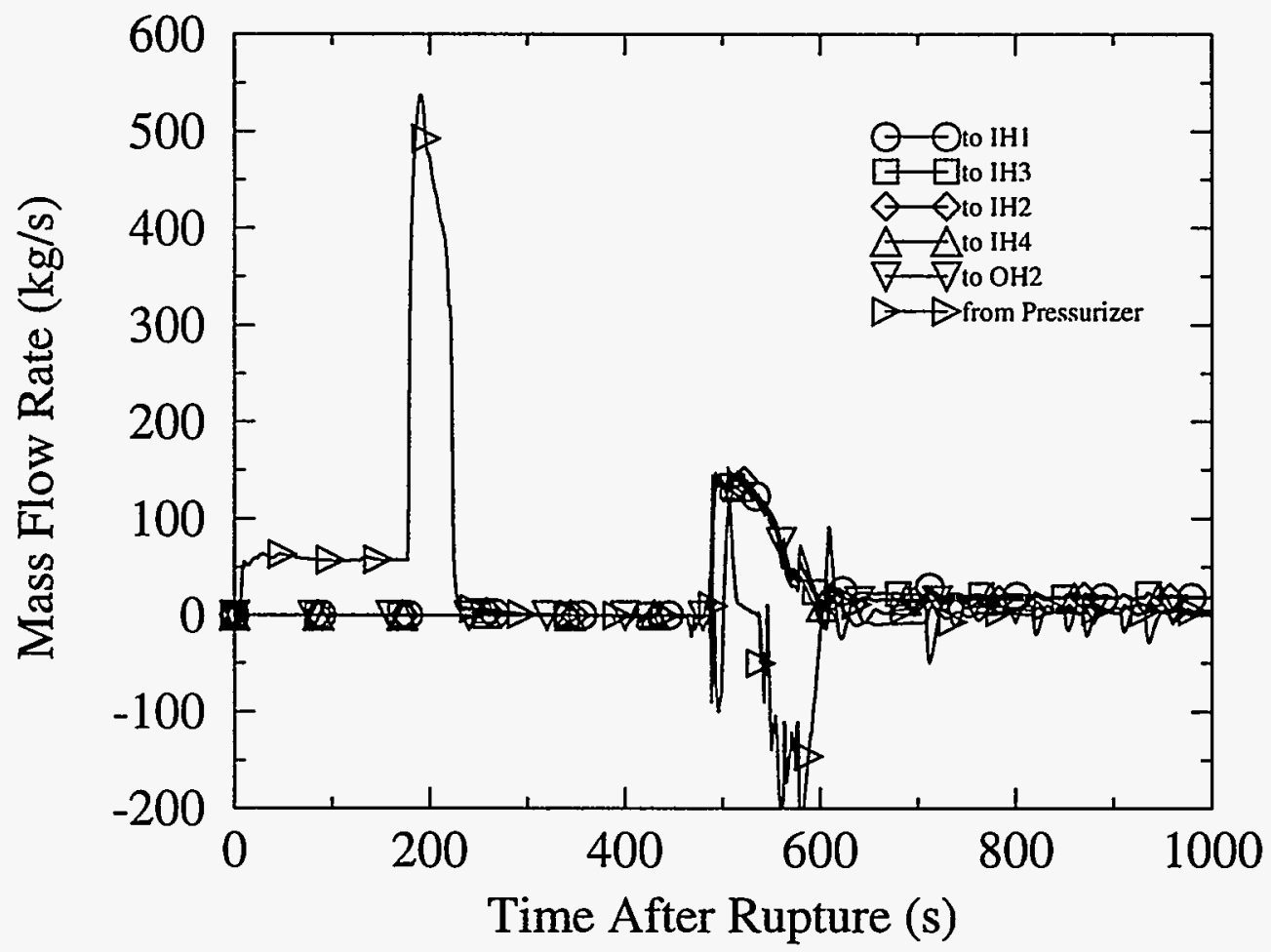

Figure 79. SBLOCA pressurizer and ECC flow. 


\section{CONCLUSIONS}

A limited number of transient scenarios were calculated using a computer code suite and input modeling provided by Atomic Energy of Canada Ltd. for the CANDU 3 design. These codes have not yet been reviewed by the NRC for adequacy, and the results described here should be viewed as unverified background information developed prior to the beginning of the licensing design review for CANDU 3 rather that a part of that review.

The base-case large-break LOCA with failure to shutdown leads to fuel or cladding melting temperatures within a few seconds due to the positive void coefficient of reactivity. Beyond this time, the calculations were not considered to be valid because the core geometry would begin to change and the code models would not apply. A severe accident analysis of this degraded-core scenario is beyond our capability at this time. NRC codes like MELCOR have not yet been modified for CANDU reactor analysis.

A sensitivity analysis with delayed shutdowns of up to about one second in the scram initiation, shows that there is no fuel melting or cladding melting during the time span analyzed. Also for nominal shutdown times, but with very degraded coolant purity (most positive-void reactivity), there is negligible fuel melting and cladding melting. For cases with failure to shutdown, the analysis shows that fuel melting and cladding melting are reached in a few seconds, before the emergency core cooling system would be activated. Only small changes in the timing and consequences of the scenario result when several parameters, of importance to the progression of the accident, are varied.

The severity of the accident is dramatically reduced when it is assumed that one of the two independent shutdown systems functions as designed. The LOCA results presented in this report are consistent with related studies performed by $\mathrm{AECL}^{4}$ and others, ${ }^{5,6}$ and do not reveal any new characteristics or phenomena.

A rod withdrawal calculation with failure to shutdown shows that the CANDU 3 reactor may have a positive power coefficient above $105 \%$ because the power is continuing to increase beyond this level. Negative Doppler feedback compensates for about half of the positive reactivity of the rod and of other positive feedbacks. Reactivity feedback mechanisms have different magnitudes and time responses in the CANDU 3 design than in light water reactors.

Five calculations were also performed for loss-of-off-site-power scenarios. These calculations assumed that the plant failed to enter the "island mode"; i.e., power to the main coolant pumps was not restored using on-site generation. Three functions were varied during the five calculations: pressure relief valves opening, the scram system rods dropping and the mechanical control absorber rods dropping. The total power rise, caused by a positive void reactivity coefficient, was negligible as long as either the scram rods or the mechanical control absorber rods entered the core. For cases where no control or shutoff rods are inserted, the effects of relief valve performance are negligible and fuel and clad melting temperatures are reached in a few seconds. No attempt was made to model ECC performance during this event.

All the above calculations had initial conditions of $103 \%$ power, a $6 \%$ power tilt towards the side of the core where the inlet header break is modelled, and a value of coolant purity of $96.36 \%$ which increases the void reactivity insertion. These are conservative conditions which are used for design-basis accidents. All the scenarios that were analyzed with failure to shutdown would be classified as a severe accidents, and therefore should be analyzed with best-estimate inputs. The effect of performing these severe accident calculations with conservative inputs leads to differences of at most 1 second in the time to onset of core damage and therefore has a negligible effect on the calculation results.

All the calculations that invoke the actuation of the Emergency Core Cooling System were performed using CATHENA as a stand-alone code. That is, precalculated (by AECL) power evolutions were input to CATHENA rather than coupling it to the other codes in the code suite (e.g., CERBERUS). The power evolution is similar to that given in Reference 4 for a large-break LOCA with shutdown on rods only. Calculations performed for the large-break LOCA with shutdown show that the Emergency Core Cooling System is actuated after about 20 seconds. The large-break LOCA transients were run using a 
four-channel model. There was a $100 \mathrm{~K}$ increase in the maximum cladding surface temperature for this case.

Calculations of a small-break LOCA $(0.76 \%$ break in inlet header No.2) with shutdown were made using only the four-channel model. Results show that the Emergency Core Cooling System is actuated at 500 seconds in this case, and there is only a small increase in the maximum cladding surface temperature.

The large-break and small-break LOCA calculations with ECC show how that the ECC performs its intended function and cools the core. For the CANDU 3, the ECC injection is with light water, and that also serves to add negative reactivity to the core and keep the core subcritical. 


\section{REFERENCES}

1 Atomic Energy of Canada, Limited, "The CANDU 3 Technical Outline," Rev. 11, June 1992.

2 J. R. Wolfgong, M. A. Linn, A. L. Wright, M. Olszewski, M. H. Fontana, Systems Analysis of the CANDU 3 Reactor, NUREG/CR-6065, July 1993.

3 Atomic Energy of Canada, Limited, CANDU 3 Conceptual Safety Report, Volumes 1 and 2, 1989.

4 Atomic Energy of Canada, Limited,EXTERNAL ANALYSIS REPORT - Power Pulse Break Survey Analysis, AECL 74-03310-AR-001, Revision 0, October 25, 1991.

$5 \quad$ Nuclear Studies and Safety Department and Civil Design Department of Ontario Hydro,"Analysis of the Consequences of Failure to Shutdown Following a Large Loss of Coolant Accident in a Pickering NGS A Unit," October 1987.

6 Assessment of Early Disruption Events during a Postulated Power Excursion Accident in Pickering a CANDU Reactor, ANL/RAS-OH-1, September 1987.

7 B. N. Hanna, Atomic Energy of Canada, Limited Research, CATHENA MOD3.2n Theoretical Manual, THB-CD-002, November 1989.

8 E.S.Y. Tin and D.B. Miller, Atomic Energy of Canada, Limited, Powderpufs-V Physics Manual, TDAI-31 Part 1 of 3, July 1979.

9 B. Rouben, Atomic Energy of Canada, Limited, MATMAP Program Description, TDAI-318, October 1984

10 A.R. Dastur, B. Rouben and D.B. Buss, Atomic Energy of Canada, Limited, CERBERUS - A Code for Solving the Space-Dependent Neutron Kinetics Equations in Three Dimensions, TTR-392, February 1992.

11 Atomic Energy of Canada, Limited, ECCS Performance Analysis for Breaks in Large HTS Piping, Project 74 CANDU 3, AECL 74-68500-AR-001, Revision 1, March 3, 1993.

12 R. W. Shumway, J. L. Judd, and D. D. Ebert, CANDU 3 Transient Analysis Using AECL Codes, Proceedings of the USNRC Twenty-First Water Reactor Safety Information Meeting, NUREG/CP0133, April 1994.

13 E. S. Y. Tin and D. P. Tregunno, Atomic Energy of Canada, Limited, CANDU 3 Conceptual Safety Report. AECL U90004 I/T-CSR Part 3 Rev 0, 1989 page 2-44. 


\begin{tabular}{|c|c|}
\hline $\begin{array}{l}\text { NRC FORM } 335 \\
\text { (2.89) } \\
\text { NRCM 1102, } \\
3201,3202, \\
\text { BIBLIOGRAPHIC DATA SHEET } \\
\text { (See instructions on the reverse) }\end{array}$ & $\begin{array}{l}\text { 1. REPORT NUMBER } \\
\text { (Anjigned by NAC. Add Vol, Supp., Rev., } \\
\text { and Addendum Numbers, If any.) } \\
\text { NUREG/CR-6257 } \\
\text { TNET-95/0070 }\end{array}$ \\
\hline \multicolumn{2}{|l|}{ 2. TITLE AND SUBTITLE } \\
\hline \multirow[t]{2}{*}{ Codes } & 3. DATE REPORT PUBLISHED \\
\hline & \begin{tabular}{|l|r|} 
MONTH & YEAR \\
January & 1995 \\
4. FIN OR GRANT NUMBER \\
L2445
\end{tabular} \\
\hline \multirow[t]{2}{*}{$\begin{array}{l}\text { 5. AUTHOR(S) } \\
\text { J.L. Jedd, R.W. Shumway/INEL } \\
\text { D.D. Ebert/NRC }\end{array}$} & 6. TYPE OF REPORT \\
\hline & $\begin{array}{l}\text { 7. PERIOD COVERED (Inclusive Dates) } \\
\text {. }\end{array}$ \\
\hline \multicolumn{2}{|c|}{$\begin{array}{l}\text { 8. PERFORMING ORGANIZATION - NAME AND ADORESS (If NRC, provide Division, Office or Region, U.S. Nuclear Regulatory Commission, and mailing address; if contractor, provide } \\
\text { name and malling address) } \\
\text { Idaho National Engineering Laboratory } \\
\text { Lockheed Idaho Technologies Company } \\
\text { Idaho Falls, ID } 83415\end{array}$} \\
\hline \multicolumn{2}{|l|}{$\begin{array}{l}\text { 9. SPONSORING ORGANIZATION - NAME AND ADDRESS (If NRC, type "Sam } \\
\text { andmalling address) } \\
\text { Division of Systems Technology } \\
\text { Office of Nuclear Regulatory Research } \\
\text { U.S. Nuclear Regulatory Commission } \\
\text { Washington, DC 20555-001 }\end{array}$} \\
\hline \multicolumn{2}{|l|}{ 10. SUPPLEMENTARY NOTES } \\
\hline \multicolumn{2}{|c|}{$\begin{array}{l}\text { 11. ABSTRACT }(200 \text { words orless) } \\
\text { suite and input modeling provided by the Atomic Energy of Canada limited (AECL) for } \\
\text { the CANDU } 3 \text { design. Emphasis was placed on a large-break loss-of-coolant accident } \\
\text { with delays in actuation of the two independent shutdown systems (shutdown rods and } \\
\text { liquid poison injection). Although an extremely unlikely scenario, it was studied } \\
\text { because of the potential consequences that would result from a positive void } \\
\text { coefficient of reactivity. Results indicate that a few seconds delay in shutdown } \\
\text { would result in quickly reaching fuel or cladding melting temperatures before the } \\
\text { emergency core cooling system would be activated. only small changes in the timing } \\
\text { and consequences of the scenario result when several parameters, of potential } \\
\text { importance to the progression of the accident, are varied. Five calculations were } \\
\text { also performed for loss-of-off-site-power scenarios. These calculations assume that } \\
\text { the plant failed to enter the island mode, i.e., power to the main coolant pumps was } \\
\text { not restored using on-site power generation. }\end{array}$} \\
\hline \multirow[t]{4}{*}{$\begin{array}{l}\text { 12. KEYWOADS/DESCR!PTORS (List words or phrases that will assist researchers in locating the report.l } \\
\text { CANDU, transient analysis, thermohydraulic, design confirmation, } \\
\text { safety analysis }\end{array}$} & $\begin{array}{l}\begin{array}{l}\text { 13. AVAILABILITY STATEMENT } \\
\text { ún1imited }\end{array} \\
\text { 14.SECURITY CLASSIFICATION }\end{array}$ \\
\hline & $\begin{array}{l}\text { (This Pagel } \\
\text { unclassified } \\
\text { (This Report) } \\
\text { unclassified }\end{array}$ \\
\hline & 15. NUMBER OF PAGES \\
\hline & \\
\hline
\end{tabular}

